Portland State University

PDXScholar

Winter 4-21-2013

\title{
Application of GIS and Spatial Analysis of Golden Eagle Fatalities Caused by Wind Turbines at the Altamont Pass Wind Resource
}

Andrew James Pinger

Portland State University

Follow this and additional works at: https://pdxscholar.library.pdx.edu/open_access_etds

Part of the Environmental Indicators and Impact Assessment Commons, Oil, Gas, and Energy Commons, and the Poultry or Avian Science Commons Let us know how access to this document benefits you.

\section{Recommended Citation}

Pinger, Andrew James, "Application of GIS and Spatial Analysis of Golden Eagle Fatalities Caused by Wind Turbines at the Altamont Pass Wind Resource" (2013). Dissertations and Theses. Paper 197.

https://doi.org/10.15760/etd.197

This Thesis is brought to you for free and open access. It has been accepted for inclusion in Dissertations and Theses by an authorized administrator of PDXScholar. Please contact us if we can make this document more accessible: pdxscholar@pdx.edu. 


\title{
Application of GIS and Spatial Analysis of Golden Eagle Fatalities
}

Caused by Wind Turbines at the Altamont Pass Wind Resource Area, CA

by

Andrew James Pinger

A thesis submitted in partial fulfillment of the requirements for the degree of

\author{
Master of Science \\ in \\ Biology
}

\section{Thesis Committee: \\ Luis A. Ruedas, Chair \\ Deborah A. Duffield \\ Michael T. Murphy}

\section{Portland State University \\ 2013}




\begin{abstract}
The Altamont Pass Wind Resource Area (Altamont) near Livermore, California is the oldest and largest wind farm in the United States. It is known as a location of high avian mortality, especially for diurnal raptors such as the Golden Eagle (Aquila chrysaetos). Using the avian monitoring data collected at Altamont for over thirteen years (1998-2003, 20052011), records were analyzed of 134 golden eagle deaths caused by wind turbine collisions. All wind turbines present during the same temporal range were characterized according to turbine variables, and geographic placement characteristics. Values of turbines that killed golden eagles were compared to values of turbines that did not. It was discovered that turbines that have killed golden eagles (kill turbines) share characteristics that are significantly different from those that have not. Kill turbines are more often situated on lattice structure towers, have larger rotor blade-swept areas, are placed in less dense turbine arrays, are further away from the next nearest turbine and are less often placed on top of ridgelines compared to nonkill turbines. Finally, kill turbines are more often situated at the end of a turbine row than are nonkill turbines. The differences between kill and nonkill turbine model, hill slope, tower height, generating capacity, array diversity, row count of turbines and placement in a hill saddle were found to be not significant. These findings support, in part, earlier turbine studies at Altamont, but do not concur with all previous findings. The methods used in this study can be applied to any bird species at Altamont and at any wind resource area throughout the world. As the wind industry continues to grow, techniques used in studies such as this are an important tool that can be used to direct wildlife conservation policies.
\end{abstract}

Abstract 


\section{Table of Contents}

Abstract.

Table of Contents

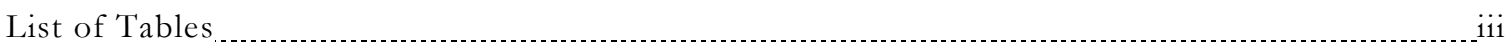

List of Figures

Introduction $\ldots$

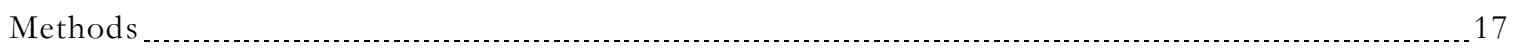

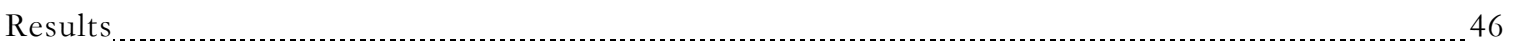

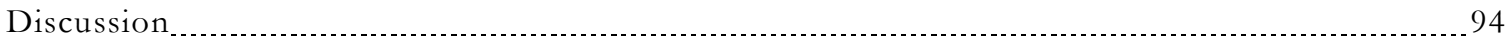

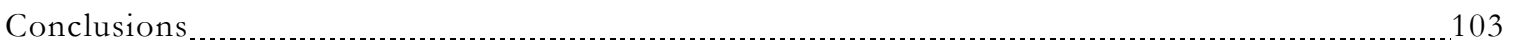

Acknowledgments

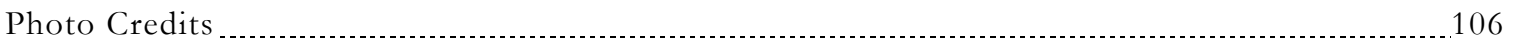

References

Appendix A: List of Fields in the SRC Fatalities Table

Appendix B: Fatality Detection Form

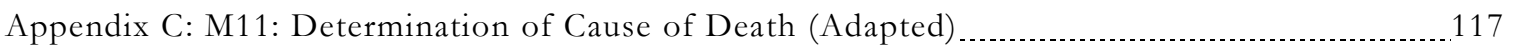

Appendix D: List of Fields in the SRC Turbine Table 119

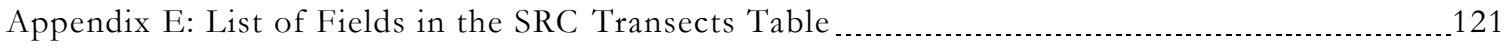

Appendix F: Use of Circular Package in R to Calculate Aspect Statistics _

Appendix G: Calculations of Hilltop Ridgelines 125

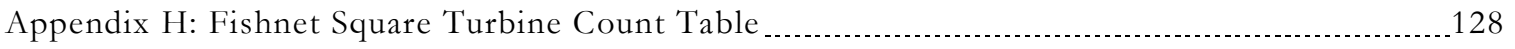

Appendix I: Abridged Records of Status Id 1 Golden Eagle Fatalities ......................................135

Appendix J: Additional Fields Calculated for Turbine Table

Table of Contents 


\section{List of Tables}

Table

Title

Page Number

I-2 Morphometric Characteristics of Golden Eagles 16

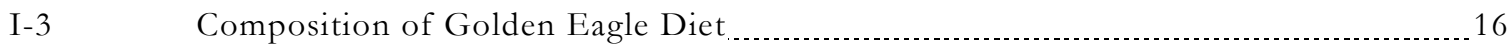

M-1 Given and Calculated Turbine Table Variables

R-1 All Fatality Records by Status Id

R-2 Top 10 Species of Turbine Caused Bird Fatalities at Altamont 1998-2011.............. 53

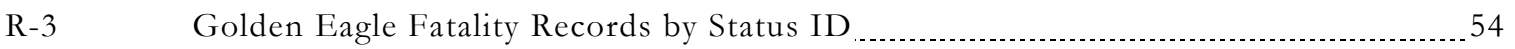

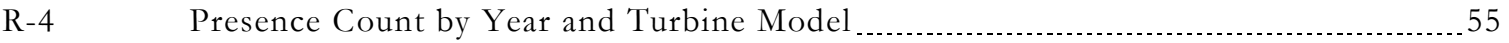

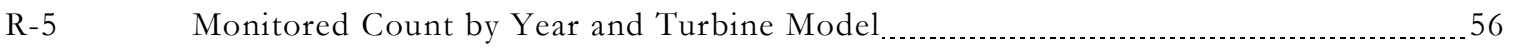

R-6 Monitored Turbines as a Proportion of Total Annual Monitoring Effort

R-7 Summary Table - Turbine Presence and Monitored Count Totals .......................... 58

R-8 Kill Turbines with Golden Eagle Fatality Census .............................................. 59

R-9 Count of Golden Eagle Fatalities by Year and Turbine Model

R-10 Target Species Annual Fatality Count Totals $\ldots$

R-11 Search Effort Required per Golden Eagle Fatality ............................................... 78

R-12 Summary Table of Test Findings

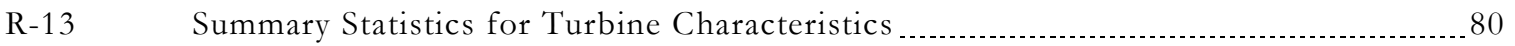

R-14 End Row Status by Golden Eagle Age Class _...

R-15 Tower Type by Golden Eagle Age Class

R-16 Rotor Swept Area by Golden Eagle Age Clas s................................................ 92

R-17 Ridgetop Status by Golden Eagle Age Class ................................................... 93

R-18 Nearest Turbine Distance by Golden Eagle Age Class

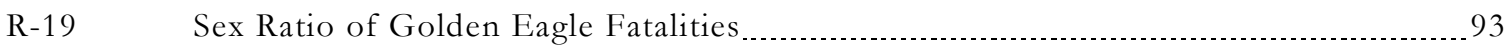

List of Tables 


\section{List of Figures}

Figure Title

Page Number

I-1 Map of Altamont Pass Wind Resource Area, CA 12

I-2 Map of Historic Turbine Array, Altamont Pass Wind Resource Area …..................... 13

I-3 Aquila chrysaetos Range Map

M-1 Wind Turbine Tower Types

M-2 Historic Turbine Array and Fishnet Grid

R-1 Golden Eagle Fatalities and Monitored Turbines at the

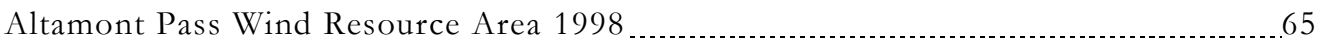

R-2 Golden Eagle Fatalities and Monitored Turbines at the

Altamont Pass Wind Resource Area 1999

R-3 Golden Eagle Fatalities and Monitored Turbines at the

Altamont Pass Wind Resource Area 2000

R-4 Golden Eagle Fatalities and Monitored Turbines at the

Altamont Pass Wind Resource Area 2001

R-5 Golden Eagle Fatalities and Monitored Turbines at the

Altamont Pass Wind Resource Area 2002

R-6 Golden Eagle Fatalities and Monitored Turbines at the

Altamont Pass Wind Resource Area 2003

R-7 Golden Eagle Fatalities and Monitored Turbines at the

Altamont Pass Wind Resource Area 2005

R-8 Golden Eagle Fatalities and Monitored Turbines at the

Altamont Pass Wind Resource Area 2006

R-9 Golden Eagle Fatalities and Monitored Turbines at the

Altamont Pass Wind Resource Area 2007

R-10 Golden Eagle Fatalities and Monitored Turbines at the

Altamont Pass Wind Resource Area 2008

R-11 Golden Eagle Fatalities and Monitored Turbines at the

Altamont Pass Wind Resource Area 2009

R-12 Golden Eagle Fatalities and Monitored Turbines at the

Altamont Pass Wind Resource Area 2010

R-13 Golden Eagle Fatalities and Monitored Turbines at the

Altamont Pass Wind Resource Area 2011 77

List of Figures 
R-14 Golden Eagle Fatalities by Turbine Model and Total Search Count

R-15 Golden Eagle Fatalities and Search Totals $\ldots \ldots \ldots \ldots$

R-16 Circular Aspect Histogram of Nonkill Turbines

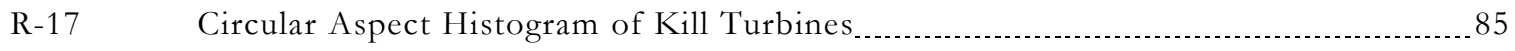

R-18 Golden Eagle Fatalities by Quarter of Death Date

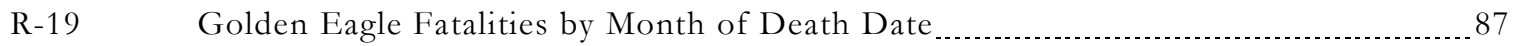

R-20 Radar Chart of Golden Eagle Fatalities with Known Death Dates .......................... 88

R-21 Age Class and Death Dates of Golden Eagle Fatalities ........................................ 89

R-22 Golden Eagle Fatalities by Age 


\section{Introduction}

The wind resources in North America have the potential to provide massive amounts of clean energy without emissions of greenhouse gases or harmful toxins (U.S. Government Accountability Office 2005). The U.S. Department of Energy calculated that land in the United States has an annual potential for 38.5 million gigawatt hours (GWh) of wind energy production (NREL 2010). Wind is a growing domestic industry. In 2012, 13,124 megawatts of new wind power capacity was installed in the United States bringing the U.S. total to $60,007 \mathrm{MW}$. This energy is generated by over 45,000 individual wind turbines throughout the nation (AWEA 2012). In 2008, the U.S. Department of Energy released 20\% Wind Energy by 2030, a report that details realistic strategies for how U.S. energy demand can be met with increasing wind power supply (U.S. Department of Energy 2008). It is reasonable to expect that many more wind turbines will become a regular part of the nation's skylines.

Although wind energy is a plentiful, domestic product that does not pollute the air or water, it does come with a biological cost. New constructions of turbine arrays and distribution systems including transmission lines have the potential to disturb or destroy crucial wildlife habitats (GAO 2005). The costs of developing wind energy are more concrete when you consider the direct conflicts between wind turbines and the animals that also use the wind.

Many birds have adapted to use winds for soaring and as an aid in migratory flight. This suite of adaptations has developed over deep time; however, these animals have had far less time to adapt to sharing airspace with the spinning blades of wind turbine propellers. Unfortunately, this nascent competition for winds often brings birds into lethal contact with

Introduction 
tower structures and turbine blades. Ground zero for this conflict lies in a rural setting fifty miles east of San Francisco, CA.

The Altamont Pass Wind Resource Area (Altamont), near Livermore, California serves as an example of the conflict between wind energy and birds. No wind farm in the world has done more to solidify the idea that energy-generating wind turbines are dangerous to wildlife (Erickson 2002). Altamont was developed in the 1980's as the nation's first largescale wind farm. With over 5,000 towers, the skies over Altamont are a deadly place for birds. Altamont lies in the northeast corner of Alameda County with a small portion of the array occupying and area in the south east corner of Contra Costa County (Fig. I-1).

Altamont's terrain consists of rolling hills of mostly open grassland with gradual elevation changes and dispersed patches of deciduous hardwood trees including oaks, California buckeye, and eucalyptus (Hunt 1999, Orloff and Flannery 1991). Much of the land continues to be used for grazing by local ranchers.

The wind resource area at Altamont covers between $141 \mathrm{Km}^{2}$ (Hunt 1999) - 189 $\mathrm{Km}^{2}$ (Hoover 2002) depending upon what properties are included in the calculation. There are eight companies that operate wind farms in twenty-five project sites, and a total of 5,463 individual wind turbines have been a part of the historic array at Altamont. For the purposes of this research, "historic array" refers to all turbines that have been present at Altamont between the years 1998 and 2011 (Fig. I-2). The number of turbines in the historic array is 5,463 , but at no time were that number of turbines all present. Due to turbine removals and installations throughout the temporal range of this study, the array fluctuates annually. Tables R-4 and R-7 in the Results section provide counts of turbines per year for those present (R-4) and those that were monitored (R-7).

Introduction 
Due in part to the diversity of companies operating turbines, there is a broad diversity of wind turbine models within the array. There have been 16 different turbine models present in the time of this study (Table I-1).

Unlike most contemporary wind farms in the United States that do not have a history of large bird fatalities (Erickson 2001) the turbines at Altamont are known to have caused numerous bird fatalities, including federally protected raptor species (Orloff 1992).

Although studies have identified ways in which new wind farms may reduce conflicts with birds through alternative tower design and better siting strategies (Erickson 2001), uncommonly high fatality numbers remain significant among raptor species (Smallwood \& Thelander 2004). The species that top Altamont's list of raptor fatalities are the red-tailed hawk (Buteo jamaicensis), American kestrel (Falco parverius), barn owl (Tyto alba), burrowing owl (Athene cunicularia) and golden eagle (Aquila chrysaetos) (Leslie 2012). Estimates of annual golden eagles fatalities at Altamont range between 30-70 (Smallwood 2005, Leslie 2012). The only wind farm in the country that compares with Altamont for golden eagle presence is the facility at Foot Creek Rim, WY where golden eagle deaths are reported far less frequently (Strickland 2001).

\section{Altamont settlement}

Reports of large numbers of raptors being killed by wind turbines at Altamont activated the San Francisco Bay area conservation community. By January 2006, a number of local Audubon Society chapters, together with the group Californians for Renewable Energy brought suit against wind farm operators and Alameda County to stop the killings of federally protected bird species. A number of wind farm operators chose to settle the suit outside of court and agreed to take measures to decrease bird fatalities. The settlement goal

Introduction 
was a $50 \%$ reduction in annual fatalities for target species. This reduction goal was based on a calculated baseline estimate of annual fatalities prior to the agreement (Golden Gate Audubon Society 2007). The target species were four among the raptor species listed above: red-tailed hawk, American kestrel, burrowing owl, and golden eagle.

The settlement agreement also chartered a Scientific Review Committee (SRC) to oversee the progress of the fatality reduction goal. The committee's composition is:

"... five members, each of whom is appointed by one of the following interests: permittees (i.e. wind farm companies), environmental community, County Planning Department, California state agency (California Energy Commission or Department of Fish \& Game), and federal resources agency (US Fish \& Wildlife Service). "

The SRC commissioned consulting groups to undertake the bird fatality monitoring work at Altamont. The current contract is with ICF International (ICFI). Staffers of ICFI conduct the field monitoring and post search data analysis. The work of ICFI is to determine and verify whether the settling parties have achieved the 50\% fatality reduction goal. Annual reports that track the status of the $50 \%$ reduction goal are published, but those reports are not the only product that results from all of the monitoring program's data collection. A publicly accessible, multi-year, fatality data set that can be analyzed for trends in bird mortalities now exists. Specifically, an investigation of all the wind turbine-caused fatalities of any single species may reveal patterns or variables that are important in turbines that killed those birds. The bird fatalities at Altamont that have gained the most attention are those of golden eagles, hence golden eagles are the focus of the present investigation.

\section{Study organism}

Introduction 
The Golden Eagle, Aquila chrysaetos is North America's largest bird of prey, and has a global range in the northern hemisphere (Kochert 2002b). Aquila chrysaetos has a Holarctic distribution with populations throughout Europe, North Africa and Asia. Six subspecies are currently recognized, including A.c. Kamtschatica, distributed in Siberia from the Altai Mountains in the west to the Kamchatka peninsula in the east. Aquila c. chrysaetos is found in Europe, from the British Islands as far east as the Altai Mountains. Aquila chrysaetos daphanea is found from Turkestan through India, Pakistan, and into China. Aquila chrysaetos homeyeri is limited to the Iberian Peninsula and coastal areas around the Mediterranean Sea including North Africa. Aquila chrysaetos japonica is limited to the Japanese archipelago and Korean peninsula (Kochert 2002b). Aquila chrysaetos canadensis is the only subspecies of golden eagle recognized in North America (Fig I-3), and is the taxon that occurs in the Altamont Pass Wind Resource Area.

The golden eagle is a long-lived species. Banded individuals in North America have lived as long as 31 years, although in California, the record is 20 years (Lutmerding 2013). They display sexual dimorphism with the females being larger in measurements (Bortolotti 1984).

Golden eagles are known to prey on a diversity of terrestrial wildlife as well as avian prey. It has a highly adaptable diet that consisting mainly of small mammals. Drawing from primary sources throughout North America, a 1976 survey of faunal remains in golden eagles nests recorded a diet heavily weighted toward mammals.

Larger mammals and birds don't make up a large proportion of the golden eagle diet, so it is remarkable when these events are recorded. There are published accounts of golden eagles preying on island foxes (Urocyon littoralis littoralis) (Coonan 2005), pronghorn antelope

Introduction 
(Antilocapra americana) (Tigner 1973), calves of domestic cattle (Bos taurus) (Phillips 1996), mule deer (Odocoileus hemionus), (Olendorff 1976), and birds such as the red-tailed hawk (Buteo jamaicensis), great horned owl (Bubo virginianus), and American coot (Fulica americana) (Dixon 1937). They are not known to regularly pursue fish like the bald eagle, but as opportunistic scavengers may consume fish as carrion (Ollendorff 1976).

Golden eagles near the Altamont Pass Wind Resource area feed predominantly on California ground squirrels (Spermophilus beechyii), which account for $69 \%$ of prey items found at golden eagle nests in the area (Hunt 1999). The rolling hills and open grassland of the wind resource area seem to be very good habitat for ground squirrels, and so it is likewise an equally good hunting ground for golden eagles. The abundant presence of ground squirrels may help to explain the high golden eagles presence in the area.

\section{Mating \& reproduction}

After maturity, golden eagles form mating pairs that occupy and defend a territory. They usually breed every year, and their brood is typically one or two chicks (sometimes three) with facultative fratricide not uncommon in the nest (Edwards 1983). Individuals appear to prefer nest sites high on cliff faces or when rocky outcrops are not available, in large trees (Menkens 1987).

Fledgling eagles leave the nest after an incubation period of 45 days and a fledging period of ten to eleven weeks (Hunt 1999). Until this time, both male and female parents provision the young with food. Once the juvenile birds leave the nest, they remain in the area for approximately two months with increasing independence from their parents. Soon thereafter, the mating pair is known to chase juvenile birds away from their nest and breeding territory. At this point the juvenile birds are on their own with respect to feeding.

Introduction 
Survival probability estimates for juvenile golden eagles have been made on the central California and Denali National Park populations. These estimates show a probability of survival between 78\% in Denali (McIntyre 2006) and 84\% in central California (Hunt 2002) in the months following fledging.

\section{Population composition}

The golden eagle population in the lands surrounding Altamont has been well studied. A 1995 survey found 44 breeding pairs occupying territories in the $820 \mathrm{Km}^{2}$ area surrounding Altamont. This is one of the highest recorded population densities of golden eagles, and the figure is considered by many to underestimate real numbers (Hunt 1995).

A typical population of golden eagles is composed of four groups. Adult eagles form breeding pairs when breeding territories become available. Juvenile are volant up to one year old. They do not breed and do not control territory. Sub-adults are immature and range in age between 1-3 years old. Sub-adults do not breed and do not control a home territory. Finally, there are mature adult eagles that do not possess or defend territories. These nonbreeding adults are referred to as floaters (Hunt 1995). Floaters serve as a reserve in a population for when breeding adult birds are eliminated (Hunt 1999).

\section{Flight}

Golden eagles display a number of flying styles including flapping, gliding, soaring, stooping and undulating flight (Kochert 2002b). Observations of golden eagles at Altamont reveal that two types of flight are used primarily. These consist of thermal soaring and gliding (Hoover 2002). Thermal soaring helps eagles to gain elevation above the hunting grounds, after which they employ gliding to gradually move into position to pounce on prey.

Introduction 
While actively hunting, the characteristic flight pattern of these eagles is referred to as contour hunting and is characterized by low elevation flight, 1-5 meters above the ground, during which the ridges and contours of the hillsides are followed (Carnie 1954, Collopy 1983). It is thought that this low profile flying allows eagles to get within close proximity to their prey without the latter having much advance notice. This low elevation contour flight brings golden eagles into close proximity with the height of wind turbine blades and is thought to be the primary reason why golden eagles are struck by turbine blades.

\section{Migration}

The ecology of golden eagle migration has been well studied in several parts of the United States and Canada (Applegate 1987, Omland 1996, Yates 2001, McIntyre 2006, Good 2007), but migratory tendencies of the Altamont golden eagles are less known. The Coast Range of California hosts resident golden eagles (Carnie 1954), and it is assumed that the same holds for Altamont. Whether or not golden eagles that are killed by turbines at Altamont are resident eagles, or are rather migrating or dispersing individuals is a question that is important to pursue, because it may explain how the population of golden eagles around Altamont remains so seemingly stable in spite of the annual fatality estimates that 3070 golden eagles are killed at Altamont annually (Hunt 2002, Smallwood 2005, Leslie 2012). No studies so far have provided answers to these questions, so they remain unexplained.

\section{Federal Protection}

In 1918, the Migratory Bird Treaty Act was signed by the United States and Great Britain on behalf of Canada. The act created criminal penalties for the taking or harming of an extensive list of native migratory and resident birds in North America. The law was

Introduction 
initiated as a corrective measure to alleviate the damage to bird populations by market hunters in the previous years. The MBTA protects all native North American birds with the exception of certain game birds. In 1962, the golden eagle gained added protection when it was added to the 1940 Bald Eagle Protection Act, which was then renamed the Bald and Golden Eagle Protection Act. This act prohibits the taking of any eagle or eagle part without a permit, and it provides increased penalties for violations of the act.

\section{Threats}

As the largest raptor in North America, the golden eagle has few predators (Hunt 2002) besides humans. Although the Bald and Golden Eagle Protection Act has outlawed hunting of these birds, eagles do still suffer indirectly from of human hunting activity. There are over 12.5 million deer hunters in the United States (Aiken 2011). Not every hunter successfully kills a deer and of those that do, many do not recover the deer they shoot. Unrecovered deer carcasses and discarded gut piles of deer that were shot by hunters using jacketed and unjacketed lead bullets or slugs are a source of microscopic lead fragments that are easily ingested by scavenging animals (Hunt 2006). As opportunistic scavengers, golden eagles may feed on these carcasses and can ingest large quantities of lead particles. Surveys conducted in Montana and California have shown between 35\% and 85\% of golden eagles have elevated blood lead levels (Harmata 1995, Pattee 1992).

Other causes of golden eagle deaths come from a variety of human related sources. A 1995 survey of golden eagle carcasses conducted by the National Wildlife Health Center showed that electrocutions claimed $25 \%$ and gunshots were responsible for $15 \%$. Poisoning accounted for $6 \%$ of deaths and accidental trauma was responsible for $27 \%$ of the deaths of specimens in the survey. The remaining 27\% were not described (Franson 1995). Accidental

Introduction 
trauma included birds killed by collisions with cars, buildings, structures, and wind turbines. Among these causes of unnatural deaths of golden eagles, deaths caused by wind turbines are the subject of the present study.

With Altamont's thirteen years of bird fatality data being available to the public, unique opportunities for research exist. Investigations can now be conducted to better understand the factors contributing to bird deaths at Altamont. The goal of the present study is to determine whether there are unique spatial factors and turbine characteristics that contribute to golden eagle turbine collisions.

I hypothesized that a turbine's physical attributes or its placement in the landscape or within an array of turbines will lead to a relative increase or decrease in golden eagle fatalities. In particular, I was interested to discover what differences existed between turbines that displayed relatively increased fatalities versus turbines that had relatively reduced fatalities. To test for this difference, every record of a golden eagle fatality at Altamont between 1998 and 2011 was examined and filtered to establish those killed by turbine collisions, and from these a roster of fatal turbines was established.

A comprehensive survey of every turbine at Altamont was undertaken and each turbine described according to a set of characteristics. These wind turbine attributes can be divided into two categories. Innate turbine characteristics are those that would be the same no matter where the turbine was placed. This includes tower height, turbine model, tower type, rated energy generating capacity and rotor swept area. Placement characteristics are those that are dependent upon where in the landscape, or within a turbine array a turbine is erected. These characteristics include base elevation at placement, the number of other turbines that are in the same row, aspect and slope of the ground on which the turbine 
stands, density of turbines, diversity of local turbines, whether or not an individual turbine is in a saddle of a hilltop ridge, as well as the distance to the next nearest turbine. Much of this information is readily available through the SRC website, but a portion of the placement data must be calculated. Once the turbine survey was complete, the attributes of turbines that killed golden eagles were compared to the characteristics of turbines that did not produce kills. If spatial factors or turbine characteristics do not appear in a significantly higher frequency in turbines that have killed golden eagles than in those turbines that have not killed golden eagles, the hypothesis that innate or placement characteristics contribute to eagle fatalities from wind turbines will be rejected.

To investigate how demographic characteristics and temporal variation may influence wind turbine-caused fatalities, I examined age class and sex designations as well as calculated death dates of golden eagle fatalities at Altamont. A demographic analysis is important to determine whether or not any age class is being disproportionately killed by turbines. Further analysis illustrates which temporal intervals are most deadly for each age class and sex of golden eagle. 
Figure I-1: Map of Altamont Pass Wind Resource Area, CA

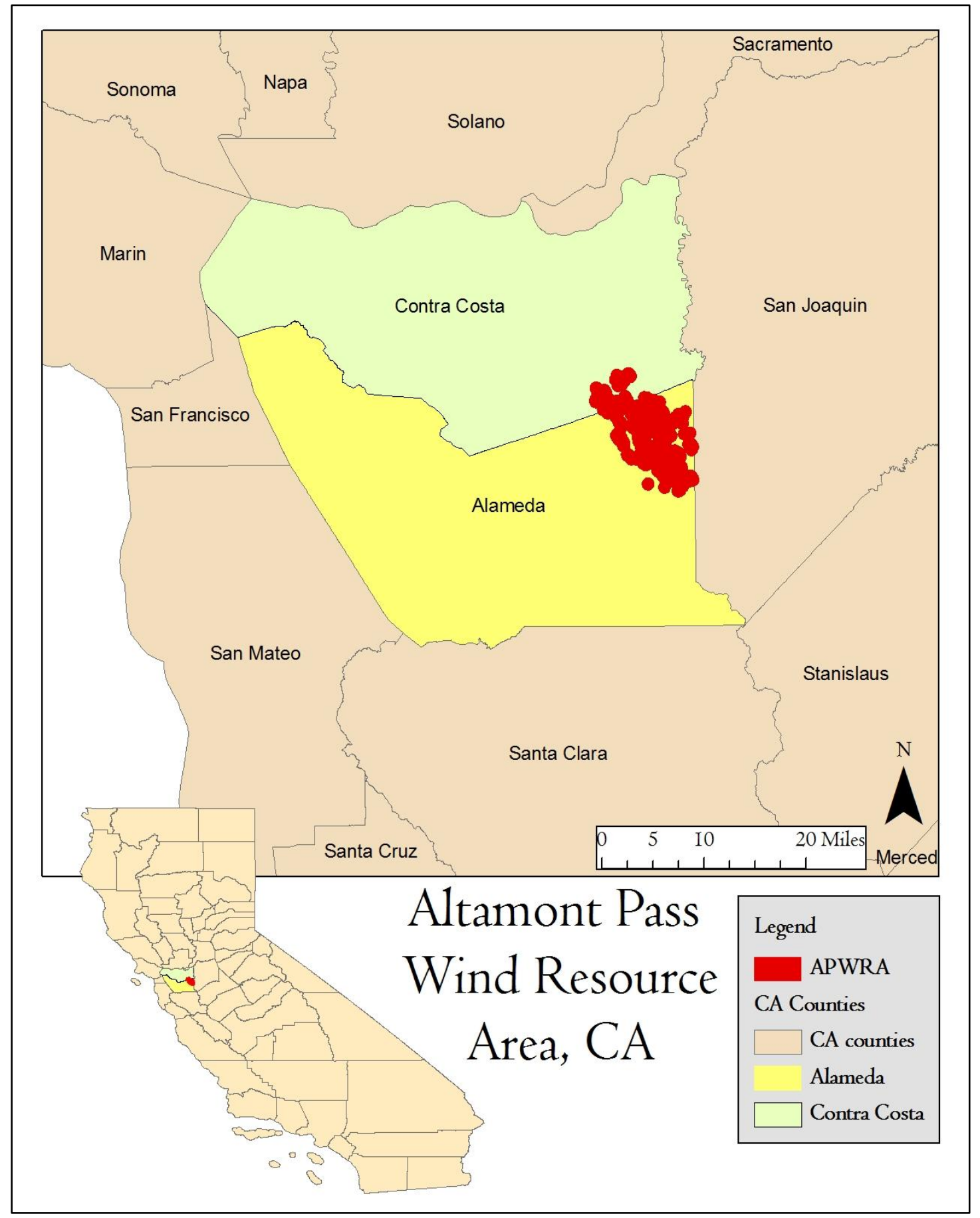

All maps created by Andrew Pinger in ArcMap 10.0, 2011-2012 


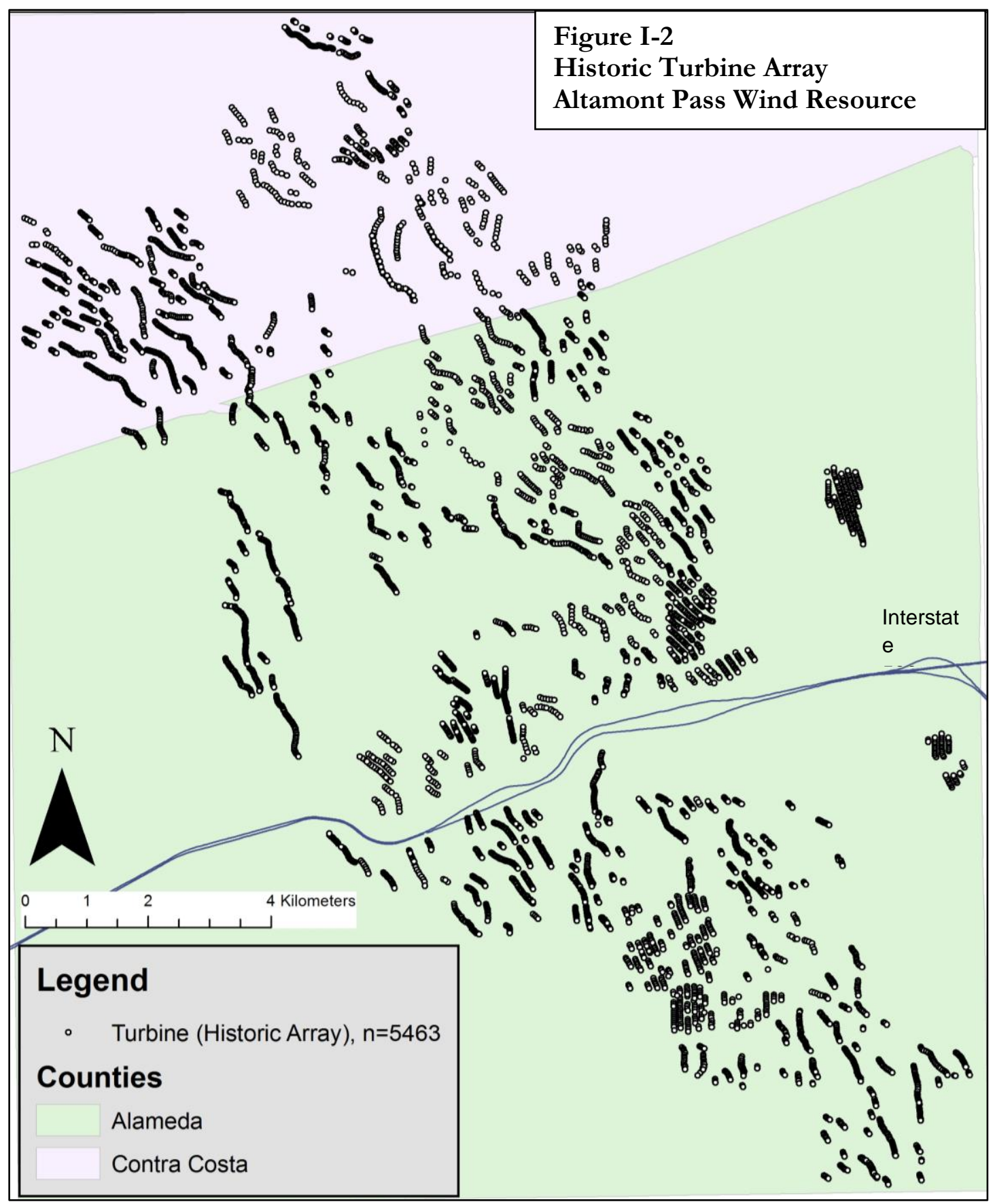

Introduction 
Figure I-3: Aquila chrysaetos Range Map

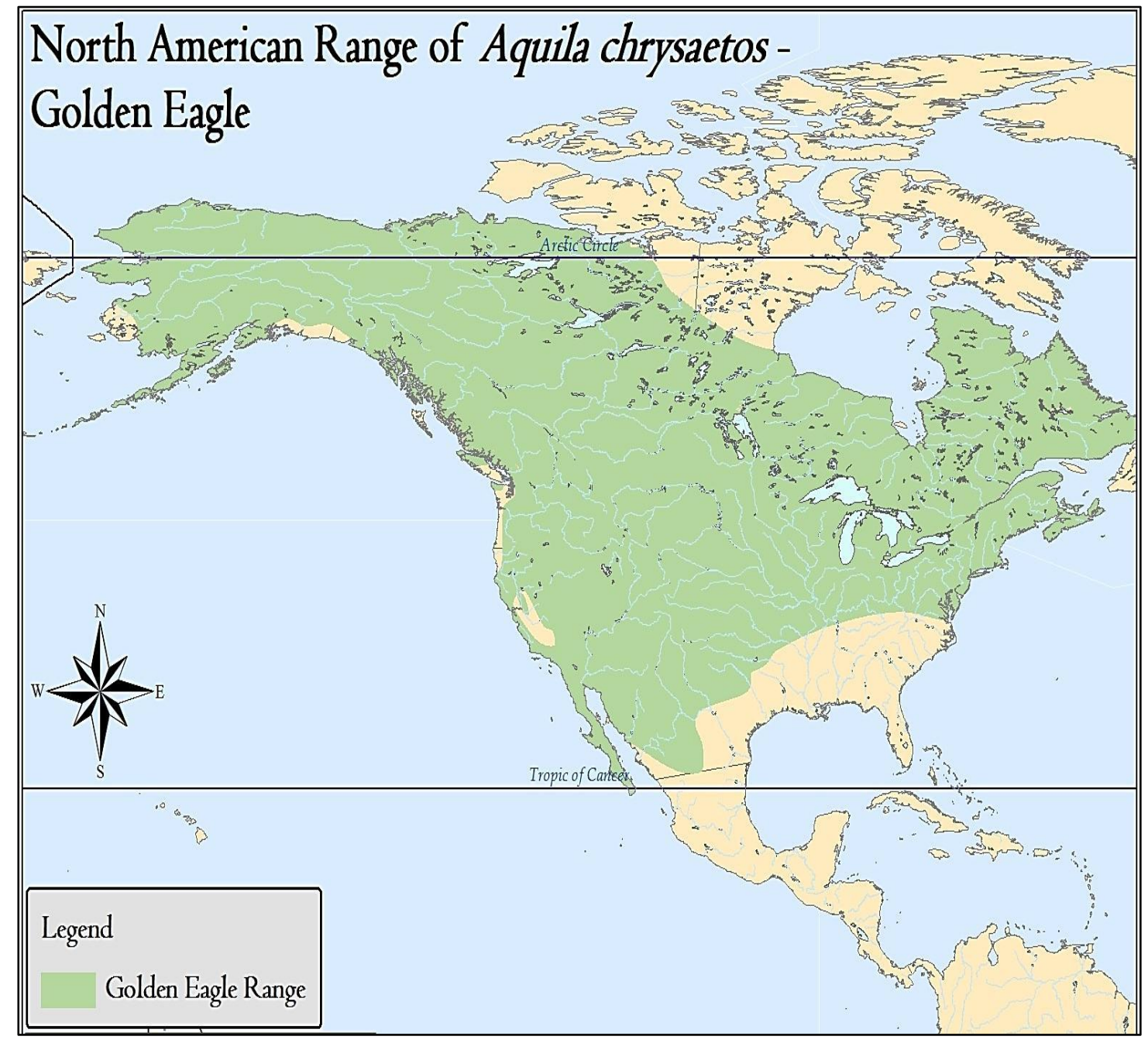

Map data provided by NatureServe in collaboration with Robert Ridgely, James

Zook, The Nature Conservancy, Migratory Bird Program, Conservation International,

Center for Applied Biodiversity Science, World Wildlife Fund, U.S. and Environmental Canada and WILDSPACE. 
Table I-1: Turbine Models in the Historic Array

\begin{tabular}{|c|c|c|c|c|c|}
\hline Turbine Model & $\mathbf{n}$ & $\begin{array}{l}\text { Tower } \\
\text { Type(s) }\end{array}$ & $\begin{array}{l}\text { Tower Height } \\
\text { (m) }\end{array}$ & $\begin{array}{c}\text { Generating } \\
\text { Capacity }(\mathrm{kW} / \mathrm{h})\end{array}$ & $\begin{array}{c}\text { Rotor Swept } \\
\text { Area } \\
\left(\mathrm{m}^{2}\right)\end{array}$ \\
\hline $250 \mathrm{KW}$ & 20 & Tubular & 80 & 250 & 490.6 \\
\hline Bonus & 536 & Tubular & $60-80$ & $65-150$ & $197.1-421.2$ \\
\hline Danwin & 39 & Tubular & 80 & $110-160$ & $283.1-421.2$ \\
\hline Enertech & 170 & Lattice & $60-80$ & $40-60$ & 141.3 \\
\hline Flowind & 169 & $\begin{array}{l}\text { Vertical } \\
\text { Axis }\end{array}$ & $92-102$ & $150-250$ & $228.8-280.5$ \\
\hline Howden & 86 & Tubular & 112 & $330-750$ & na \\
\hline Kenetech 56-100 & 3400 & Lattice & $60-140$ & 100 & 253.9 \\
\hline KVS 33 & 41 & $\begin{array}{l}\text { Lattice \& } \\
\text { Tubular }\end{array}$ & $80-120$ & 400 & 855.3 \\
\hline Micon & 221 & Tubular & 80 & 65 & 197.3 \\
\hline Mitsubishi 1000A & 38 & Tubular & 60 & 1000 & 253.8 \\
\hline Nordtank & 371 & Tubular & $78-80$ & $65-150$ & $197.1-421.2$ \\
\hline Polenko & 12 & Tubular & 80 & 100 & 254.0 \\
\hline V-47 & 31 & Tubular & $164-180$ & 660 & 1730.4 \\
\hline Vestas & 202 & Tubular & $45-80$ & 95 & $226.4-260.0$ \\
\hline Windmaster & 101 & Tubular & 23 & $50-250$ & 294.0 \\
\hline Windmatic & 26 & Lattice & 60 & 65 & 168.2 \\
\hline Total & 5463 & & & & \\
\hline
\end{tabular}

Introduction 
Table I-2: Morphometric Characteristics of Golden Eagles

\begin{tabular}{|c|c|c|c|}
\hline Trait & Female & Male & Source \\
\hline Mass (grams) & $3374-6124$ & $2495-4281$ & Edwards, 1986 \\
\hline Mean Wing Chord (mm) & 640.4 & 595.0 & \multirow{2}{*}{ Bortolotti 1984 } \\
\cline { 1 - 2 } Wing Chord Range (mm) & $601-674$ & $569-619$ & \\
\hline
\end{tabular}

Table I-3: Composition of Golden Eagle Diet

\begin{tabular}{|c|c|}
\hline \multicolumn{1}{|c|}{ Animal Group } & Percent \\
\hline Rabbits and hares & $54.1 \%$ \\
\hline Marmots, prairie dogs and ground squirrels & $21.8 \%$ \\
\hline Game birds & $8.0 \%$ \\
\hline Hoofed animals & $4.4 \%$ \\
\hline Passerine birds & $3.2 \%$ \\
\hline Deer & $1.9 \%$ \\
\hline Domestic Livestock & $1.4 \%$ \\
\hline Mammalian predators & $1.2 \%$ \\
\hline Avian predators & $0.9 \%$ \\
\hline Waterfowl & $0.5 \%$ \\
\hline
\end{tabular}




\section{Methods}

Rather than undertake a novel study that would likely be limited in scope and breadth to what a single researcher could collect in one or two seasons, publicly available data including thirteen years of observations, fatality searches, and geographic data, were accessed and used. The Altamont Pass Wind Resource Area's Scientific Review Committee (SRC) provided these data on their website's avian monitoring data portal. This portal was created and is maintained by the Portland, OR, staff of ICF International, a Virginia-based company that was contracted by the SRC to conduct bird monitoring and analysis of fatalities at Altamont.

The available data can be manipulated in standard, publicly available software such as Microsoft Excel. Three tables in particular were used to calculate and analyze bird fatality information. The first is a fatalities table that includes all fatality records from 1998 to present. The second is a turbine table that holds information of the wind turbine array at Altamont. Finally, there is a transect table that consists of records of searches, dates, and protocols of the Altamont bird monitoring program. The following section contains details of each of these tables, and the most pertinent fields from each table are described.

\section{SRC Fatalities Table}

This table includes every record of a bird or bat fatality recorded at Altamont since May 1998. There are 7,560 records between May 1998 and December 2011. Each record has 73 fields including such characters as species, discovery date, carcass condition, searchers' initials, etc. A full listing of the 73 fields can be seen in Appendix A, including metadata for each field. 
Biologists conducting monitoring surveys at Altamont completed a fatality report for each detection of a bird or bat fatality they found. Each fatality report appears as a record in the fatality table. A copy of a fatality report completed in the field appears as Appendix B.

Protocols for detecting bird fatalities at Altamont have evolved over many years. Current protocols include search transects walked by field biologists along a predefined route (SRC 2007). The distances between transect routes in a search area is $6-8$ meters. This distance accounts for a 3-4 m sightline on either side of the searcher. The searched area surrounding a turbine in Alameda County continues to a $50 \mathrm{~m}$ radius from the turbine base. For some turbines in Contra Costa County, the radius extends to 60 and $75 \mathrm{~m}$, depending upon the height of the turbine. The taller turbines are afforded a larger search radius because it is reasoned that a taller turbine with longer blades may throw a bird carcass further than the smaller bladed turbine.

The array of turbines monitored at Altamont (Fig. I-2) is divided in two by Altamont Pass Road with approximately half of the array on the north side of the road and half on the south. Turbines are grouped into plots, which may contain multiple strings. Each string contains numerous turbines. Each turbine is searched once a month according to a predetermined transect schedule.

When a dead bird is discovered, biologists complete a fatality report by collecting information about location of the body relative to the nearest turbine or other structures. Global Positioning System (GPS) coordinates of the carcass are recorded using a handheld GPS device. Also recorded at the time of detection are the plot, string number, and the turbine label or turbine id. 
Valid detections of a bird fatality do not require a complete or even a partial carcass. Due to the presence of numerous bird and mammal scavenging species at Altamont, it is clear that a bird could be killed by a turbine and completely removed by an animal such as a badger or coyote. When this happens, few traces of the bird may remain. The M1 protocol indicates that discovery of either 5tail feathers, or 2 primaries, or any combination of 10 total feathers, all can be considered a valid, turbine-related fatality. A detection such as this is referred to as a "feather spot". The discovery of a feather spot suggests the presence of a scavenger in the area, and that this scavenger may have removed the remainder of the carcass (SRC 2007).

Carcasses or remains are identified to the species and the age and sex of the bird is determined if possible. Plumage patterns, carcass size, and beak, foot or other morphological feature may be used to determine the taxonomic identity of a given fatality.

The condition of the carcass is described in the detection form. Through the notes and body parts fields, the monitoring team describes what was found. This will include descriptions of feathers, parts of a carcass or a complete carcass. Given the description and details regarding stage of decomposition, an estimate may be made of time since death and cause of death. Evidence of scavenging can also be assessed by presence of insects, gnawed bones or feathers, or absence of body parts.

A bird fatality may be discovered the day it was killed, or months after its death. It is because of this temporal uncertainty that the date of discovery must be recorded in order to estimate the date of death. Estimates take into account carcass condition, or state of decay of the carcass and amount of time elapsed since the last search was performed at that site. For 
this study, the specific day or month of death is not used. Only the year of the bird's death was used to create annual fatality counts.

Causes of death for bird fatalities are determined using protocols in the M11 determination of cause of death manual (SRC 2008a). Any golden eagle that is found within the search area and does not show signs of electrocution is considered to have been killed by a turbine collision unless the condition of the carcass is so scattered or deteriorated that the cause of death is considered Unknown. The unknown designation may be used when only bone fragments or loose feathers remain. The M11 cause of death protocol is available as Appendix C.

Following the initial collection of fatality data in the field, fatality records were given unique identifying numbers. They were then filtered and given a status id that indicated how the record would be considered for future analysis. For example, it may be determined that a single dead bird was detected more than one time and/or on more than one day. When multiple fatality records refer to the same bird, then detections after the first one are given a status id of 11, which is a duplicate detection of a known fatality. If a bird is found more than 125 meters from the closest turbine, it is given a status id of 4, and is excluded from this study. Excluding records of birds found outside of the turbine search radius ensures that extraneous non-wind turbine caused fatalities are not added into fatality estimates. All records were graded according to the M26 decision tree for Altamont bird fatality data filtering protocol (SRC 2008b). Only golden eagle records with a status ID of 1 - valid turbine related fatality - were used in this study. 
The first step in working with the fatality table was to filter records at the species level and remove all records that were not golden eagles. The second step was to filter the table by status id and remove all records that had a status id other than 1.

Among the most important fields in the fatality table is the turbine label field. The turbine label is an identifier that appears on the wind turbine tower. When a biologist finds a bird fatality, he identifies the nearest turbine to the fatality and records its turbine label. This creates the initial pairing of a fatality to a specific turbine, hence to that turbine's attributes.

This leads to one of the assumptions of this work. It is assumed that the turbine closest to a bird fatality is the turbine that killed that bird. This is potentially problematic for several reasons. It is possible that a scavenger could have moved a bird's body. Alternatively, birds injured by turbine strikes that did not die right away may have sufficient mobility to cross from one search area into another. If an injured bird then died in the adjacent search area, a non-offending turbine would be credited with the bird's death. In fact, Hunt found that five of 42 blade-stuck golden eagles his study were able to live through the initial trauma long enough to wander away from the turbine's search radius (2002).

Because there are rarely if ever eyewitnesses to bird collisions with wind turbines this assumption must be made. The work of the SRC is to verify annual fatality counts for target species in accordance with the settlement agreement (Golden Gate Audubon Society 2007). Because this charge is narrowly focused on counting and calculating fatalities, there have not been efforts introduced to verify the relationship between a carcass location and the identity of the turbine that was responsible for killing it. As Hunt's findings demonstrate, there is clearly room for error, but no estimate has been suggested.

\section{SRC Turbine Table}

Methods 
The turbine data table available from the SRC bird monitoring data portal includes ownership and operator information as well as location and model details for each of the 5,463 turbines that have operated at Altamont between 1998 and 2011, the temporal range of the present study. These data come from wind farm operators and includes $\mathrm{X}$ and $\mathrm{Y}$ coordinates for each turbine. A listing of the 27 fields in the turbine table can be seen in Appendix D, including metadata for each field.

The turbine table was used to join fatality data to turbine data. By matching turbine labels with string ids, turbine ids were assigned to fatality records. Once this process was completed, a new variable and field was created denoting whether a turbine is a golden eagle killer or not. Turbines that have fatalities connected to them were considered "kill turbines," while those that had no golden eagle fatalities connected to them were considered "nonkill" turbines.

Two of the most important fields in the turbine table are "date installed" and "date removed" fields. The values in these fields give calendar dates for when the turbine was installed and when or whether a turbine has been uninstalled. With these data, an annual census of the turbine array was calculated. Turbines have been removed from Altamont for a number of reasons including repair, disuse or repowering, a strategy of removing many smaller turbines and replacing them with fewer, larger, more efficient turbines.

The presence census is just an initial step in describing the turbine array. Because not every turbine is monitored every year by the field biologists, it is important to determine what turbines were searched and how often they were monitored. This is done by incorporating the transect table from the SRC data portal.

\section{SRC Transect Table}


The transect table is a document that consists of 20 fields and 26,601 transect records. A transect is a record of when the turbines of a given string were searched. Initially the string number referred to a unique set of wind turbines that were geographically grouped together in a line or string on the landscape. Over the years with additions and removals of turbines, the geographic cohesiveness of the turbines in any given string has been inconsistent. Because of this, string numbers became anachronistic and data managers had to code each turbine with a string number and create a string id field that would be constant. Because neither the string number nor string ID fields currently reflect cohesive, consistent or accurate geographic relationships of turbines, I created a new field called screen id that does capture accurate geographic relationships among turbines. More about screen ids will be described in the next section.

The two most valuable fields in the transect table are the string number and the monitoring year fields. Each transect can be joined to the turbine table through the string number. This allows one to tally the number of times each turbine was searched each year. The number of times a turbine was monitored each year was calculated and added as a new field to the turbine table.

This introduces the second major assumption of this research. When a string number appears in the transect table, there is a corresponding field called "number of turbines." This refers to the count of turbines in that string number group. When the transect table shows a string number searched on a particular date, it is assumed that all of the turbines on that string are searched on that date. This assumption is made because the transect table is not detailed enough to display a list of transects for every turbine, for every occasion that it is searched. The turbines are grouped into strings, and only the string number is listed. The 
transect table is simply the document of record and does not indicate partial string searches, so it must be assumed that all turbines were searched. A listing of the 20 fields in the transect table is provided in Appendix E, including metadata for each field.

\section{Data Production}

In this section I describe how I generated new data by manipulating the data from the three tables described above, and how I created new information using Microsoft Excel tools and Esri's ArcGIS programs. Table M-1 lists each turbine variable, a brief description and an indication of the origin of the data. Many of the data come directly from the SRC monitoring data tables, but a significant portion of it was calculated using the tools mentioned above. What follows is a description of each variable and what was done to calculate its values.

The first step in calculating and analyzing data was to ensure that all of the provided information was error checked and corrected. Fields that included N/A values or spelling errors had to be rectified, and any numerical field values with supernumerary digits fixed. Many of the variables in Table M-1 required the use of a GIS program to calculate. I used ESRI's ArcGIS software suite including ArcMap version 10.0 and ArcCatalog version 10.0 to import data and geographic files to compute these values.

Once the downloaded turbine, fatalities and transect tables were cleaned up and error checked, they were combined into a single Excel file. From this point forward, all new calculations were added as fields into a singular table. In the following descriptions of this process I will make distinctions between the original provided data tables by prefacing them with SRC: for example, SRC turbine table. 
Using X, Y and Z (elevation) coordinates, I imported turbine data into ArcMap to establish the historic array geographically. Once the historic array was mapped, sequential annual map layers were created according to whether each turbine from the historic array was present or not. To undertake this step I referred to annual presence fields detailed on the next page. I added an elevation raster dataset from the United States Geological Survey's National Elevation Dataset (NED). The N38122W dataset has 1/3 arc-second resolution with the following bounding coordinates: West: -122.00056, East: -120.99944 , North: 38.00056 and South: 36.99944. I converted the raster set into a shape file, and used the clip tool to reduce its size to an area just larger than that covered by the Altamont turbine array. Clipping the elevation layer made data calculations and rendering more manageable and nimble. This clipped NED layer was used throughout this study and provides the foundation for many thousands of calculations.

\section{Kill Turbine}

This is the response variable in this study and refers to whether or not a turbine has been responsible for killing a golden eagle. This binomial variable was calculated through Excel vertical lookup formulas that combined the turbine label and string number fields from the SRC fatalities table to the string number and turbine id fields of the SRC turbines table. The new binomial field was populated as true for those turbine records that were linked to golden eagle fatalities records, or false for those turbines that were not associated with any golden eagle deaths.

\section{Number of dead golden eagles}


This variable represents the number of golden eagle fatalities per turbine, per year. A "dead eagles" field was created in the turbine table for each year of the study and a field for total dead eagles was included. Filtering the turbine table for kill turbines populated these fields. Golden eagle records from the fatalities table were then put into a pivot table that produced an accounting of how many eagles per year were killed. The number of dead golden eagles was then entered into the appropriate field for each turbine.

The SRC fatality table includes fields for sex and age, but the data collected by the biologists at the time of discovery are not complete. Fig. R-3 in the results section shows the distribution of age class for golden eagle fatalities. The sex of an eagle carcass must be difficult to establish because among the records used for this study, only 2 were identified as female, and the rest were unidentified. Age class can more easily be established through feather molt sequence and patterns of color that change over the course of an eagle's age (Liguori 2004, Ellis 2004). This may account for why the age records are more complete.

\section{Presence}

For the purposes of this study it is necessary to determine what turbines were present each year. The SRC turbine table has installation and removal dates for many of the records, but not all of them. There are no installation data for 2,145 of 5,463 records; I therefore assume that they were present at the beginning of the study in 1998. The remaining 3,318 records were counted as present according to the published installation date. The SRC table has no removal data for 3,468 records, so I assumed that these 3468 turbines continued to be present through the end of the study period, 2011. Using this information, annual presence fields were added to the turbine table and were named PRE98-PRE03, PRE05PRE11. 
These presence fields were populated by the binomial variables true and false. When the turbine table was later imported into ArcMap for rendering, these annual presence fields were used as the source for creating presence turbine shape files in ArcMap. This allowed me to create maps of turbines present for each year. Details on how these maps are created appear in the screen id section. These generated maps are critical in calculating other variables such as end row status, screen count, nearest turbine model, nearest turbine distance, density, diversity index, etc. An annual presence summary table appears in the Results section as Table R-4.

\section{Monitored \& Monitored Count}

Annual presence of turbines is important in calculating numerous variables, but before testing can begin, another filter must be created to account for what turbines were monitored or not. Because the array at Altamont is so large, it is both financially and logistically prohibitive to monitor or search every turbine. Biologists and statisticians, along with the Scientific Review Committee have designed a monitoring protocol in which turbines are search every 4-6 weeks. There are however, some turbines in the annual array that are never monitored. And there are some turbines that are monitored some years but not others. Therefore annual monitored fields were calculated.

Merging the SRC turbine and transect tables produced this variable. Using the transect table as a source, an Excel pivot table was created that displayed the sum of transects for each string id for every year. These data were then referenced back into the turbine table through a vertical lookup formula using sting id as a lookup value. This was done per turbine per year. The result was the creation of "yearly monitored count" fields for each turbine. 
The yearly monitored count fields were copied and pasted onto the end of the turbines table to be converted into binomial variables so that data manipulation was more efficient. Rather than monitored counts, each value was converted to true or false. If the monitored count was greater than zero, it was converted to True. If it was zero, the value was changed to False. This step provided new ways to sort and manipulate the data and allowed for more calculations. It also provided the definitive list of what turbines were monitored for each year. A summary table of annual monitored turbine counts is included in the results section as Table R-5.

An important correction was necessary before this dataset was ready to analyze, having to do with presence vs. monitored status. As new turbines were added into the array, they often were included into previously established turbine strings. Because the monitoring count calculations were made using the string id on the historic array table, some turbines were given credit for being monitored even before they were present. This was corrected by using the AND function formula in Excel: the yearly monitored fields were checked to see if they were getting credit for monitoring when they were not present.

$$
=A N D(A E 16=F A L S E, A S 16=T R U E)
$$

This formula checks to see whether the value in the presence was false, and if the value in the monitored field was true. When cells with incorrect values were found, each was corrected in both the yearly monitored and yearly monitored count fields. Once the turbine table included yearly monitored fields, it was possible to import it into ArcMap to create turbine array maps of only monitored turbines.

\section{Turbine ID}


As mentioned in the sections above, this is a unique value for each wind turbine that has ever been placed at the Altamont Pass Wind Resource Area. Through joining the turbine table to the SRC transect table, golden eagle fatalities were permanently linked to the characteristics of turbines that are considered responsible for each bird's death.

\section{Turbine Model}

The turbine model field is populated directly from the SRC turbine data table. There are 16 different models that have been present at Altamont. The list of turbine models appears in Table I-1 as well as in several tables in the results section.

\section{Elevation, Slope and Aspect}

These are the first three geographic placement variables considered. Elevation is height above sea level at the base of the wind turbine tower, measured in meters. It is important to know if a wind turbine's elevation plays any role in golden eagle deaths because the widely varying landscape throughout Altamont provides opportunities for diverse placements of towers.

Most turbines at Altamont are placed somewhere on a hillside. Slope is a measurement of prevailing pitch of the hill under which the turbine tower stands. It is measured as a proportion of the amount of elevation gain over a measured distance.

Aspect is a measurement of the prevailing direction that the hillside faces and is measured in degrees. Because it is measured in degrees, it is circular data, and is analyzed as such. There is a package available for $\mathrm{R}$ named 'circular' that calculates circular statistics and creates graphic displays of data. It was used to analyze all aspect data for this study. Appendix F includes the R scripts and explanations for how the 'circular' package is used. 
The majority of elevation, slope and aspect values were already populated in the SRC table, but some of the more recently installed turbines had incomplete records, and were calculated using ArcMap.

To calculate missing values, a turbine table was imported into ArcMap and converted into an object-oriented shape file using the $\mathrm{X}$ and $\mathrm{Y}$ coordinates for turbines placements. The 1/3 arc-second resolution National Elevation Dataset (NED) raster file previously mentioned was added as a layer into the document. With the NED file and turbine locations assembled together, each turbine with missing slope, elevation or aspect was selected and the missing information was displayed in the object's attribute table. The data were manually entered into the turbines table for analysis.

\section{Tower Type}

This variable refers to the type of structure that elevates the actual turbine mechanism to heights where it harnesses wind to generate electricity. There are three tower types that prevail in the Altamont array (Fig. I-3) - lattice, tubular and vertical axis. Lattice towers have an open architecture that somewhat resembles of the Eiffel Tower, with exposed rails and girders. These types of towers may also include guy wires for additional support. Tubular towers resemble solid columns from the ground to the turbine and include internal ladders for maintenance workers to access turbines. Finally, vertical axis turbines (also known as egg-beater turbines) are a novel design. They typically have two curved blades that emanate from the base and reconnect to the top of the axis. Guy wires are incorporated for additional support. Most of the records in the SRC turbine table were complete for this field, but some were calculated using other turbine records as references. 


\section{Tower Height}

The height of the tower is measured in meters from the base to the turbine axis in horizontal axis models. In vertical axis models, this measurement is from the base to the top of the axis. This variable was provided in the SRC turbine table. Higher tower height was found to be linked with increased bat fatalities, but not with increased bird fatalities (Barclay 2007, Thelander 2003). Due to the golden eagle's low elevation contour flight pattern, investigating tower height was seen as important to this study.

\section{Rotor Swept Area}

Rotor swept area refers to the total space swept by wind turbine blades as they operate. This is a value that was given in the SRC turbine table for most turbines, and was converted from square feet into square meters.. For the towers in which the value was not given, rotor swept area was calculated by using the blade length (given in the SRC table) as the radius in the following formula:

$$
\pi \mathrm{r}^{2}=\text { Area of a circle }
$$

\section{Generating Capacity}

This variable was given in the SRC turbines table, and refers to the rated energy generating capacity measured in kilowatts per turbine. Generating capacity is one measure of the size of a turbine. There is a question of whether or not a smaller turbine is more dangerous to birds. If the turbine is less conspicuous, or has faster spinning blades, perhaps birds would not notice the turbine's presence before they were struck. By comparing the generating capacity of fatal turbines to those that have not killed golden eagles, one may be able to begin finding evidence for or against some of these concepts. The Altamont 
settlement parties measure biological costs of energy production in the form of fatalities/megawatt/hour/year, and the industry uses this same metric to compare bird and bat fatality rates of one wind farm to another.

\section{Settling Party}

This is a binomial variable calculated using the SRC turbine table. Preceding the settlement agreement, seasonal experimental shutdowns of some wind turbines had been practiced. Following the 2007 settlement, those wind operators identified as Settling Parties commenced a regimented seasonal shutdown program. A list of turbines that were shutdown was not available, but the turbine table includes ownership information. AES Seawest, Altamont Power, Altamont Winds, enXco, and NextEra are the wind operators that are considered settling parties, so all turbines owned by those companies were marked as true. Those owned by other companies were marked false.

\section{Ridge Top Turbines}

To calculate whether a turbine exists on or near a hilltop ridgeline, a series of calculations were made according to the steps outlined on ESRI's support page (Article 39093 October 2011). Using the Digital Elevation raster (DEM) along with the map algebra and hydrology toolsets, line features were created that represent continual high point ridges throughout the APWRA. Briefly, the hydrology toolset can be used along with a DEM to discover watershed features and low points throughout a map. This is helpful in determining where a stream is or should be and predicting which direction water flow will occur. Using the map algebra tool, all of the values in the DEM layer were multiplied by -1 . This step 
inverted the elevation layer turning the high points at Altamont into low points so the hydrology tools could be used.

The hydrology toolset picked out the lowest points and probable stream channels. Inverted, these were the ridgelines, or complete opposites (-1) of streambeds. Ridgelines were then exported as a separate line feature layer and added to the map. The complete sequence of steps in this calculation is available in Appendix G.

Next, the near tool in the analysis tools toolbox was used to calculate what turbines in the historic array are located within $10 \mathrm{~m}$ of previously calculated ridgelines. The historic turbine array table was used as the input for this calculation because it is the complete list and because the turbines never moved from the locations in that table. The ridgelines shape file was used as the near feature and a search radius of $10 \mathrm{~m}$ was selected. This calculation returned distance values for every turbine that was at or within $10 \mathrm{~m}$ of a ridgeline. These data were then joined to the turbines table as a single binomial field named RDGTP with values of either true for those at or within the $10 \mathrm{~m}$ radius or false for those that were outside of the $10 \mathrm{~m}$ radius.

\section{End Row Turbines}

As a bird approaches a row of turbines on an intersecting path, it may consider the row as a single entity on the landscape rather than a collection of individual turbines. With the turbines as densely arrayed as they are at Altamont, this idea merits consideration. If a bird attempts to fly around the turbine row rather than through it, it may instead be in close proximity to the turbines at the end of the row. If this does occur, then end row turbines should have more opportunities to kill birds and should have a higher fatality count to support this hypothesis. 
Like screen count, end row turbines are determined on an annual basis. Using the annual turbine presence layers described above, a visual survey of every turbine screen was performed to determine end row turbines. Standalone turbines were not considered to be in a row and were given a value of false.

\section{Saddle}

A saddle refers to a dip in ridgeline on a hill or mountain. From ground level it will appear as a depressed area between two peaks of higher elevations. Another name used by mountaineers for this feature is col. With elevations between zero and $650 \mathrm{~m}$ above sea level, the terrain at Altamont does not offer the most dramatic examples of hill saddles, but they are present. Hill saddles are of particular interest in this study because they represent probable flight paths for birds that are intent on overcoming a ridgeline by using the lowest elevation passage possible. Turbines placed in a hill saddle would then be close to more birds passing by, therefor theoretically having an increased chance at making contact.

Turbines in hill saddles were located using ArcMap. Unfortunately I was not aware of any single tool, $3^{\text {rd }}$ party package, SQL script or formula that can easily identify hill saddles from an elevation profile or dataset. Therefore the calculations for whether or not a turbine stands in a hill saddle are a mix of new mapping technologies and old map reading techniques as described below.

I used the contour tool in the spatial analyst toolbox. The $1 / 3$ arc-second resolution NED raster was once again used as the input raster and a contour interval of 10 meters was selected. This produced a tidy polyline feature that was incorporated into the base map. Hill shades were created using the $3 \mathrm{D}$ analyst hillshade tool to make the map easier to read and understand. I then loaded the historic turbine array shape file and displayed the turbines 
according to their $\mathrm{X}$ and $\mathrm{Y}$ coordinates. Then I examined each of the 5,463 turbines of the historic array and characterized each as being in a hill saddle or not. Turbines that were obviously not saddle turbines due to the character of the contour lines, I marked as false. For those turbines that were closer to obvious saddles I used a distance-measuring tool in ArcMap. If a turbine was within $25 \mathrm{~m}$ of the center of a hill saddle, I marked it as true. I used $25 \mathrm{~m}$ as a measurement to include those turbines that were not centered in the saddle path, of which there were few. Because the contour line interval was set to $10 \mathrm{~m}$, the resolution is not very high. Hill saddles are typically not narrow avenues. Most at Altamont were 30 - 50 meters wide measured from one contour line to the same contour line on the other side of the saddle, so a $25 \mathrm{~m}$ radius is reasonable.

\section{Fishnet ID}

Both the turbine density and Shannon diversity index variables rely on the creation of a parameter that defines a geographic space. This was done in several steps by creating a grid that overlays the full extent of the Altamont Pass Wind Resource Area. First the buffer tool in the proximity toolkit was used to create $100 \mathrm{~m}$ buffers around each turbine of the historic array. This step was done to increase the footprint of the array. The buffer tool was set to dissolve all of buffers into several large polygons in a single shape file.

The next step was to run the create fishnet tool in the data management toolkit and use the previously created footprint shape file as the extent input. By using this input, the fishnet that was produced would be confined to the smallest area that would cover the entire array. Ideally the fishnet would consist of squares that were each $1000 \mathrm{~m}$ by $1000 \mathrm{~m}$, but because of some limitations of the tool and the size and shape of the array, the finalized fishnets were not exactly that size. 
The finished fishnet grid consists of 19 rows and 16 columns (Fig. M-2). Each fishnet square measures $1011.76 \mathrm{~m}$ long by $981.25 \mathrm{~m}$ wide. This equals $992795.41 \mathrm{~m}^{2}$ per fishnet square, or $0.993 \mathrm{Km}^{2}$ per fishnet square. The finished fishnet grid was saved as a polygon shapefile. Using the spatial join tool in the analysis toolkit, the turbine table shape file and the fishnet polygon shape file were joined. This step added new fields to the turbines shape file attribute table that included the name of the fishnet id for every turbine record. The updated turbine attribute table with the new relationship between turbine ids and fishnet ids was exported back into Excel for further manipulation including calculations of fishnet diversity and density.

\section{Density}

The density of the turbine array is an important variable to consider. The array at Altamont was established well before many of the best practices for wildlife collision avoidance were created. Altamont's turbine towers were placed in close proximity to each other and turbine rows are sometimes established so closely to each other that they create a "wind wall." It is thought that a less dense array could provide birds with more space to maneuver through the three dimensional landscape without making contact with a turbine.

Density is calculated using the turbine table with the fishnet id field and Excel pivot tables and formulae. The first step in calculating turbine density per fishnet square was to determine which fishnet polygons contained turbines and which did not. This was done with Excel pivot tables using the updated turbine table as a data source. Pivot tables were created and filtered for turbine presence for each year. These tables calculated the count of turbines by turbine model for each fishnet id and provided a grand total of turbines per fishnet square. Fishnet squares with zero turbines were dismissed. The count of turbines present per 
fishnet id was then divided by $0.993 \mathrm{Km}^{2}$, the area of each fishnet sq. This gave each fishnet id a measure of turbines per square kilometer, per year. These density values were then added to the turbines table by way of the fishnet id.

\section{Shannon Diversity Index}

Because this is a biological study of a complex system, the diversity of actors within that system is an important variable to consider. As I calculated a measure of diversity in this study, turbines were treated as organisms (species) within the landscape, and each species being designated by its turbine model. There are, or have been, 16 different turbine models present at Altamont, so species richness for the full historic array is 16. The turbines however, are not evenly distributed throughout the array and turbine models have varying levels of dominance within designated smaller plots, which changes annually.

The question is whether or not the response variable (dead golden eagles) has a relationship with the measure of diversity that is calculated. Will the turbines that have killed eagles be more often members of a monoculture of just one turbine model, or the turbine be a member of a more diverse array of turbine models?

To calculate a measure of turbine diversity, the fishnet squares shape file and the turbine table were used. Excel pivot tables were used extensively to produce output tables that described each fishnet square, and the count of each turbine model within it. An example of this pivot table is the table for 1999 shown in Appendix H. Once tables were created for each year of the study, they were merged together to produce a Shannon diversity index.

The Shannon index is a widely used measure in biology and ecology, although it was originally developed in the telecommunications industry. It is considered a suitable measure 
of habitat diversity (Brower 1997) as it accounts for both evenness of species presence, as well as overall abundance. The formula is:

\section{$H^{\prime}=-\Sigma p_{i} \ln \left(p_{i}\right)$}

where $H^{\prime}$ is the Shannon diversity index (Shannon 1948) and $\mathrm{p}_{\mathrm{i}}$ is the proportion of total number of species in the community, made up of the $i^{\text {th }}$ species.

The final calculation expresses the Shannon index as $e^{\mathrm{H} t}$. This calculation was completed for every fishnet square that contained at least one turbine and for every year of the study. The Shannon index values were then joined to the turbines table through the fishnet id field.

\section{Nearest Turbine Distance}

The proximity of the nearest turbine may be a factor in bird collisions with wind turbines. The array at Altamont is, in some places, quite densely arranged with turbines as close as eleven meters from one another. Using the "near" tool in ArcMap's proximity toolkit, the distance was calculated between a turbine and the turbine closest to it. It was necessary to calculate this for every year of the study. The near tool adds new fields into the turbine attribute table including the object id of the nearest turbine and the calculated distance. The attribute tables were exported back into Excel and the vertical lookup formula was used to populate the turbine table with these new nearest turbine distance field values.

\section{Screen ID and Screen Count}

In efforts to simplify monitoring efforts at Altamont, turbines were organized by project sites and strings. Project sites were operated by individual companies and strings were rows of contiguous turbines. After many turbine removals and new installations, some 
of these classifications were not appropriate measures for geographic analysis. To investigate how a line of contiguous turbines might affect the response variable, new fields were created as required.

Turbine screens refer to landscape-level entities composed of a consecutive, unbroken line of turbines. As turbines were added to or removed from the array, turbine screens would lengthen, shorten or dissolve entirely so screen ids and screen counts were calculated for each of the thirteen years of this study.

To do this, the historic array's attribute table was sorted through a structured query language (SQL) formula, selecting only the turbines present in 1998. This new subset of turbines present in 1998 was exported as a data table into the same ArcMap document. The 1998 presence turbine file underwent previously described conversions and was added as a shape file named Pre98. This sequence of creating turbine presence shape files was completed for each year of the study.

Turbine counts for each screen were determined through visual inspection of the annual presence layers created in ArcMap. When a screen appeared to have a gap in the middle (due to removals or repowering) then the distance tool was used to determine if the distance between turbines on either side of the gap was wider than 70 meters. If it was, then the screens were considered separate.

The following criteria were used to determine screen membership. Standalone turbines that were more than 70 meters from the next closest turbine were considered single member turbine screens. Each was given a screen count of 1 and a screen id that equaled its turbine id. 
Turbines in an easily recognizable line grouping were counted as a single screen as long as there were no gaps more than 70 meters between a given turbine and its nearest neighbor. Each turbine was given a screen id consisting of the turbine id of the most northerly or westerly turbine id, followed by the turbine id on the most southerly or easterly turbine id. These screens had a screen count equal to the number of turbines present in the screen. In cases where screens contained "wind walls", or turbine screens with a visual double stack of turbines, all turbines were counted as members of one screen.

\section{Turbine Variable Testing}

Variables were tested using Student's t-test and Chi-squared analysis to determine significance of summary statistics. These tests are consistent with those of previouse studies investigating wind turbine attributes as they apply to avian fatalities (Orloff 1991, Thelander 2003) and will provide easily comparable results. Chi-squared analysis was conducted on the categorical variables including turbine model, tower type, settling party, ridgetop, end row and saddle variables. T-tests were conducted on continuous variables including elevation, slope, aspect, tower height, rotor swept area, generating capacity, density, diversity, nearest turbine distance, monitoring count and screen count.

\section{Analysis of Demographic and Temporal Data}

To produce demographic data, I filtered the SRC fatality table by age class. This determined the proportion of golden eagle fatalities that were juvenile, sub-adult/immature, adult, and those that were undetermined. After testing each turbine variable (as indicated above) to discern which were significant and which were not, I applied fatality records by age class into each significant turbine variable. This allowed me to see if any of the significant 
turbine variables affected one age class more than another. The same procedure was done for the sex of the bird. The SRC fatalities table was sorted by the sex field to determine the proportion of golden eagle fatalities that were female, male, and undetermined. Due to the low fidelity of the sex data, it was not compared to significant turbine variables.

Temporal data was largely available in the SRC fatalities table. A death date field was already calculated for a majority of the records (109 of 134). This field was poplulated by taking the fatality detection date and subtracting the estimated number of days dead which was also a given field in the SRC fatalities table. For those that did not have a death date, no additional calculation was made because each of these 25 records was missing a carcass age estimation, so no death date could accurately be determined. Temporal trends were graphically plotted to illustrate seasonal and monthly fatality tendencies. 
Figure M-1: Wind Turbine Tower Types

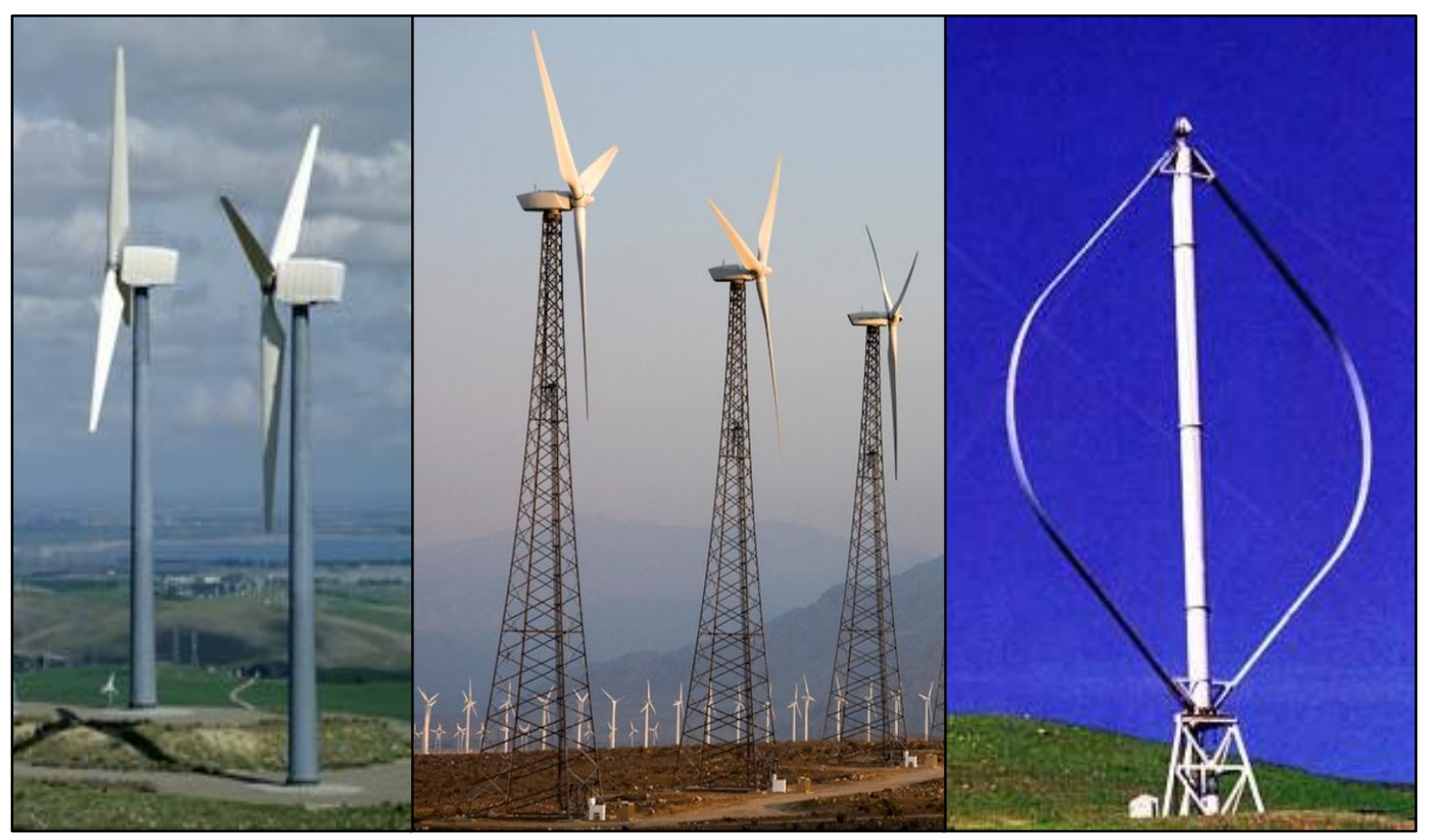

Tubular (left), lattice (middle) and vertical axis (right) tower types. 


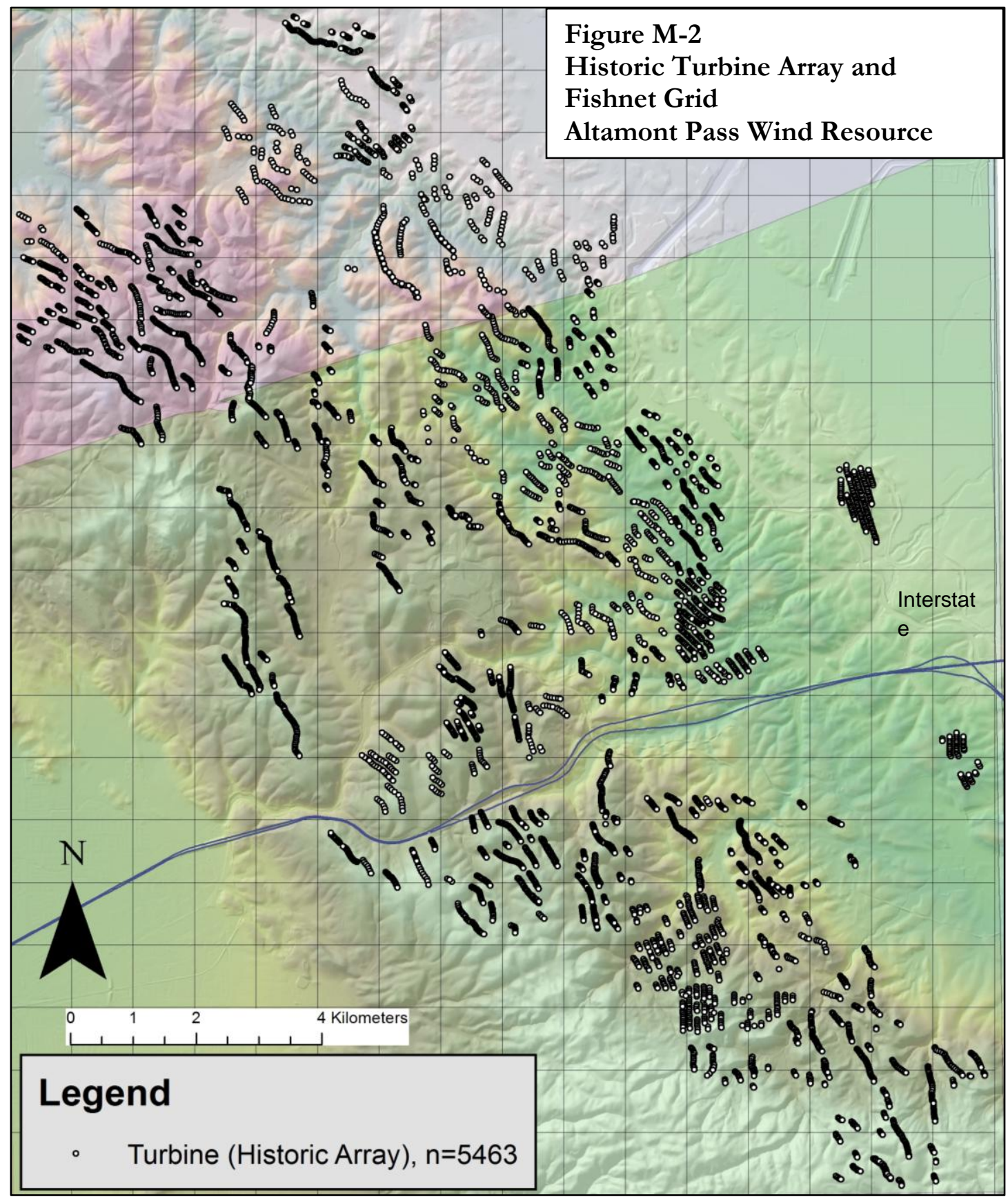


Table M-1: Given and Calculated Turbine Table Variables

\begin{tabular}{|c|c|c|c|}
\hline Variable & Variable type & Source & Code \\
\hline $\begin{array}{l}\text { Turbine has killed a golden eagle } \\
\text { or not }\end{array}$ & $\begin{array}{l}\text { Categorical, } \\
\text { Binomial }\end{array}$ & Calculated value & KILL \\
\hline Number of dead golden eagles & Continuous & Annually calculated value & $\mathrm{D}$ \\
\hline Turbine is present in the array & $\begin{array}{l}\text { Categorical, } \\
\text { Binomial }\end{array}$ & Annually calculated value & PRE \\
\hline Turbine is monitored, per year & $\begin{array}{l}\text { Categorical, } \\
\text { Binomial }\end{array}$ & Calculated value & $\mathrm{MON}$ \\
\hline Turbine's unique turbine identifier & Continuous & Given, SRC turbine table & TID \\
\hline The model of the turbine & Categorical & Given, SRC turbine table & TMO \\
\hline Elevation at the base of turbine & Continuous & $\begin{array}{l}\text { Some given, SRC turbine table } \\
\text { and some calculated values }\end{array}$ & ELV \\
\hline $\begin{array}{l}\text { Slope of the hill where the turbine is } \\
\text { installed }\end{array}$ & Continuous & $\begin{array}{l}\text { Some given, SRC turbine table } \\
\text { and some calculated values }\end{array}$ & SLP \\
\hline $\begin{array}{l}\text { Aspect of the hill face where the } \\
\text { turbine is installed }\end{array}$ & Continuous & $\begin{array}{l}\text { Some given, SRC turbine table } \\
\text { and some calculated values }\end{array}$ & ASP \\
\hline $\begin{array}{l}\text { The type of tower that holds the } \\
\text { wind turbine }\end{array}$ & Categorical & $\begin{array}{l}\text { Some given, SRC turbine table } \\
\text { and some calculated values }\end{array}$ & TTP \\
\hline Height of the wind turbine & Continuous & Given, SRC turbine table & THT \\
\hline $\begin{array}{l}\text { Rotor swept area of the turbine } \\
\text { blades }\end{array}$ & Continuous & $\begin{array}{l}\text { Some given, SRC turbine table } \\
\text { and some calculated values }\end{array}$ & RSA \\
\hline $\begin{array}{l}\text { Rated generating capacity of the } \\
\text { turbine }\end{array}$ & Continuous & Given, SRC turbine table & GCAP \\
\hline $\begin{array}{l}\text { Turbine is owned by one of the } \\
\text { settling party }\end{array}$ & $\begin{array}{l}\text { Categorical, } \\
\text { Binomial }\end{array}$ & Calculated value & SP \\
\hline Placement on a ridge top & $\begin{array}{l}\text { Categorical, } \\
\text { Binomial }\end{array}$ & Calculated value & RDGTP \\
\hline $\begin{array}{l}\text { Placement at the end of a row of } \\
\text { turbines }\end{array}$ & $\begin{array}{l}\text { Categorical, } \\
\text { Binomial }\end{array}$ & Annually calculated value & ER \\
\hline $\begin{array}{l}\text { Placement in the saddle of a hill } \\
\text { ridge }\end{array}$ & $\begin{array}{l}\text { Categorical, } \\
\text { Binomial }\end{array}$ & Calculated value & SDDL \\
\hline $\begin{array}{l}\text { Unique identifier of fishnet } \\
\text { square overlay map layer }\end{array}$ & Continuous & Calculated value & FISHID \\
\hline $\begin{array}{l}\text { Density of turbines in a fishnet } \\
\text { square }\end{array}$ & Continuous & Annually calculated value & DNS \\
\hline $\begin{array}{l}\text { Shannon diversity index in a } \\
\text { fishnet square }\end{array}$ & Continuous & Annually calculated value & DIV \\
\hline $\begin{array}{l}\text { Distance from turbine to nearest } \\
\text { turbine }\end{array}$ & Continuous & Annually calculated value & NTD \\
\hline Number of times a turbine is & Continuous & Annually calculated value & $\mathrm{MC}$ \\
\hline
\end{tabular}




\begin{tabular}{|l|l|l|c|}
\hline monitored & & & \\
\hline $\begin{array}{l}\text { Unique identifier of a turbine } \\
\text { screen }\end{array}$ & Continuous & Annually calculated value & SCID \\
\hline Number of turbines in a screen & Continuous & Annually calculated value & SC \\
\hline
\end{tabular}




\section{Results}

\section{Fatalities}

Initial filtering of the fatalities table provided interesting results. Table R-1 shows the status id designations for all 7,559 fatality records within the temporal bounds of this study. A number of redundant status ids have been removed from the data fields compared to what is listed in Appendix A. Currently only ten status ids were used. Of the 7,559 records, 5,086 are valid turbine related fatalities. The other 2,473 records are coded with status ids that will disqualify them from fatality analysis conducted by the Scientific Review Committee, and were likewise eliminated from the present study.

Table R-2 includes species with the most status id $=1$ fatality records. Rock pigeons and European starlings top the list, but the four target species for fatality reduction represent over a quarter of all status id $=1$ fatality records. Small and medium unidentified birds are those that were never identified to a taxonomic grouping. Often these remains included only bones or other body parts that were not confidently identifiable. Golden eagle fatalities account for $2.63 \%$ of the total.

Table R-3 shows all golden eagle records listed by status id. Of the 216 records, 82 were not used in the current study. The majority of the rejected records (66 of 82, 80\%) were removed because the carcass was in such a condition that the death date could not be calculated or because the date of the death was calculated to be greater than 90 days. These elimination protocols were developed by the APWRA Scientific Review Committee to ensure quality data, and to remove as much speculation from their process of estimating bird fatality rates. I have adopted their standards of status designations in this study for the same reasons.

Results 


\section{Turbines}

Altamont's annual turbine presence arrays are detailed in Tables R-4 and R-5. Table R-4 displays the total number of turbines present in the array for each year of the study by turbine model. 2004 is absent, as there were no data available for that year. Turbine presence trends include the phasing out of the Danwin, Flowind and Windmaster models and the inclusion of the V-47 and Mitsubishi 1000A models over the duration of the study. There has been a $26.82 \%$ reduction in the total number of turbines in the array during the present study's temporal range.

\section{Monitored turbines}

This study concerns turbines monitored for bird fatalities. There are significant differences among number of turbines present annually as seen in Table R-4, and the turbines monitored as seen in Tables R-5 and R- 6 . The early monitoring efforts at Altamont consisted of just 683 turbines in 1998 with searches conducted on just four turbine models. Table R-6 is similar to Table R-5 except that table values represent the proportion of monitoring for each turbine model. This proportion is important to keep in mind once the golden eagle fatalities are joined to the turbine table and turbine models of kill turbines are detailed.

The monitoring count data in Table R-7 show a phenomenal increase in monitoring effort in the years while the Altamont settlement agreement was finalized (2005-2007) and in the years following. This is a reflection on the amount of resources pooled to reduce bird strikes at Altamont, and it should serve to provide more confidence in the data used in the current study. 


\section{Fatalities and Turbines}

Results of combining the turbine table and the fatalities table are reported herein. Table R-8 provides a list of the individual turbines (turbine id) credited with killing golden eagles. The year of the fatality, as well as the turbine model are indexed. Turbine ids marked with $*$ are those that have killed more than one golden eagle. Each appears in the table in each year it caused a fatality. If it killed two in one year, it appears in that year one time and the fatality count is 2 .

A different way to view golden eagles deaths in relation to turbine model is to consider all turbine models. Table R-9 includes all 16 turbine types and the count of dead golden eagles per year for each turbine model. In this table, the grey shaded cells are all zero values.

The number of golden eagle fatality detections peaked in 2007 with 36 discoveries. It is unclear what drove so many detections in that year, but the higher number was not limited to just the golden eagle. In fact, each of the four target species had their highest recorded fatality rate that year as well. Table R-10 shows the 13-year fatality records for red-tailed hawks (RTHA), burrowing owls (BUOW), American kestrels (AMKE), and golden eagles (GOEA). This peak in fatality discoveries does not coincide directly with the peak in monitoring seen in Table R-7. These two trends are illustrated in Fig. R-18.

The following pages are annual Altamont turbine array maps of monitored turbines and locations of golden eagle fatalities found in each year. Some elevation and terrain features have been included in the map to provide context. What were left out were the turbines that were present each year, but were not monitored. This was an aesthetic choice as the format of this thesis does not allow much deviation in the amount of paper real estate 
that can be used. Condensing $160 \mathrm{Km}^{2}$ into a 5 by 9 inch space would necessarily crowd the features to the point of ambiguity.

Table R-11 considers the total number of searches per turbine model and how many golden eagle fatalities have been discovered at each. The number of searches was divided by the number of golden eagle fatalities to calculate the searches/eagle fatality figure.

Turbine models have not been evenly monitored, so the raw fatality count figures must be considered in light of the monitoring count. Fig. R-17 illustrates this point by measuring golden eagle fatalities on the primary y-axis (on the left) and the total number of searches for each turbine model is measured on the secondary y-axis (on the right). Turbine models are on the $\mathrm{x}$-axis as coded numbers. This figure begins to elucidate a relationship between monitoring effort and success in detecting golden eagle fatalities. By including two y-axes, a visual comparison can be made between the number of golden eagle fatalities detected and the amount of searching that was done.

Fig. R-18 illustrates the total monitoring effort, regardless of turbine model, on the secondary y-axis, and it is coupled with golden eagle fatalities on the primary y-axis. The figure illustrates positive trend lines for both variables.

\section{Turbine Characteristics}

The results of testing turbine characteristics are shown in Table R-12 below. Those values with significant differences between nonkill and kill turbines have been shaded grey and bolded. Following that is Table R-13 which contains additional summary statistics for turbine characteristics.

Summary statistics for aspect measurements of kill and nonkill turbines appear in the table above, but histograms of the data are more informative. The following circular 
histograms were calculated using R Studio and the circular data package (Lund 2011). The turbines are represented as small circles around a larger circle and placed at the degree of the aspect of the hillside where that turbine stands. The arrow in the center points toward the mean aspect as calculated by the circular package in $\mathrm{R}$. The length of the arrow indicates the relative strength of the mean calculation. The dashed line outside the circle is a measure of density for each vector.

Fig. R-16 represents the 5340 monitored turbines that have not killed golden eagles. The blue arrow points to the calculated mean of $41.2^{\circ}$. Fig. R-17 illustrates the 134 turbines that have killed golden eagles. The red arrow at the center of the figure points toward the mean direction of $317.9^{\circ}$. In both figures the short length of the arrow indicates that aspect data were not strongly skewed in any one direction or vector.

\section{Temporal Distribution, Age and Sex Frequencies of Golden Eagle Fatalities}

Figure R-18 is a histogram of fatalities grouped into quarters, while Fig. R-19 displays fatalities by death month. The summer time ( $3^{\text {rd }}$ quarter $)$ seems to be the most deadly at Altamont. The months of July, August and September account for $45.0 \%$ of the fatalities that are dated. Both August and September have the largest number of deaths at 18 each. Next are July and October, each with 13 fatalities

There is a problem however with these data. Previously it was discussed that if death dates could not be determined for golden eagle fatalities, then the records were removed from consideration. There are 25 records without calculated death dates that have been included in the present study as well as in fatality estimates for SRC reporting. These records are from the baseline fatality study that did not record carcass condition or estimation of 
days dead. These records remain valid turbine related fatalities, but ones that are missing critical data for biological analysis.

Fig. R-21 combines temporal and demographic data into a single chart. It shows fatalities by age class and death month. Undetermined ages and unknown death dates dominate the graphic.

Fig. R-22 illustrates age class data of the 134 fatalities including 43 juveniles (32.1\%), 10 immature (7.5\%), 24 adult (17.9\%), and $57(42.5 \%)$ that were of undetermined age. What stands out is the large number of juvenile birds in the record. This result contradicts Hunt's findings that juvenile golden eagles were not killed as regularly as other age groups. In that study, 1 of $117(0.9 \%)$ juveniles, 31 of $155(20.0 \%)$ sub-adults and floaters, and 2 of 47 $(4.3 \%)$ breeding adults were killed by turbines (Hunt 2002). It is not immediately clear why these two findings are so divergent. Perhaps research into natal origins of golden eagle fatalities at Altamont would better describe the assemblage and yield clues as to whether the high number of juvenile fatalities may be correlated to dispersal events.

Tables R-14 through R-18 show the turbine variables that were shown to be significant, and age classes of golden eagle fatalities were used to parse the results in more detail. Finally, Table R-19 shows the results of sex determination analysis. 
Table R-1: All Fatality Records by Status Id

\begin{tabular}{|cccl|}
$\begin{array}{c}\text { Status } \\
\text { Id }\end{array}$ & $\begin{array}{c}\text { Number } \\
\text { of Records }\end{array}$ & $\begin{array}{c}\text { Percentage of } \\
\text { total fatalities }\end{array}$ & Status \\
\hline 1 & 5,086 & $67.28 \%$ & Valid turbine related fatality \\
\hline 2 & 45 & $0.60 \%$ & $\begin{array}{l}\text { Fatality cannot be assigned to an animal group or } \\
\text { size }\end{array}$ \\
\hline 4 & 33 & $0.44 \%$ & Is not within 125 meters of the turbine \\
\hline 5 & 177 & $2.34 \%$ & Cause of death is not turbine-related \\
\hline 6 & 827 & $10.94 \%$ & Is >90 days dead or aged \\
\hline 7 & 370 & $4.89 \%$ & Incidental or WRRS find except GOEAS \\
\hline 8 & 29 & $0.38 \%$ & Injured bird, except GOEA \\
\hline 9 & 38 & $0.50 \%$ & Fatality without a valid search or valid detection \\
\hline 10 & 31 & $0.41 \%$ & Off-site carcass used for placement only. \\
\hline 16 & 923 & $12.21 \%$ & Death date could not be determined \\
\hline Total & 7,559 & & \\
\hline
\end{tabular}


Table R-2: Top 10 Species of Status Id 1 Fatalities at Altamont 1998-2011

\begin{tabular}{|l|c|c|}
\hline Species Common Name & n & $\begin{array}{c}\text { Percentage of } \\
\text { Status Id 1 Records }\end{array}$ \\
\hline Rock Pigeon & 1,180 & $23.20 \%$ \\
\hline European Starling & 629 & $12.37 \%$ \\
\hline Red-tailed Hawk * & 573 & $11.27 \%$ \\
\hline Western Meadowlark & 544 & $10.70 \%$ \\
\hline Burrowing Owl * & 347 & $6.82 \%$ \\
\hline American Kestrel * & 259 & $5.09 \%$ \\
\hline Small Unidentified Bird & 229 & $4.50 \%$ \\
\hline Barn Owl & 166 & $3.26 \%$ \\
\hline Golden Eagle * & 134 & $2.63 \%$ \\
\hline Medium Unidentified Bird & 128 & $2.52 \%$ \\
\hline 80 Other Species/ unidentified groups & 897 & $17.64 \%$ \\
\hline Total & 5,086 & $25.82 \%$ \\
\hline Target Species* Sum & 1,313 & \\
\hline
\end{tabular}


Table R-3: Golden Eagle Fatality Records by Status Id

\begin{tabular}{|c|c|c|c|}
\hline Status Id & $\begin{array}{c}\text { Record } \\
\text { Count }\end{array}$ & $\begin{array}{l}\text { Percentage of } \\
\text { Records }\end{array}$ & Status Definition \\
\hline 1 & 134 & $62.0 \%$ & Valid turbine related fatality \\
\hline 4 & 2 & $0.93 \%$ & Is not within 125 meters of the turbine \\
\hline 5 & 6 & $2.78 \%$ & Cause of death is not turbine-related \\
\hline 6 & 30 & $13.89 \%$ & Is $>90$ days dead or aged \\
\hline 7 & 5 & $2.31 \%$ & Incidental or WRRS find except GOEAs* \\
\hline 9 & 2 & $0.93 \%$ & Fatality without a valid search or valid detection \\
\hline 10 & 1 & $0.46 \%$ & Off-site carcass used for placement only. \\
\hline 16 & 36 & $16.67 \%$ & Death date could not be determined \\
\hline Total & 216 & & \\
\hline \multicolumn{4}{|c|}{$\begin{array}{l}\text { *GOEA is the alpha code for Golden Eagles. Status ID } 7 \text { is a designation for any bird fatality found first } \\
\text { by turbine operators (WRRS), or are found dead while in the APWRA, but not by biologists walking a } \\
\text { transect. A road killed bird is an example of one that would be an incidental find. Golden eagles should } \\
\text { not receive this designation, and it is unclear by } 5 \text { records have been designated as status id } 7 \text {. }\end{array}$} \\
\hline
\end{tabular}




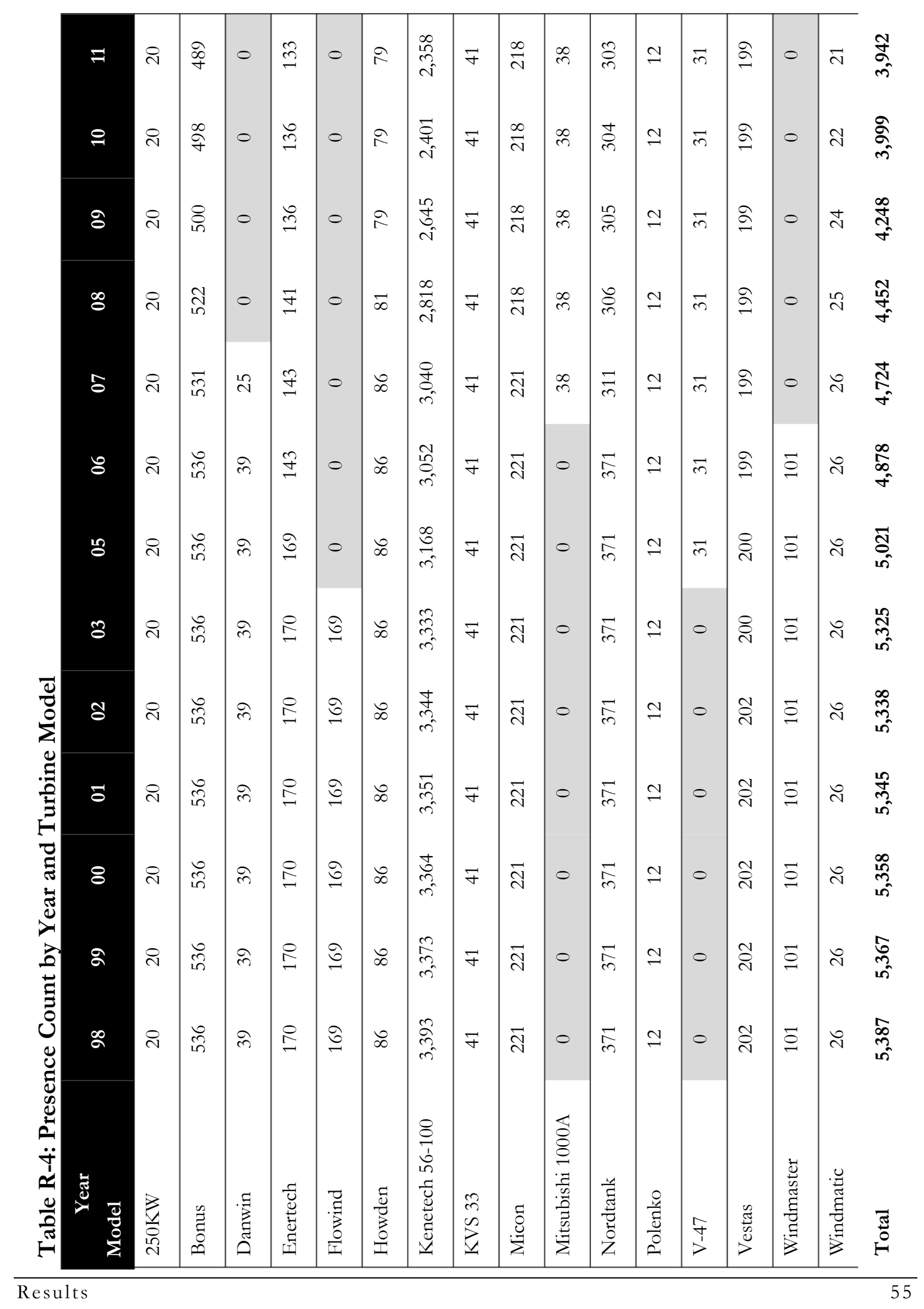




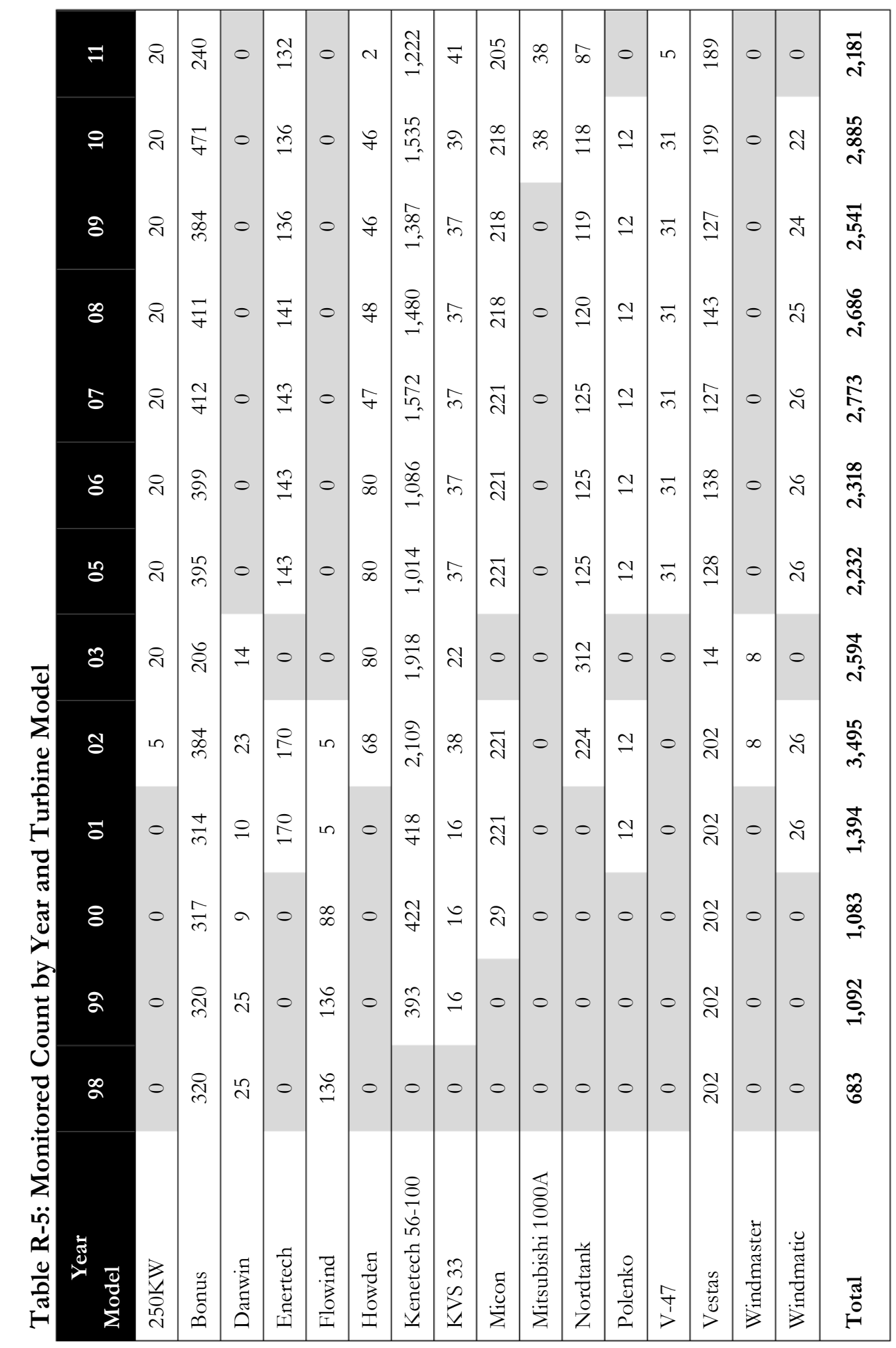

Results 


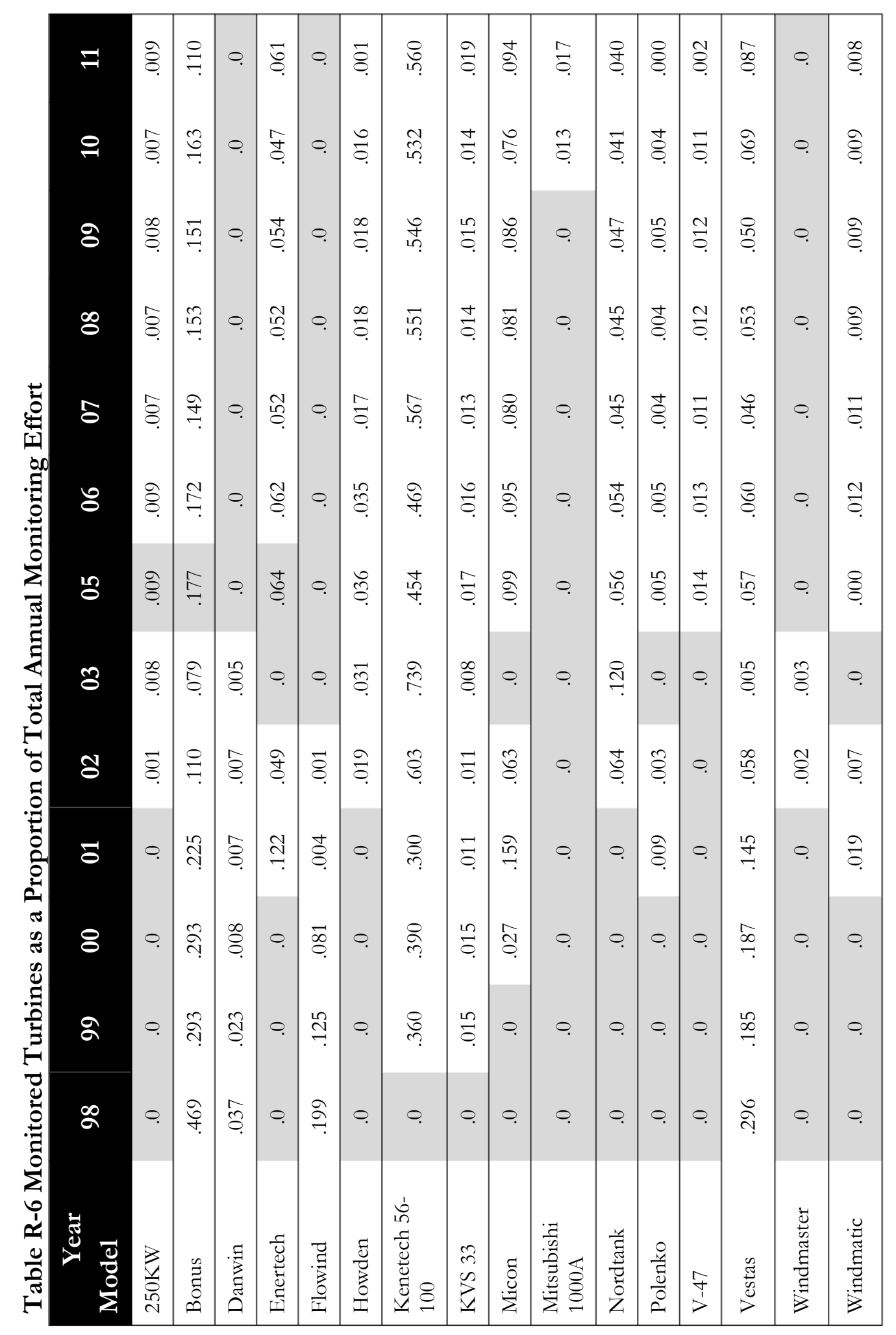

Results 


\begin{tabular}{|c|c|c|c|c|}
\hline$\exists$ & $\stackrel{\text { I }}{\stackrel{m}{m}}$ & $\stackrel{\vec{\infty}}{\vec{c}}$ & $n_{n}^{n}$ & $\begin{array}{l}\hat{n} \\
\stackrel{1}{0} \\
\sim\end{array}$ \\
\hline 윽 & $\begin{array}{l}\text { बे } \\
\text { ले }\end{array}$ & $\begin{array}{l}L_{0} \\
\infty \\
i \\
i\end{array}$ & $\vec{i}$ & $\begin{array}{l}\hat{2} \\
\hat{n} \\
\hat{i}\end{array}$ \\
\hline 8 & 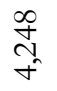 & $\begin{array}{l}\vec{f} \\
\stackrel{\sim}{n} \\
i\end{array}$ & $\begin{array}{l}\infty \\
\text { in }\end{array}$ & $\begin{array}{l}8 \\
\text { m. } \\
\text { लn }\end{array}$ \\
\hline$\stackrel{\infty}{\circ}$ & $\underset{f}{\stackrel{N}{f}}$ & $\begin{array}{l}\circ \\
\stackrel{0}{0} \\
0\end{array}$ & $\stackrel{?}{8}$ & $\stackrel{\hat{a}}{\stackrel{\hat{0}}{a}}$ \\
\hline$\hat{\sigma}$ & $\underset{\sim}{\stackrel{\leftarrow}{\sim}}$ & $\stackrel{2}{R}$ & $\stackrel{r}{\infty}$ & $\begin{array}{l}\infty \\
\stackrel{0}{0} \\
\text { Nֵ }\end{array}$ \\
\hline 8 & $\begin{array}{l}\infty \\
\infty \\
\infty \\
\sigma^{\prime}\end{array}$ & $\begin{array}{l}\infty \\
\vec{n} \\
\hat{v}\end{array}$ & $\stackrel{\stackrel{\sim}{?}}{\stackrel{f}{\sigma}}$ & $\begin{array}{l}\infty \\
\mathbb{W} \\
\stackrel{2}{n}\end{array}$ \\
\hline 18 & $\begin{array}{l}\overrightarrow{\mathrm{O}} \\
\tilde{n}^{n}\end{array}$ & $\begin{array}{l}\tilde{N} \\
\tilde{N}\end{array}$ & $\stackrel{\stackrel{\operatorname{n}}{f}}{\stackrel{f}{f}}$ & \begin{tabular}{l}
$\tilde{N}$ \\
Nิ \\
\multirow{f}{*}{}
\end{tabular} \\
\hline$\stackrel{8}{8}$ & $\begin{array}{l}\stackrel{2}{3} \\
\stackrel{\approx}{n}\end{array}$ & $\begin{array}{l}+ \\
\text { in } \\
\text { in }\end{array}$ & $\stackrel{\hat{\infty}}{+}$ & $\begin{array}{l}\text { ठ․ } \\
\text { ñ }\end{array}$ \\
\hline ชิ & $\stackrel{\infty}{\stackrel{\infty}{n}}$ & $\begin{array}{l}\stackrel{n}{g} \\
\stackrel{n}{m}\end{array}$ & $\begin{array}{l}10 \\
10 \\
0\end{array}$ & $\begin{array}{l}\text { 导 } \\
\text { a }\end{array}$ \\
\hline 5 & 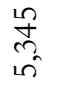 & $\underset{\sim}{\stackrel{+}{\sim}}$ & $\vec{\Xi}$ & 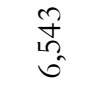 \\
\hline 8 & 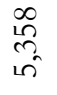 & 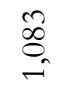 & ֻิ & $\underset{\hat{\sigma}}{\sigma}$ \\
\hline ন & $\begin{array}{l}\hat{0} \\
\text { nn } \\
i n\end{array}$ & $\stackrel{\sigma}{\sigma}$ & ?̊ & $\overbrace{0}^{N}$ \\
\hline$\stackrel{\circ}{\circ}$ & $\begin{array}{l}\hat{\infty} \\
\stackrel{2}{n} \\
i n\end{array}$ & م్రీ & $\hat{\mathrm{j}}$ & $\begin{array}{l}\text { రి } \\
\stackrel{1}{0} \\
\text { in }\end{array}$ \\
\hline$\stackrel{\vec{J}}{\mathbb{J}}$ & 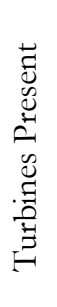 & 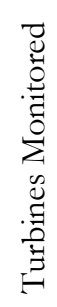 & 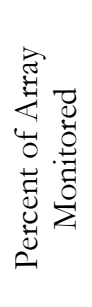 & 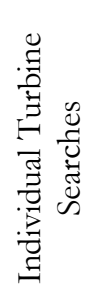 \\
\hline
\end{tabular}

Results 
Table R-8: Kill Turbines with Golden Eagle Fatality Census

\begin{tabular}{|c|c|c|c|}
\hline Year & Turbine Id & $\mathbf{n}$ & Turbine Model \\
\hline \multirow{5}{*}{1998} & 172 & 1 & Bonus \\
\hline & 192 & 1 & Bonus \\
\hline & 246 & 1 & Bonus \\
\hline & 263 & 1 & Bonus \\
\hline & $157^{*}$ & 1 & Bonus \\
\hline \multirow[t]{3}{*}{1999} & 211 & 1 & Bonus \\
\hline & 279 & 1 & Bonus \\
\hline & 837 & 1 & Kenetech 56-100 \\
\hline \multirow{3}{*}{2000} & 174 & 1 & Bonus \\
\hline & 183 & 1 & Bonus \\
\hline & $121 *$ & 1 & Bonus \\
\hline \multirow{3}{*}{2001} & 1046 & 1 & Enertech \\
\hline & $157^{*}$ & 1 & Bonus \\
\hline & $305^{*}$ & 1 & Bonus \\
\hline \multirow{7}{*}{2002} & 640 & 1 & Kenetech 56-100 \\
\hline & 923 & 1 & Kenetech 56-100 \\
\hline & 1970 & 1 & Kenetech 56-100 \\
\hline & 2080 & 1 & Kenetech 56-100 \\
\hline & 2223 & 1 & Kenetech 56-100 \\
\hline & 2262 & 1 & Kenetech 56-100 \\
\hline & 2744 & 1 & Kenetech 56-100 \\
\hline \multirow[t]{4}{*}{2003} & 2221 & 1 & Kenetech 56-100 \\
\hline & 2311 & 1 & Kenetech 56-100 \\
\hline & 3201 & 1 & Kenetech 56-100 \\
\hline & 4301 & 1 & Nordtank \\
\hline \multirow{4}{*}{2005} & 218 & 1 & Bonus \\
\hline & 1679 & 1 & Kenetech 56-100 \\
\hline & 2700 & 1 & Kenetech 56-100 \\
\hline & 3733 & 1 & Kenetech 56-100 \\
\hline \multirow{2}{*}{2006} & 69 & 1 & Bonus \\
\hline & 166 & 1 & Bonus \\
\hline
\end{tabular}




\begin{tabular}{|c|c|c|c|}
\hline & 2198 & 1 & Kenetech 56-100 \\
\hline & 2469 & 1 & Kenetech 56-100 \\
\hline & 2498 & 1 & Kenetech 56-100 \\
\hline & 2734 & 1 & Kenetech 56-100 \\
\hline & 3086 & 1 & Kenetech 56-100 \\
\hline & 3103 & 1 & Kenetech 56-100 \\
\hline & 3161 & 1 & Kenetech 56-100 \\
\hline & 3165 & 1 & Kenetech 56-100 \\
\hline & 3167 & 1 & Kenetech 56-100 \\
\hline & 3304 & 1 & Bonus \\
\hline & 3736 & 1 & Kenetech 56-100 \\
\hline & 3866 & 1 & Bonus \\
\hline & 4133 & 1 & Kenetech 56-100 \\
\hline & 4217 & 1 & Kenetech 56-100 \\
\hline & $2608 *$ & 1 & Kenetech 56-100 \\
\hline & $305^{*}$ & 1 & Bonus \\
\hline \multirow{17}{*}{2007} & 155 & 1 & Bonus \\
\hline & 210 & 1 & Bonus \\
\hline & 579 & 1 & Kenetech 56-100 \\
\hline & 903 & 1 & Kenetech 56-100 \\
\hline & 1149 & 1 & Micon \\
\hline & 1613 & 1 & Kenetech 56-100 \\
\hline & 1665 & 1 & KVS 33 \\
\hline & 1931 & 1 & Kenetech 56-100 \\
\hline & 2019 & 1 & Kenetech 56-100 \\
\hline & 2113 & 1 & Kenetech 56-100 \\
\hline & 2219 & 1 & Kenetech 56-100 \\
\hline & 2591 & 1 & Kenetech 56-100 \\
\hline & 2600 & 1 & Kenetech 56-100 \\
\hline & 2703 & 1 & Kenetech 56-100 \\
\hline & 2752 & 1 & Kenetech 56-100 \\
\hline & 2844 & 1 & Kenetech 56-100 \\
\hline & 3085 & 1 & Kenetech 56-100 \\
\hline
\end{tabular}




\begin{tabular}{|c|c|c|c|}
\hline & 3433 & 1 & Nordtank \\
\hline & 3653 & 1 & Kenetech 56-100 \\
\hline & 3738 & 1 & Kenetech 56-100 \\
\hline & 3766 & 1 & Kenetech 56-100 \\
\hline & 3793 & 1 & Kenetech 56-100 \\
\hline & 3827 & 1 & Kenetech 56-100 \\
\hline & 3848 & 1 & Kenetech 56-100 \\
\hline & 3859 & 1 & Kenetech 56-100 \\
\hline & 3941 & 1 & Kenetech 56-100 \\
\hline & 4039 & 1 & Kenetech 56-100 \\
\hline & 4048 & 1 & Kenetech 56-100 \\
\hline & 4113 & 1 & Kenetech 56-100 \\
\hline & $2701 *$ & 2 & Kenetech 56-100 \\
\hline & $3860^{*}$ & 2 & Kenetech 56-100 \\
\hline & $801 *$ & 2 & Kenetech 56-100 \\
\hline & $895^{*}$ & 1 & Kenetech 56-100 \\
\hline \multirow{17}{*}{2008} & 111 & 1 & Bonus \\
\hline & 188 & 1 & Bonus \\
\hline & 213 & 1 & Bonus \\
\hline & 975 & 1 & Micon \\
\hline & 1300 & 1 & Micon \\
\hline & 1362 & 1 & Howden \\
\hline & 1588 & 1 & Kenetech 56-100 \\
\hline & 1708 & 1 & KVS 33 \\
\hline & 2750 & 1 & Kenetech 56-100 \\
\hline & 2998 & 1 & Kenetech 56-100 \\
\hline & 3073 & 1 & Kenetech 56-100 \\
\hline & 3309 & 1 & Bonus \\
\hline & 3322 & 1 & Bonus \\
\hline & 3718 & 1 & Kenetech 56-100 \\
\hline & $3848^{*}$ & 1 & Kenetech 56-100 \\
\hline & 5070 & 1 & Kenetech 56-100 \\
\hline & $121 *$ & 1 & Bonus \\
\hline
\end{tabular}




\begin{tabular}{|c|c|c|c|}
\hline \multirow[t]{13}{*}{2009} & 201 & 1 & Bonus \\
\hline & 1616 & 1 & Kenetech 56-100 \\
\hline & 1710 & 1 & KVS 33 \\
\hline & 2307 & 1 & Kenetech 56-100 \\
\hline & 2333 & 1 & Kenetech 56-100 \\
\hline & 2473 & 1 & Kenetech 56-100 \\
\hline & 3834 & 1 & Kenetech 56-100 \\
\hline & 4036 & 1 & Kenetech 56-100 \\
\hline & 4081 & 1 & Kenetech 56-100 \\
\hline & 4264 & 1 & $\mathrm{~V}-47$ \\
\hline & 5064 & 1 & Kenetech 56-100 \\
\hline & $2608^{*}$ & 1 & Kenetech 56-100 \\
\hline & $895^{*}$ & 1 & Kenetech 56-100 \\
\hline \multirow{9}{*}{2010} & 115 & 1 & Bonus \\
\hline & 194 & 1 & Bonus \\
\hline & 2207 & 1 & Kenetech 56-100 \\
\hline & 2489 & 1 & Kenetech 56-100 \\
\hline & 2534 & 1 & Kenetech 56-100 \\
\hline & 2562 & 1 & Kenetech 56-100 \\
\hline & 2585 & 1 & Kenetech 56-100 \\
\hline & 3655 & 1 & Kenetech 56-100 \\
\hline & $2697 *$ & 1 & Kenetech 56-100 \\
\hline \multirow{10}{*}{2011} & 300 & 1 & Bonus \\
\hline & 322 & 1 & Vestas \\
\hline & 479 & 1 & Vestas \\
\hline & 790 & 1 & Kenetech 56-100 \\
\hline & 2673 & 1 & Kenetech 56-100 \\
\hline & 3759 & 1 & Kenetech 56-100 \\
\hline & 3869 & 1 & Kenetech 56-100 \\
\hline & 5000 & 1 & Kenetech 56-100 \\
\hline & $2674^{*}$ & 1 & Kenetech 56-100 \\
\hline & $2697 *$ & 2 & Kenetech 56-100 \\
\hline
\end{tabular}


Table R-9: Count of Golden Eagle Fatalities by Year and Turbine Model

\begin{tabular}{|c|c|c|c|c|c|c|c|c|c|c|c|c|c|c|}
\hline $\begin{array}{l}\text { Year } \\
\text { Model }\end{array}$ & 98 & 99 & 00 & 01 & 02 & 03 & 05 & 06 & 07 & 08 & 09 & 10 & 11 & Totals \\
\hline $250 \mathrm{KW}$ & 0 & 0 & 0 & 0 & 0 & 0 & 0 & 0 & 0 & 0 & 0 & 0 & 0 & 0 \\
\hline Bonus & 5 & 2 & 3 & 2 & 0 & 0 & 1 & 5 & 2 & 6 & 1 & 2 & 1 & 30 \\
\hline Danwin & 0 & 0 & 0 & 0 & 0 & 0 & 0 & 0 & 0 & 0 & 0 & 0 & 0 & 0 \\
\hline Enertech & 0 & 0 & 0 & 1 & 0 & 0 & 0 & 0 & 0 & 0 & 0 & 0 & 0 & 1 \\
\hline Flowind & 0 & 0 & 0 & 0 & 0 & 0 & 0 & 0 & 0 & 0 & 0 & 0 & 0 & 0 \\
\hline Howden & 0 & 0 & 0 & 0 & 0 & 0 & 0 & 0 & 0 & 1 & 0 & 0 & 0 & 1 \\
\hline $\begin{array}{l}\text { Kenetech 56- } \\
100\end{array}$ & 0 & 1 & 0 & 0 & 7 & 3 & 3 & 13 & 31 & 7 & 10 & 8 & 8 & 91 \\
\hline KVS 33 & 0 & 0 & 0 & 0 & 0 & 0 & 0 & 1 & 1 & 0 & 1 & 0 & 0 & 3 \\
\hline Micon & 0 & 0 & 0 & 0 & 0 & 0 & 0 & 0 & 1 & 2 & 0 & 0 & 0 & 3 \\
\hline $\begin{array}{l}\text { Mitsubishi } \\
\text { 1000A }\end{array}$ & 0 & 0 & 0 & 0 & 0 & 0 & 0 & 0 & 0 & 0 & 0 & 0 & 0 & 0 \\
\hline Nordtank & 0 & 0 & 0 & 0 & 0 & 1 & 0 & 0 & 1 & 0 & 0 & 0 & 0 & 2 \\
\hline Polenko & 0 & 0 & 0 & 0 & 0 & 0 & 0 & 0 & 0 & 0 & 0 & 0 & 0 & 0 \\
\hline V-47 & 0 & 0 & 0 & 0 & 0 & 0 & 0 & 0 & 0 & 0 & 1 & 0 & 0 & 1 \\
\hline Vestas & 0 & 0 & 0 & 0 & 0 & 0 & 0 & 0 & 0 & 0 & 0 & 0 & 2 & 2 \\
\hline Windmaster & 0 & 0 & 0 & 0 & 0 & 0 & 0 & 0 & 0 & 0 & 0 & 0 & 0 & 0 \\
\hline Windmatic & 0 & 0 & 0 & 0 & 0 & 0 & 0 & 0 & 0 & 0 & 0 & 0 & 0 & 0 \\
\hline $\begin{array}{l}\text { Annual } \\
\text { Fatalities }\end{array}$ & 5 & 3 & 3 & 3 & 7 & 4 & 4 & 19 & 36 & 16 & 13 & 10 & 11 & 134 \\
\hline
\end{tabular}


Table R-10: Target Species Annual Fatality Count Totals

\begin{tabular}{|ccc|cccccccccccccc|}
$\begin{array}{c}\text { Year } \\
\text { Species }\end{array}$ & $\mathbf{9 8}$ & $\mathbf{9 9}$ & $\mathbf{0 0}$ & $\mathbf{0 1}$ & $\mathbf{0 2}$ & $\mathbf{0 3}$ & $\mathbf{0 5}$ & $\mathbf{0 6}$ & $\mathbf{0 7}$ & $\mathbf{0 8}$ & $\mathbf{0 9}$ & $\mathbf{1 0}$ & $\mathbf{1 1}$ & $\mathbf{T o t a l s}$ \\
\hline RTHA & 11 & 50 & 25 & 13 & 26 & 17 & 34 & 102 & $\mathbf{1 0 9}$ & 63 & 41 & 26 & 56 & 573 \\
\hline BUOW & 3 & 27 & 14 & 15 & 6 & 1 & 2 & 33 & $\mathbf{1 2 7}$ & 47 & 31 & 26 & 15 & 347 \\
\hline AMKE & 3 & 10 & 11 & 9 & 14 & 8 & 6 & 18 & $\mathbf{5 4}$ & 45 & 39 & 22 & 20 & 259 \\
\hline GOEA & 5 & 3 & 3 & 3 & 7 & 4 & 4 & 19 & $\mathbf{3 6}$ & 16 & 13 & 10 & 11 & 134 \\
\hline Grand Total & $\mathbf{2 2}$ & $\mathbf{9 0}$ & $\mathbf{5 3}$ & $\mathbf{4 0}$ & $\mathbf{5 3}$ & $\mathbf{3 0}$ & $\mathbf{4 6}$ & $\mathbf{1 7 2}$ & $\mathbf{3 2 6}$ & $\mathbf{1 7 1}$ & $\mathbf{1 2 4}$ & $\mathbf{8 4}$ & $\mathbf{1 0 2}$ & $\mathbf{1 , 3 1 3}$ \\
\hline
\end{tabular}

Results 


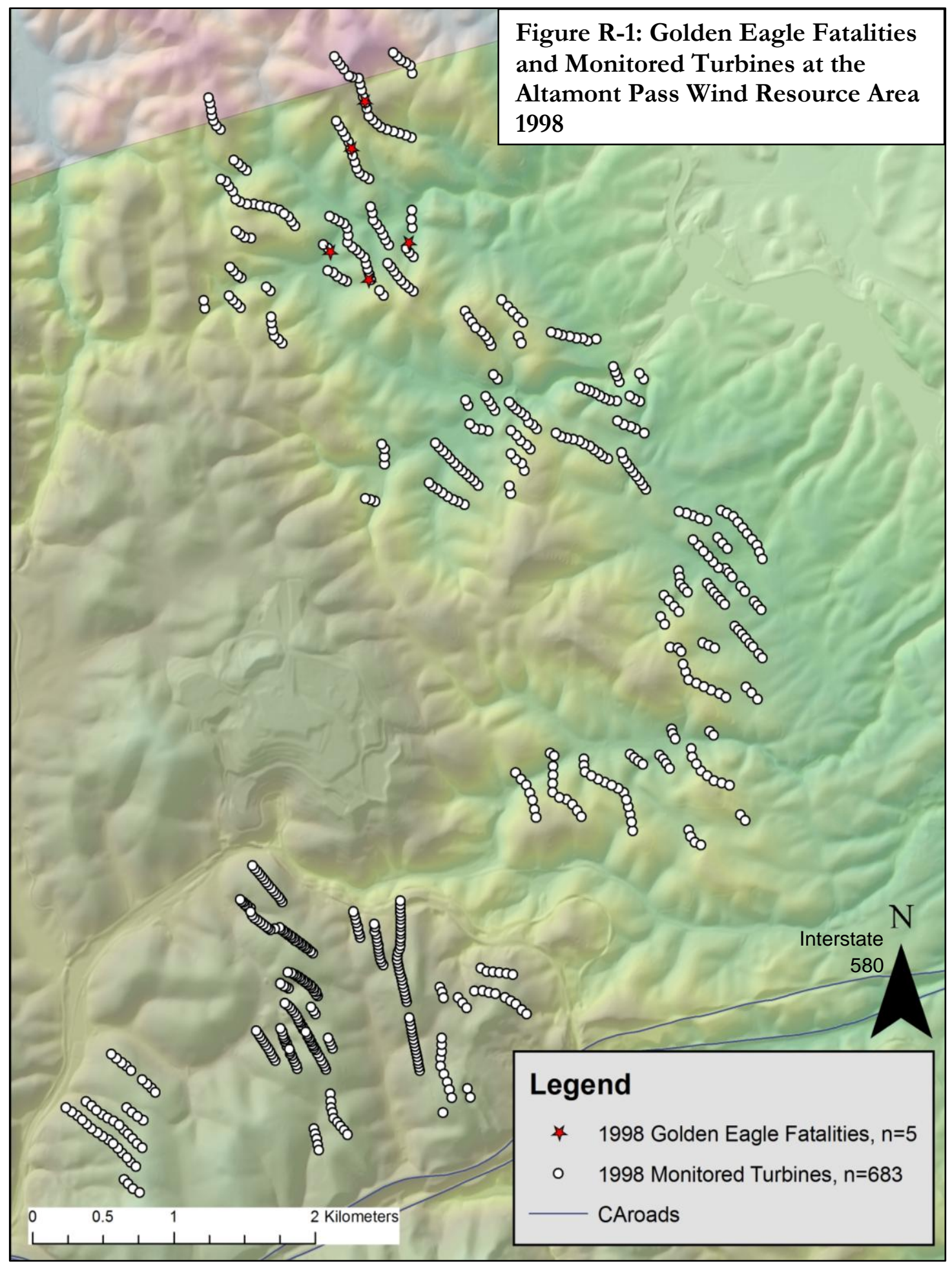

Results 


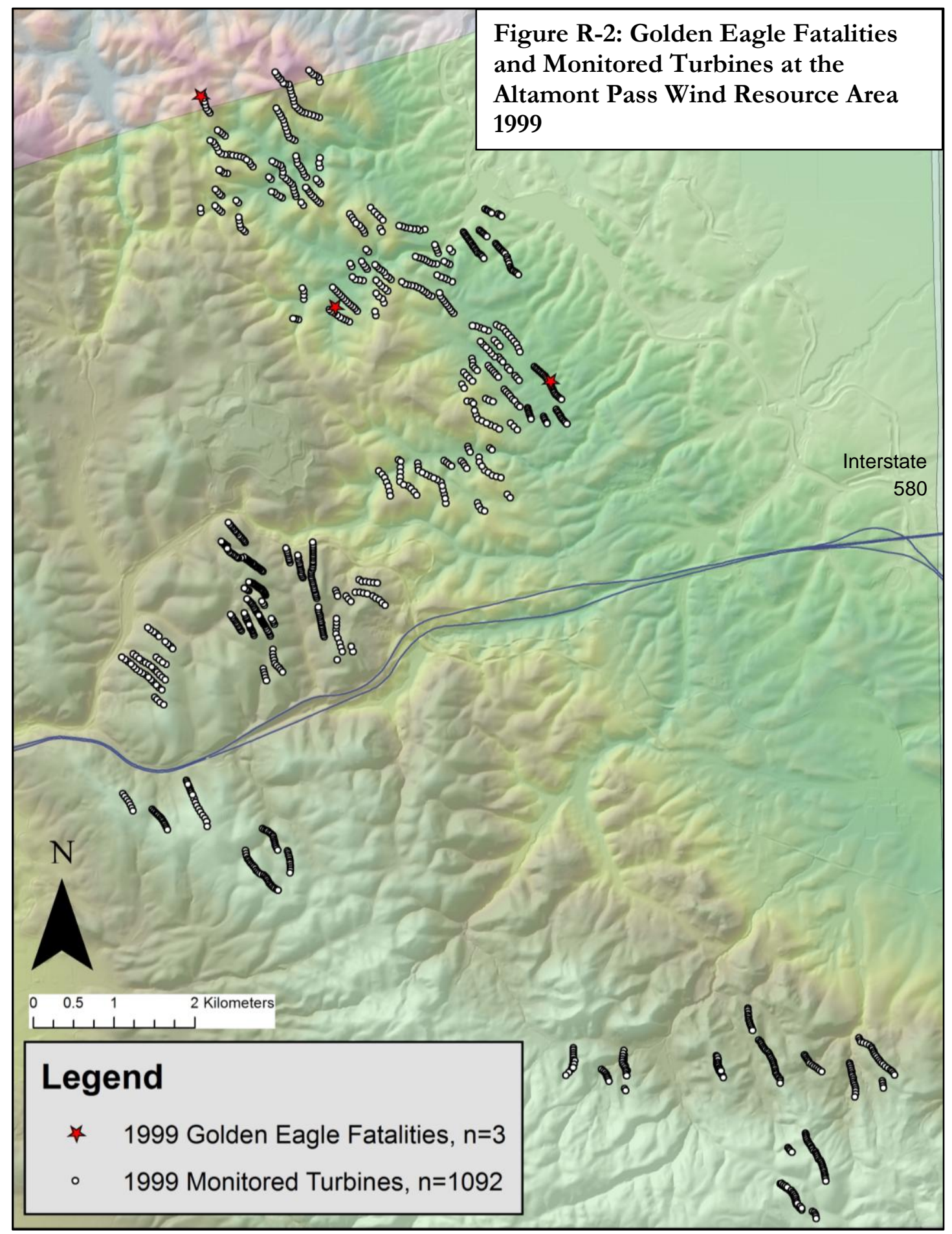

Results 


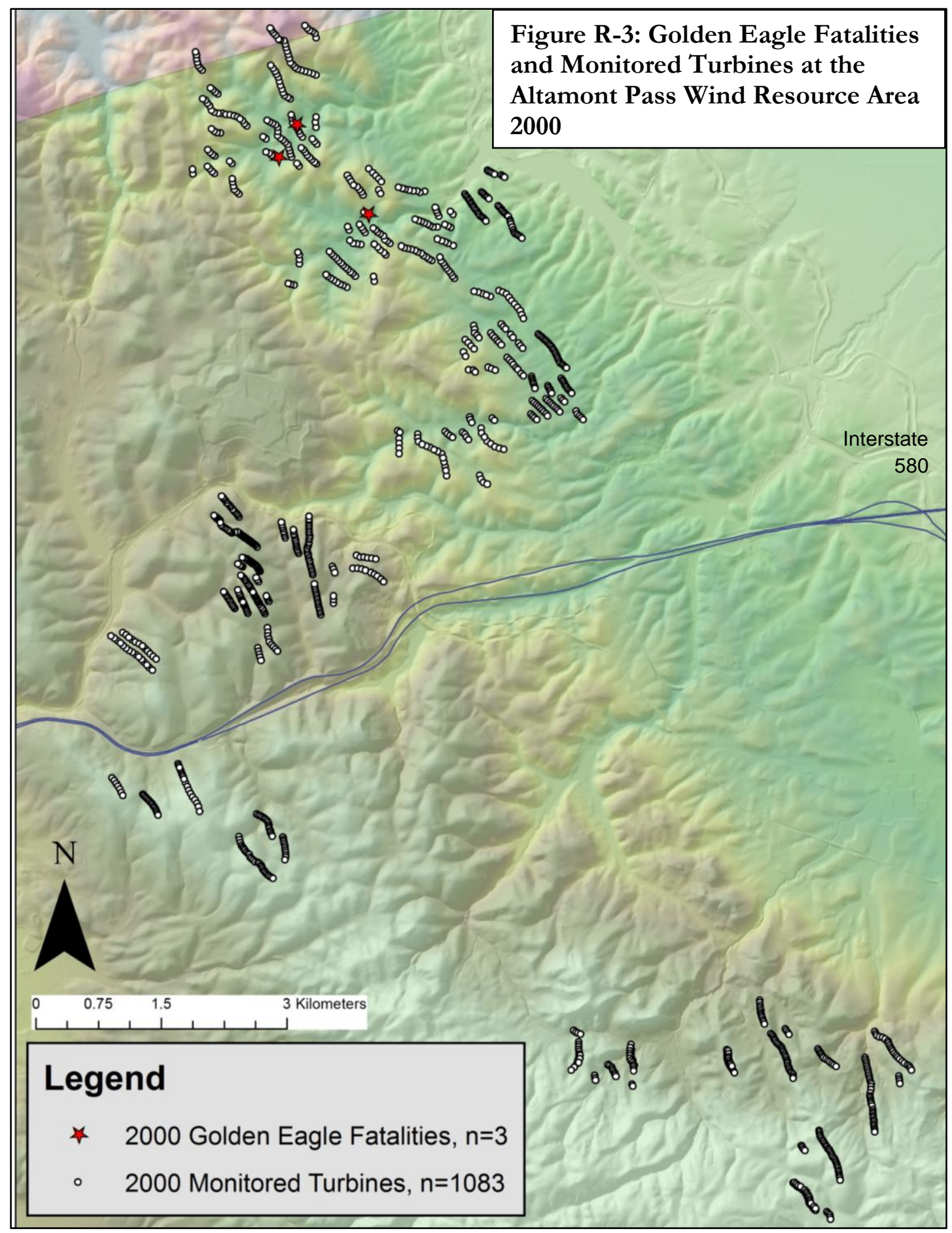

Results 


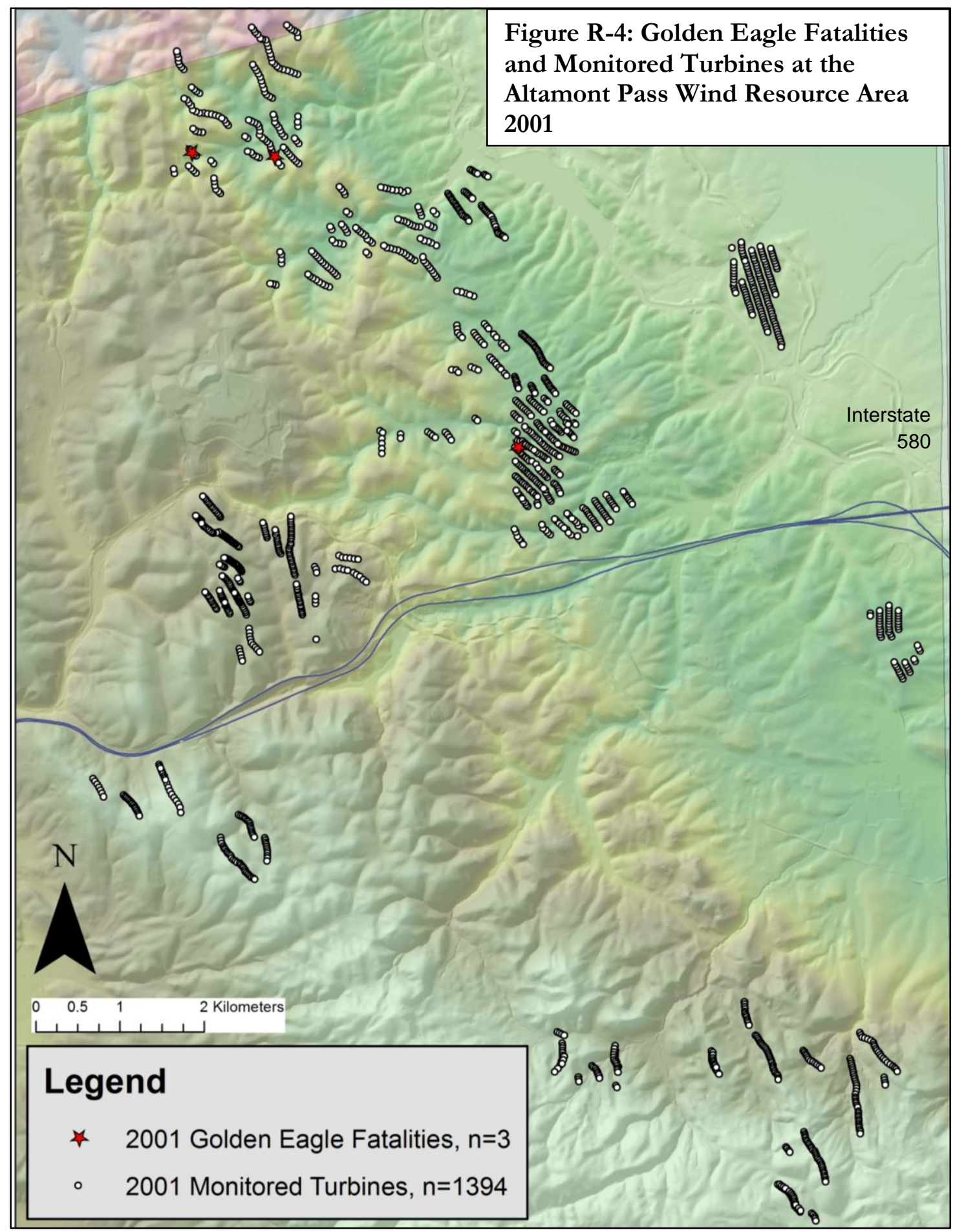

Results 


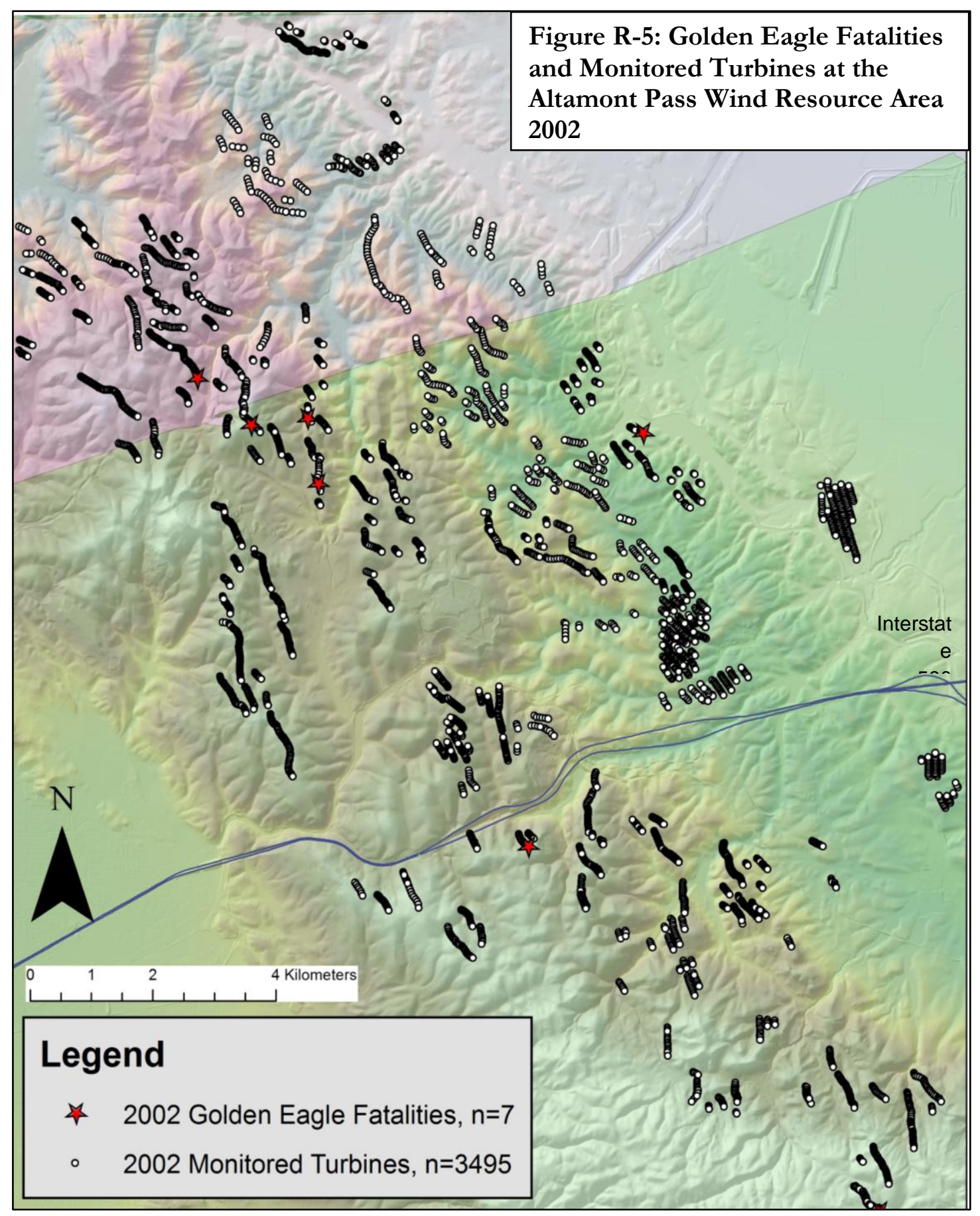

Results 


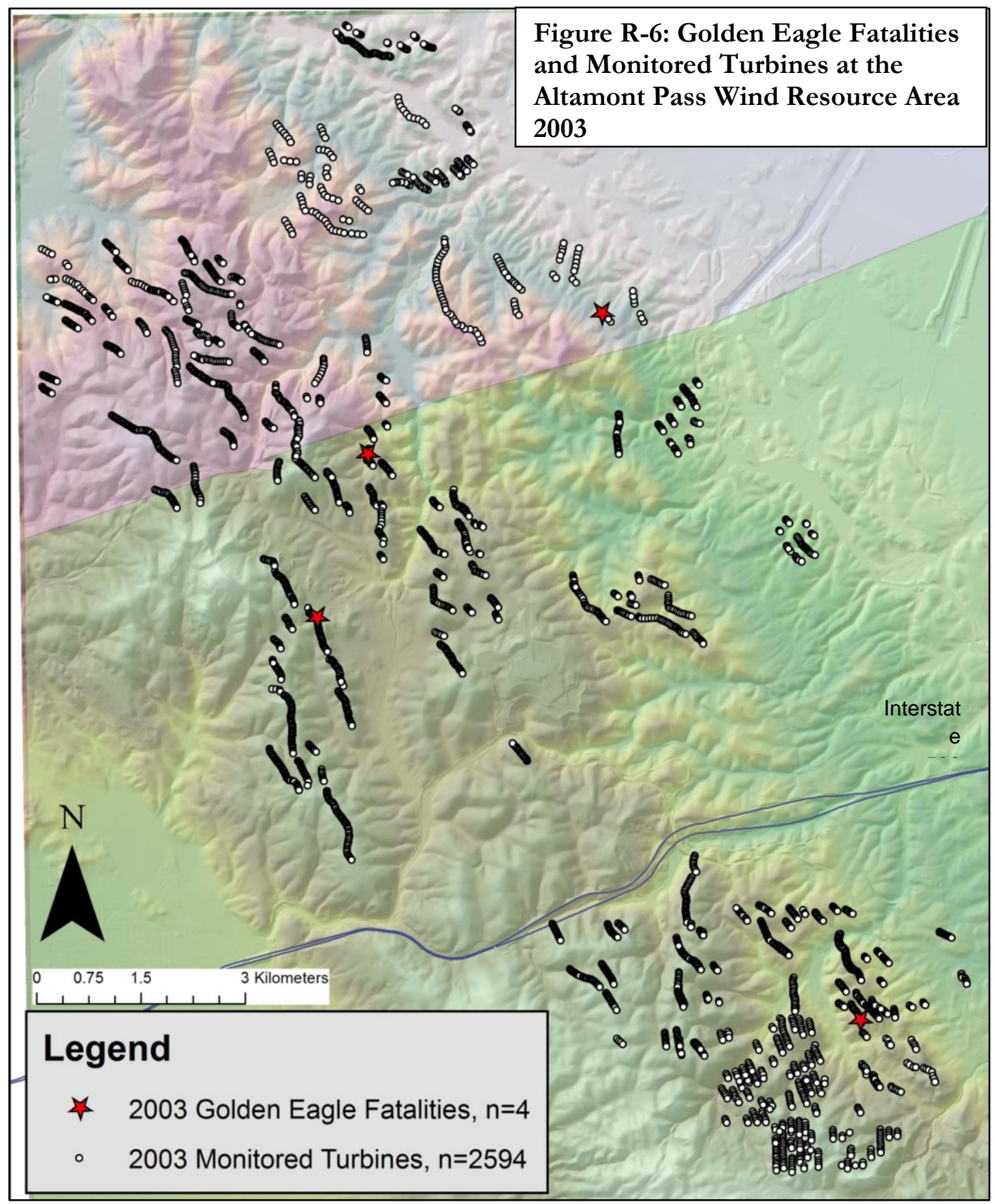

Results 


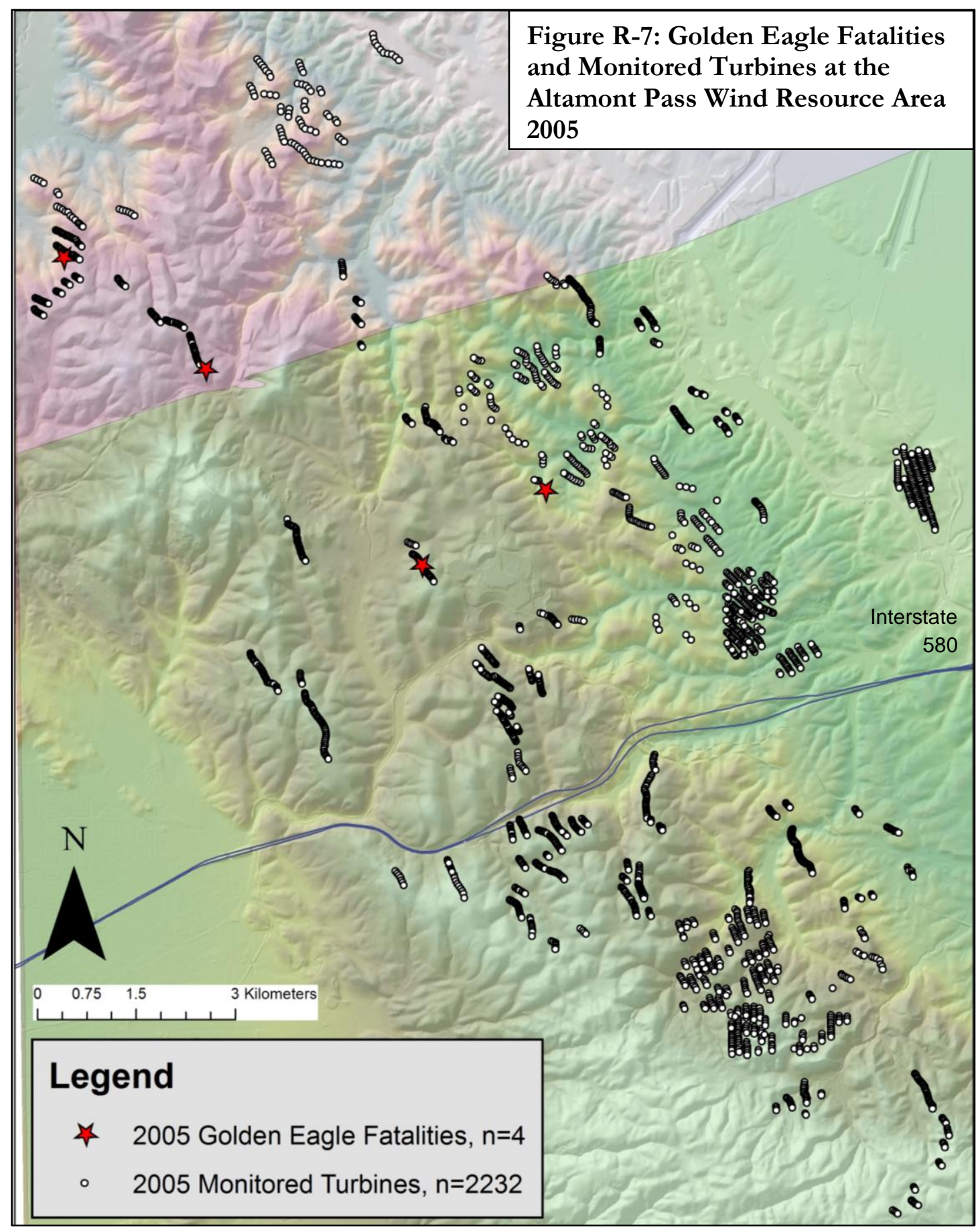

Results 


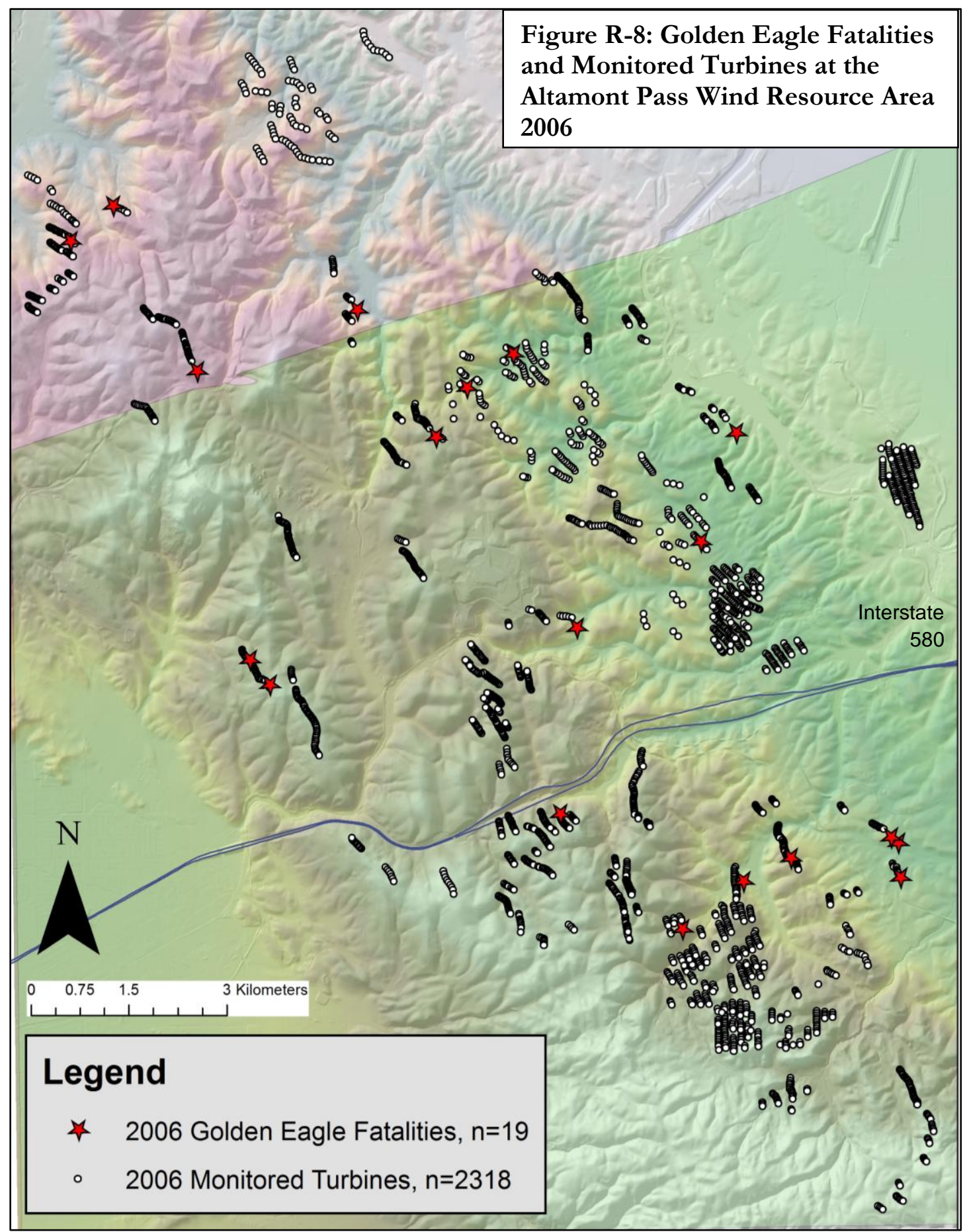

Results 


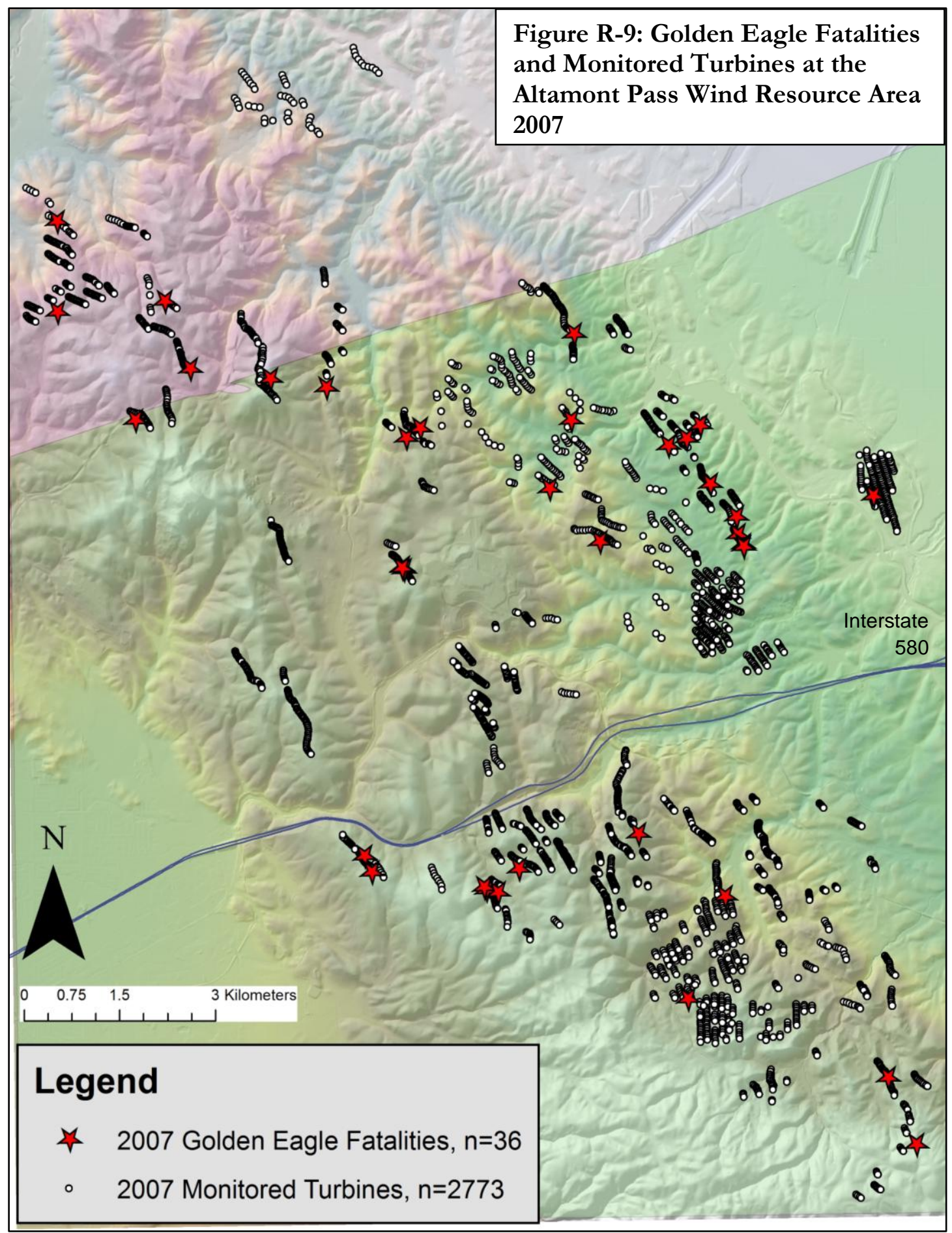

Results 


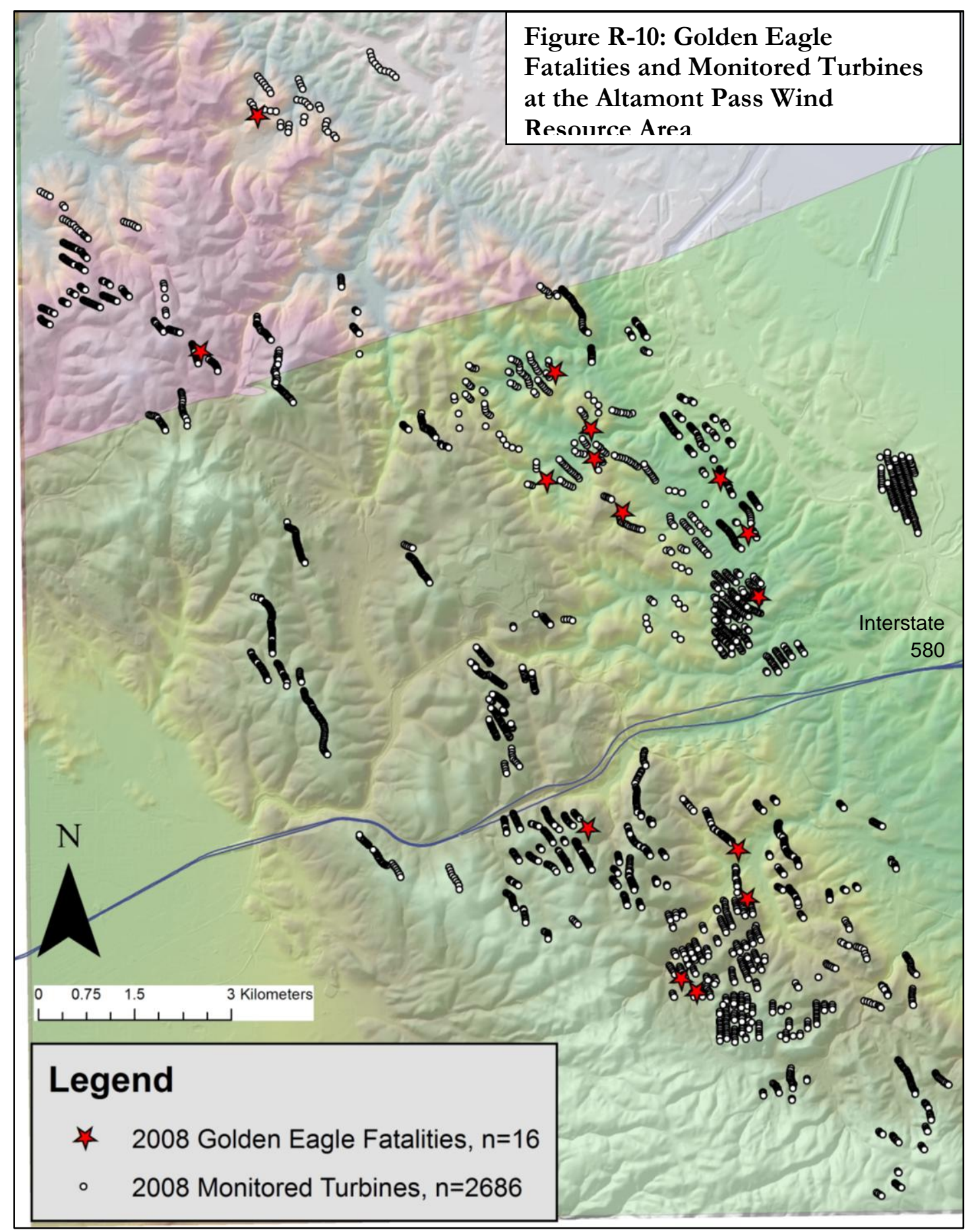

Results 


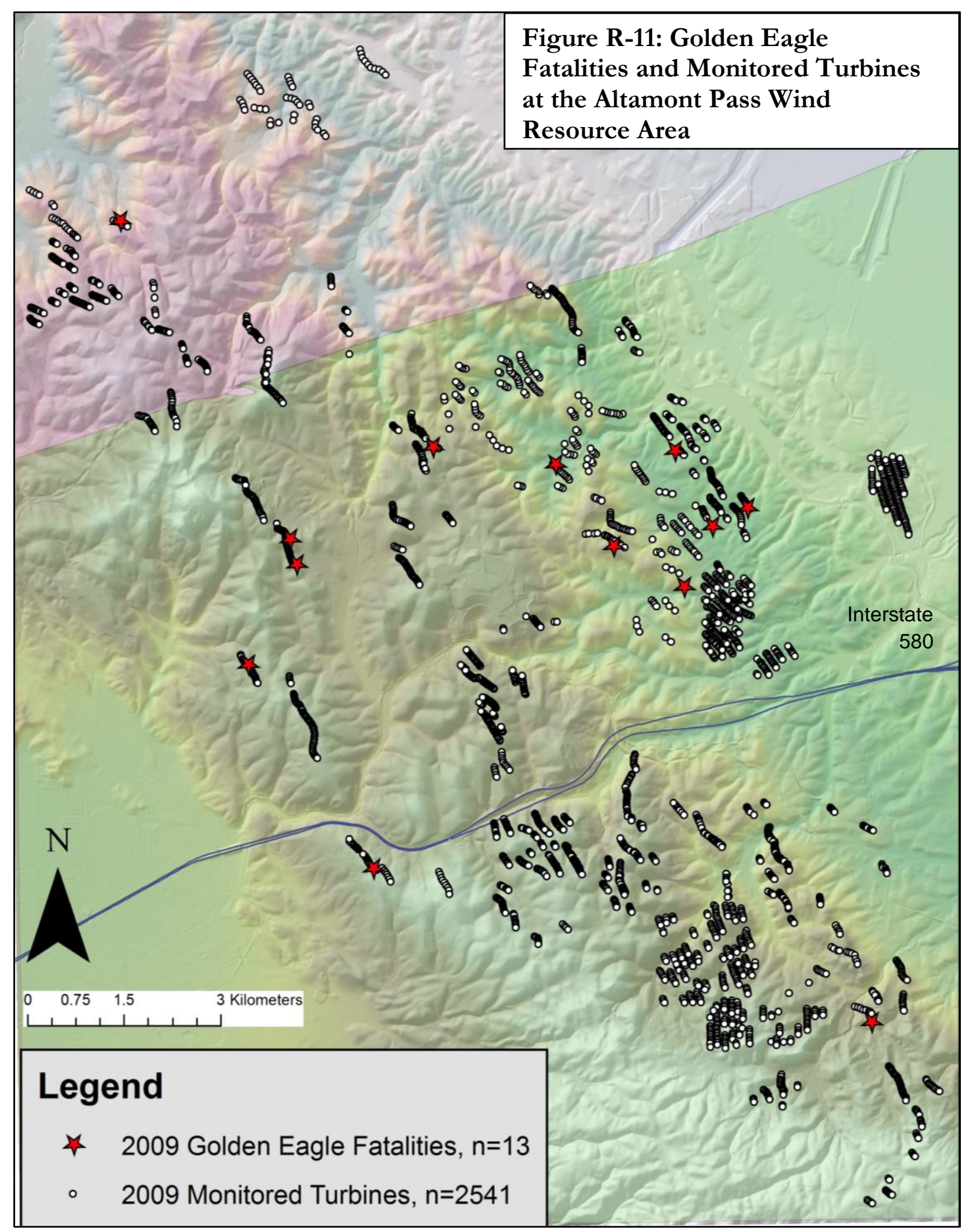




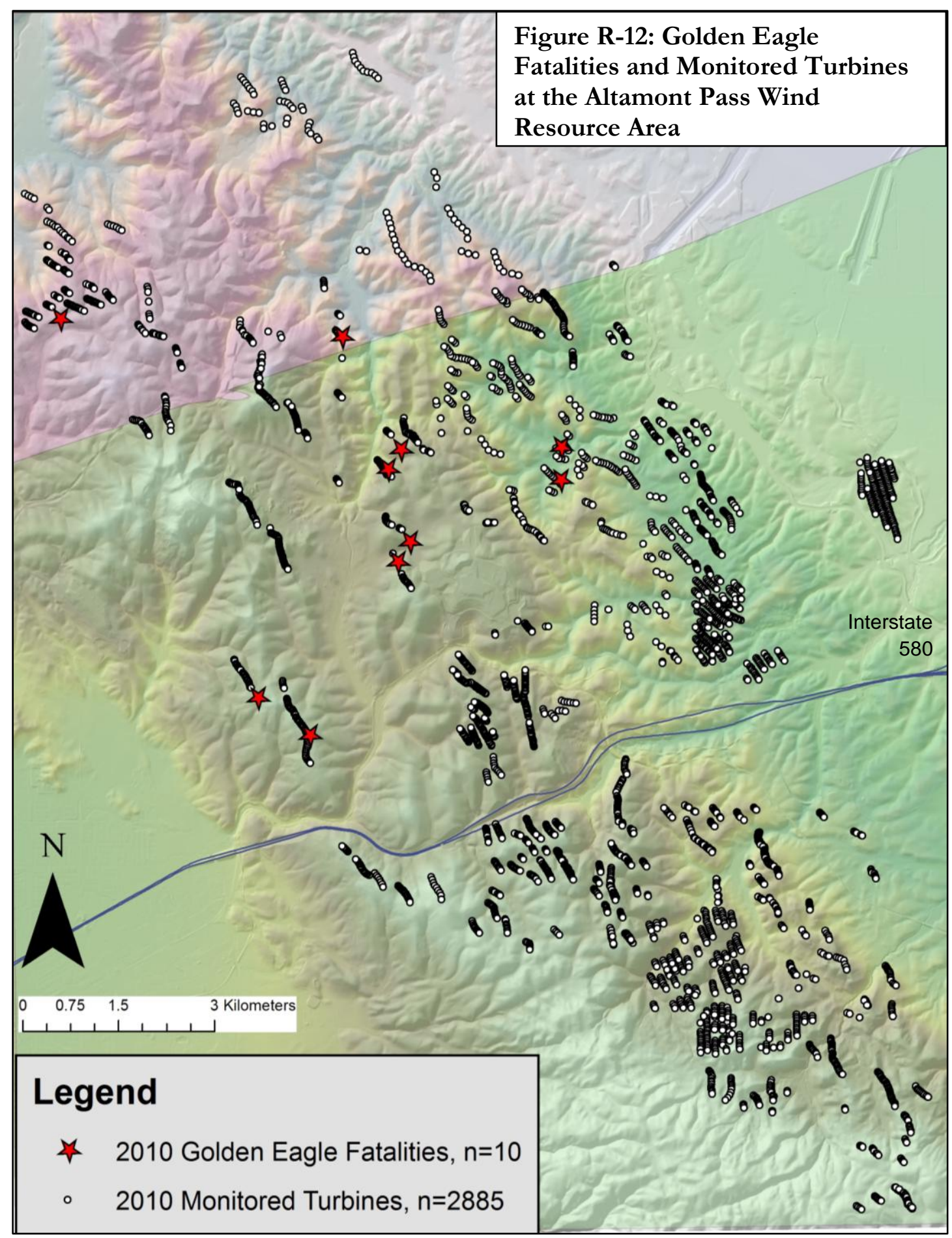

Results 


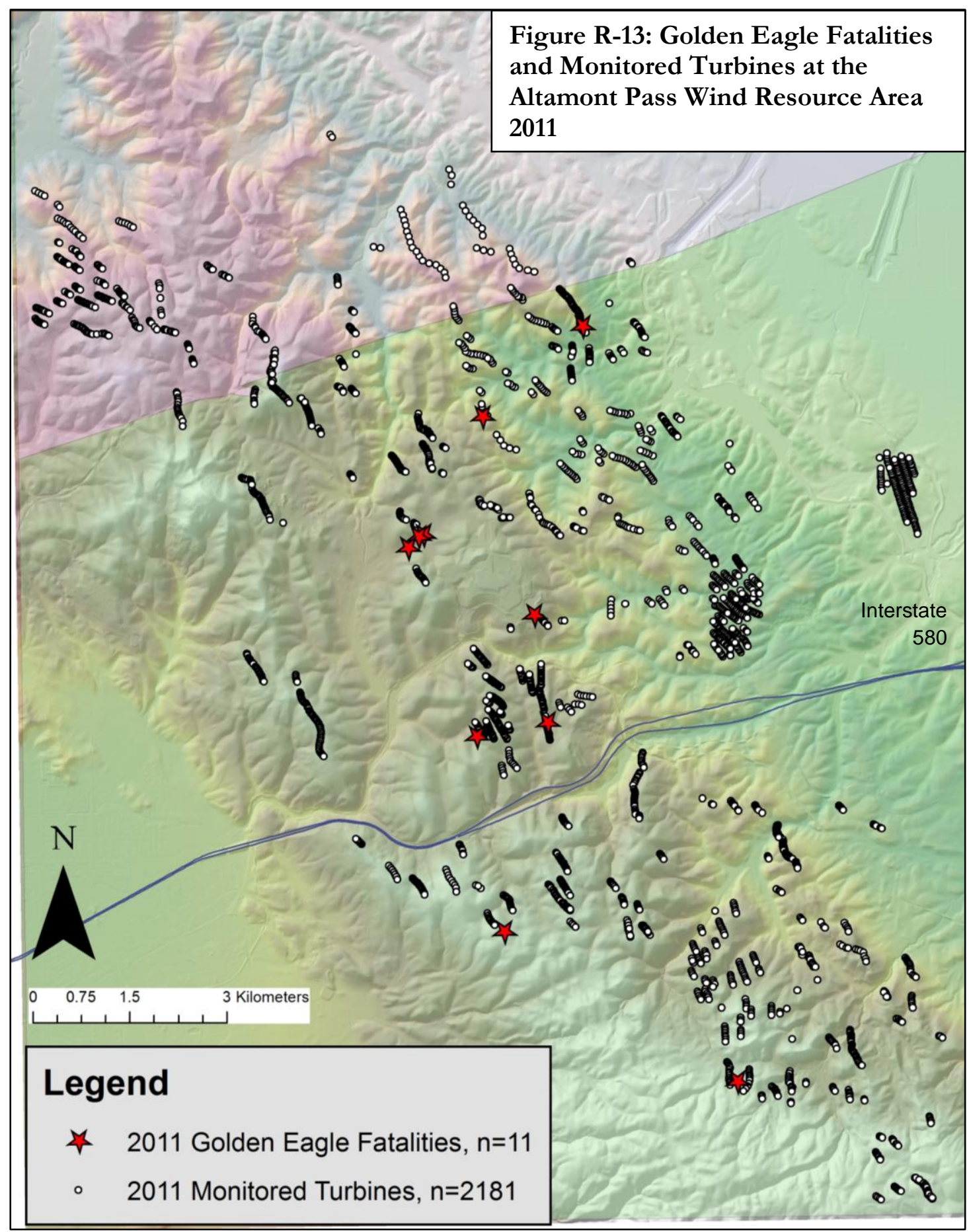

Results 
Table R-11: Search Effort Required per Golden Eagle Fatality

\begin{tabular}{|c|c|c|c|}
\hline Turbine Model & $\begin{array}{c}\text { Count of } \\
\text { Eagle Fatalities }\end{array}$ & $\begin{array}{c}\text { Total } \\
\text { Searches }\end{array}$ & $\begin{array}{l}\text { Searches per } \\
\text { Eagle Fatality }\end{array}$ \\
\hline $250 \mathrm{KW}$ & 0 & 1,113 & 0 \\
\hline Bonus & 30 & 37,567 & 1,252 \\
\hline Danwin & 0 & 497 & 0 \\
\hline Enertech & 1 & 13,681 & 13,681 \\
\hline Flowind & 0 & 1,965 & 0 \\
\hline Howden & 1 & 2,593 & 2,593 \\
\hline Kenetech 56-100 & 91 & 107,815 & 1,184 \\
\hline KVS 33 & 3 & 2,376 & 792 \\
\hline Micon & 3 & 16,667 & 5,556 \\
\hline Mitsubishi 1000A & 0 & 266 & 0 \\
\hline Nordtank & 2 & 9,588 & 4,794 \\
\hline Polenko & 0 & 732 & 0 \\
\hline V-47 & 1 & 1,832 & 1,832 \\
\hline Vestas & 2 & 15,534 & 7,767 \\
\hline Windmaster & 0 & 34 & 0 \\
\hline Windmatic & 0 & 1,564 & 0 \\
\hline Mean & & 13,364 & 2465 \\
\hline
\end{tabular}


Figure R-14: Golden Eagle Fatalities by Turbine Model and Total Search

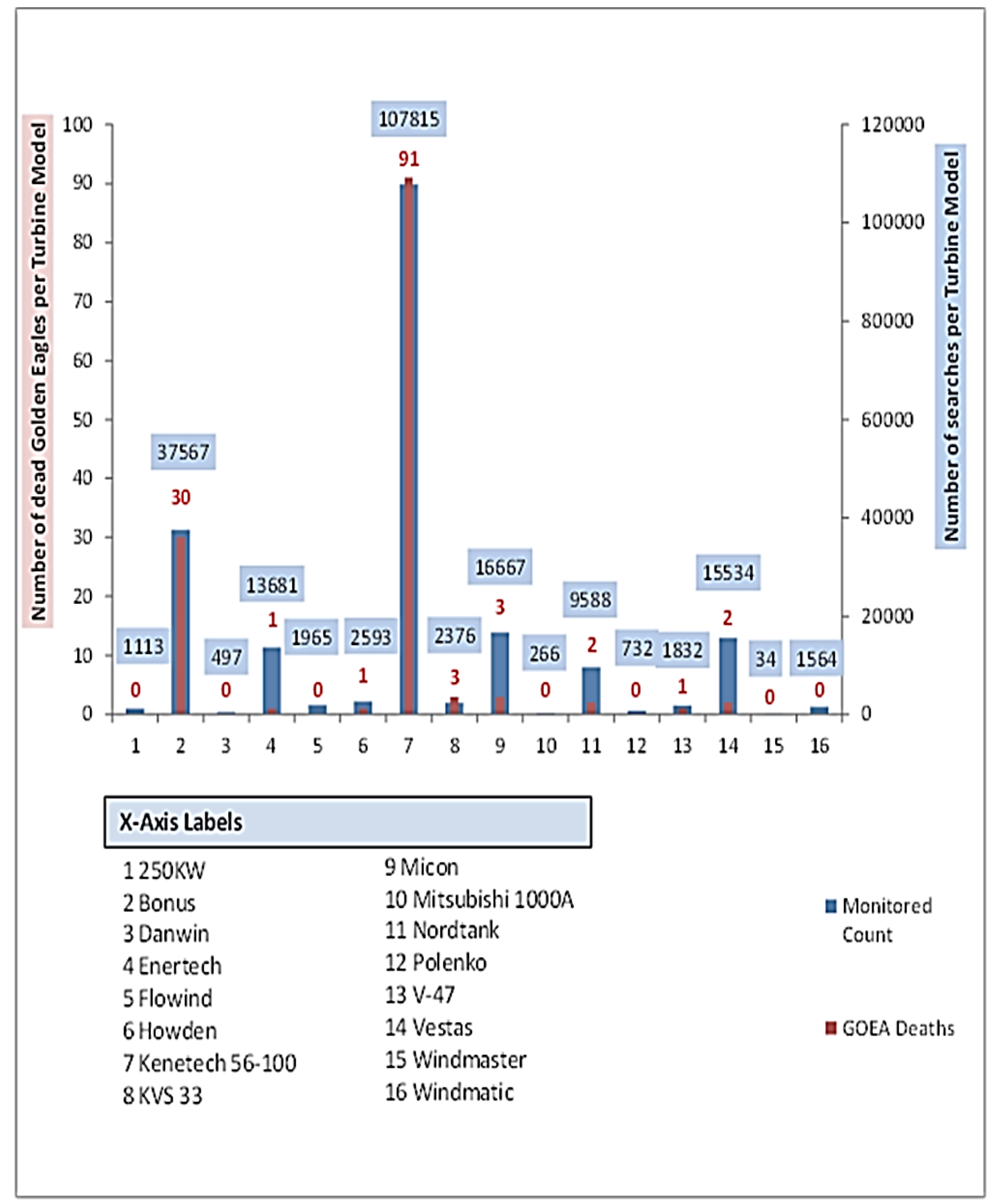

Results 


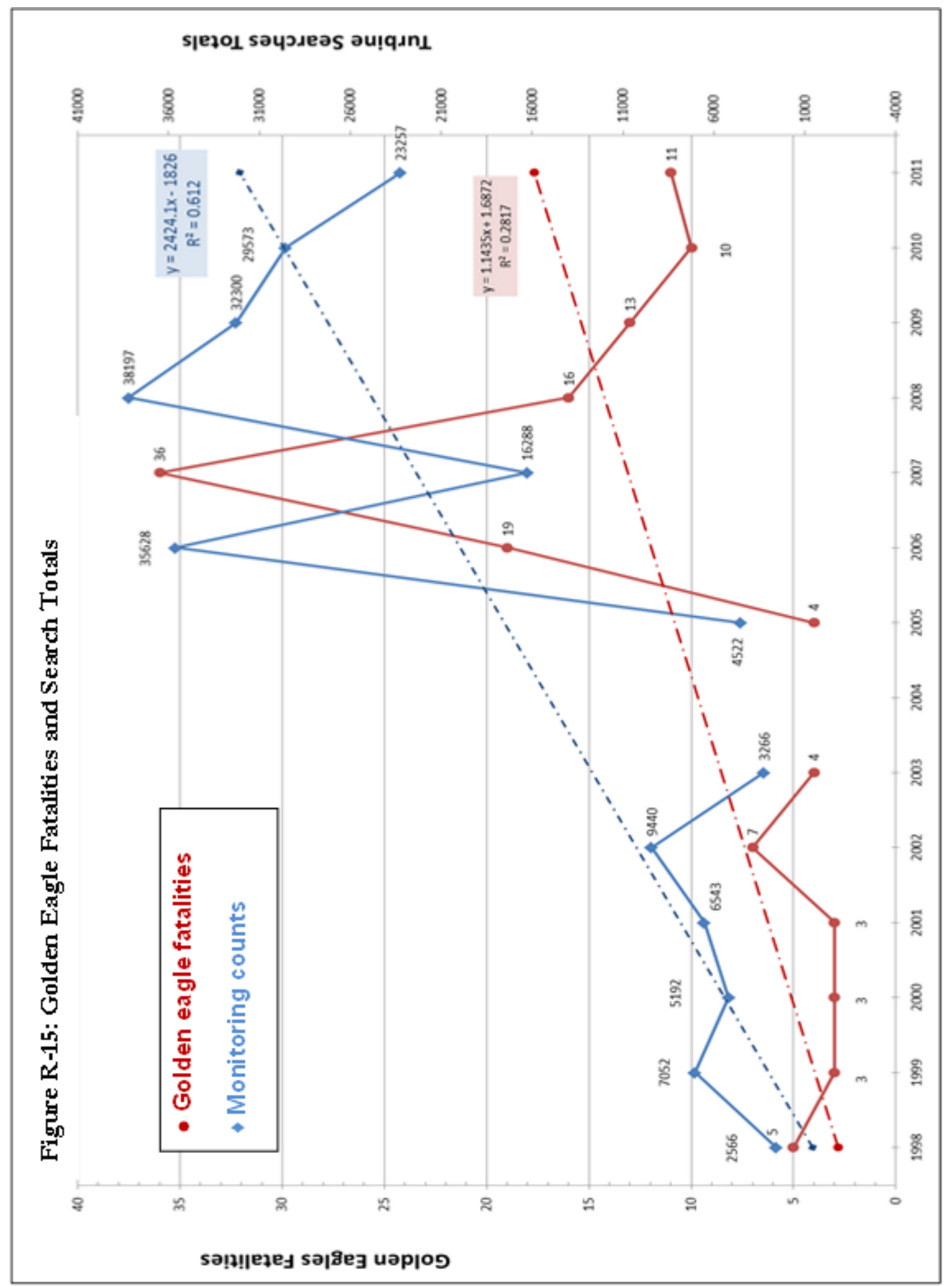

Results 
Table R-12: Summary Table of Test Findings

\begin{tabular}{|c|c|c|c|c|}
\hline Variable & Test & Test Value & $\begin{array}{l}\text { Degrees } \\
\text { freedom }\end{array}$ & p-value \\
\hline $\begin{array}{l}\text { Turbine Model } \\
1998\end{array}$ & $x^{2}$ & 5.67 & 3 & $>0.10$ \\
\hline 1999 & & 2.48 & 5 & $>0.75$ \\
\hline 2000 & & 7.25 & 6 & $>0.25$ \\
\hline 2001 & & 5.65 & 9 & $>0.75$ \\
\hline 2002 & & 4.65 & 13 & $>0.95$ \\
\hline 2003 & & 1.13 & 8 & $>0.99$ \\
\hline 2005 & & 2.37 & 11 & $>0.99$ \\
\hline 2006 & & 10.93 & 11 & $>0.25$ \\
\hline 2007 & & 14.88 & 11 & $>0.10$ \\
\hline 2008 & & 13.56 & 11 & $>0.10$ \\
\hline 2009 & & 13.19 & 11 & $>0.25$ \\
\hline 2010 & & 4.48 & 12 & $>0.95$ \\
\hline 2011 & & 4.3 & 10 & $>0.90$ \\
\hline Elevation & t-test & 2.34 & 142 & 0.02 \\
\hline Slope & t-test & -1.71 & 138 & 0.09 \\
\hline Aspect & t-test & -2.20 & 134 & 0.03 \\
\hline Tower Type & $x^{2}$ & 4.59 & 2 & $<0.05$ \\
\hline Tower Height & t-test & 0.67 & 134 & 0.50 \\
\hline Rotor Swept Area & t-test & -2.014 & 134 & 0.046 \\
\hline Generating Capacity & t-test & -1.13 & 135 & 0.26 \\
\hline Settling Party & $x^{2}$ & 8.02 & 1 & $<0.01$ \\
\hline Ridgetop & $x^{2}$ & 4.842 & 1 & $<0.05$ \\
\hline
\end{tabular}

Results 


\begin{tabular}{|ccccc|}
\hline End Row & $\mathrm{x}^{2}$ & $\mathbf{1 9 . 0 6}$ & $\mathbf{1}$ & $<\mathbf{0 . 0 1}$ \\
\hline Saddle & $\mathrm{x}^{2}$ & 0.56 & 1 & $<.50$ \\
\hline Density & t-test & 7.10 & $\mathbf{1 4 5}$ & 0.36 \\
\hline $\begin{array}{c}\text { Shannon Diversity } \\
\text { Index }\end{array}$ & t-test & 0.92 & 140 & $\mathbf{0 . 0 4 9}$ \\
\hline $\begin{array}{c}\text { Nearest Turbine } \\
\text { Distance }\end{array}$ & t-test & $\mathbf{- 1 . 9 9}$ & $\mathbf{1 3 3}$ & $\mathbf{0 . 0 0 1}$ \\
\hline $\begin{array}{c}\text { Monitored Count } \\
\text { t-test }\end{array}$ & t-test & $\mathbf{- 3 . 5 5}$ & $\mathbf{1 3 4}$ & 0.06 \\
\hline \begin{tabular}{c} 
Screen Count \\
\hline
\end{tabular}
\end{tabular}


Table R-13: Summary Statistics for Turbine Characteristics

\begin{tabular}{|c|c|c|c|c|c|c|c|c|}
\hline Variable & Turbine & Min. & $1^{\text {st }} \mathbf{Q}$ & Med. & Mean & $\begin{array}{l}3^{\text {rd }} \\
\text { Q. }\end{array}$ & Max & $\sigma$ \\
\hline \multirow{2}{*}{$\begin{array}{l}\text { Elevation } \\
\quad(\mathrm{m})\end{array}$} & Kill & 84.24 & 164.00 & 251.70 & 250.80 & 322.70 & 524.60 & 95.99 \\
\hline & Nonkill & 37.54 & 177.90 & 288.60 & 270.50 & 357.70 & 567.00 & 109.11 \\
\hline \multirow{2}{*}{ Slope } & Kill & 0.000 & 0.100 & 0.165 & 0.172 & 0.220 & 0.500 & 0.10 \\
\hline & Nonkill & 0.000 & 0.090 & 0.140 & 0.157 & 0.210 & 0.830 & 0.09 \\
\hline \multirow{2}{*}{ Aspect } & Kill & 1.14 & 123.17 & 212.02 & $317.00^{*}$ & 308.06 & 359.44 & 106.31 \\
\hline & Nonkill & 0.03 & 91.05 & 158.84 & $41.23 *$ & 300.10 & 359.90 & 111.63 \\
\hline \multirow{2}{*}{$\begin{array}{l}\text { Tower Height } \\
\text { (m) }\end{array}$} & Kill & 60.00 & 60.00 & 60.00 & 70.85 & 80.00 & 164.00 & 18.93 \\
\hline & Nonkill & 22.86 & 60.0 & 60.00 & 69.93 & 80.00 & 180.00 & 20.14 \\
\hline \multirow{2}{*}{$\begin{array}{l}\text { Rotor Swept } \\
\quad \text { Area } \\
\left(\mathrm{m}^{2}\right)\end{array}$} & Kill & 141.31 & 254.00 & 254.00 & 292.19 & 258.55 & 1730.80 & 160.27 \\
\hline & Nonkill & 141.31 & 253.90 & 254.00 & 264.24 & 254.00 & 1730.80 & 130.06 \\
\hline \multirow{2}{*}{$\begin{array}{l}\text { Generating } \\
\text { Capacity } \\
(\mathbf{k W} / \mathbf{h})\end{array}$} & Kill & 40.0 & 100.0 & 100.0 & 116.7 & 100.0 & 660.0 & 69.57 \\
\hline & Nonkill & 40.0 & 100.0 & 100.0 & 115.3 & 100.0 & 1000.0 & 98.41 \\
\hline \multirow{2}{*}{$\begin{array}{c}\text { Density } \\
\text { (Turbines/Km²) }\end{array}$} & Kill & 2.98 & 28.05 & 39.71 & 41.83 & 55.60 & 115.20 & 19.81 \\
\hline & Nonkill & 0.99 & 31.77 & 45.67 & 49.52 & 67.51 & 118.10 & 26.09 \\
\hline \multirow{2}{*}{$\begin{array}{l}\text { Shannon } \\
\text { Diversity } \\
\text { Index }\end{array}$} & Kill & 1.000 & 1.000 & 1.000 & 1.345 & 1.620 & 4.420 & 0.63 \\
\hline & Nonkill & 1.000 & 1.000 & 1.000 & 1.361 & 1.692 & 4.419 & 0.65 \\
\hline \multirow{2}{*}{$\begin{array}{l}\text { Nearest } \\
\text { Turbine } \\
\text { Distance }(\mathrm{m})\end{array}$} & Kill & 19.51 & 24.38 & 24.38 & 39.23 & 37.63 & 343.90 & 49.21 \\
\hline & Nonkill & 8.81 & 24.38 & 24.40 & 30.68 & 32.41 & 343.90 & 11.14 \\
\hline \multirow{2}{*}{$\begin{array}{l}\text { Monitored } \\
\text { Count }\end{array}$} & Kill & $0.00 * *$ & 7.00 & 9.00 & 9.03 & 12.00 & 43.00 & 6.35 \\
\hline & Nonkill & 1.00 & 2.00 & 7.00 & 7.05 & 11.00 & 44.00 & 6.16 \\
\hline \multirow{2}{*}{ Screen Count } & Kill & 1.00 & 5.00 & 11.00 & 13.95 & 20.00 & 49.00 & 11.18 \\
\hline & Nonkill & 1.00 & 6.00 & 12.00 & 15.66 & 22.00 & 53.00 & 11.66 \\
\hline \multicolumn{9}{|c|}{$\begin{array}{l}* \text { Mean values for aspect were calculated as circular data using the } \mathrm{R} \text { "circular" package. All other data was } \\
\text { calculated linearly. ** The zero monitored count is explained by incidental finds of golden eagles, not } \\
\text { found on a search. }\end{array}$} \\
\hline
\end{tabular}

Results 
Figure R-16: Circular Aspect Histogram of Nonkill Turbines

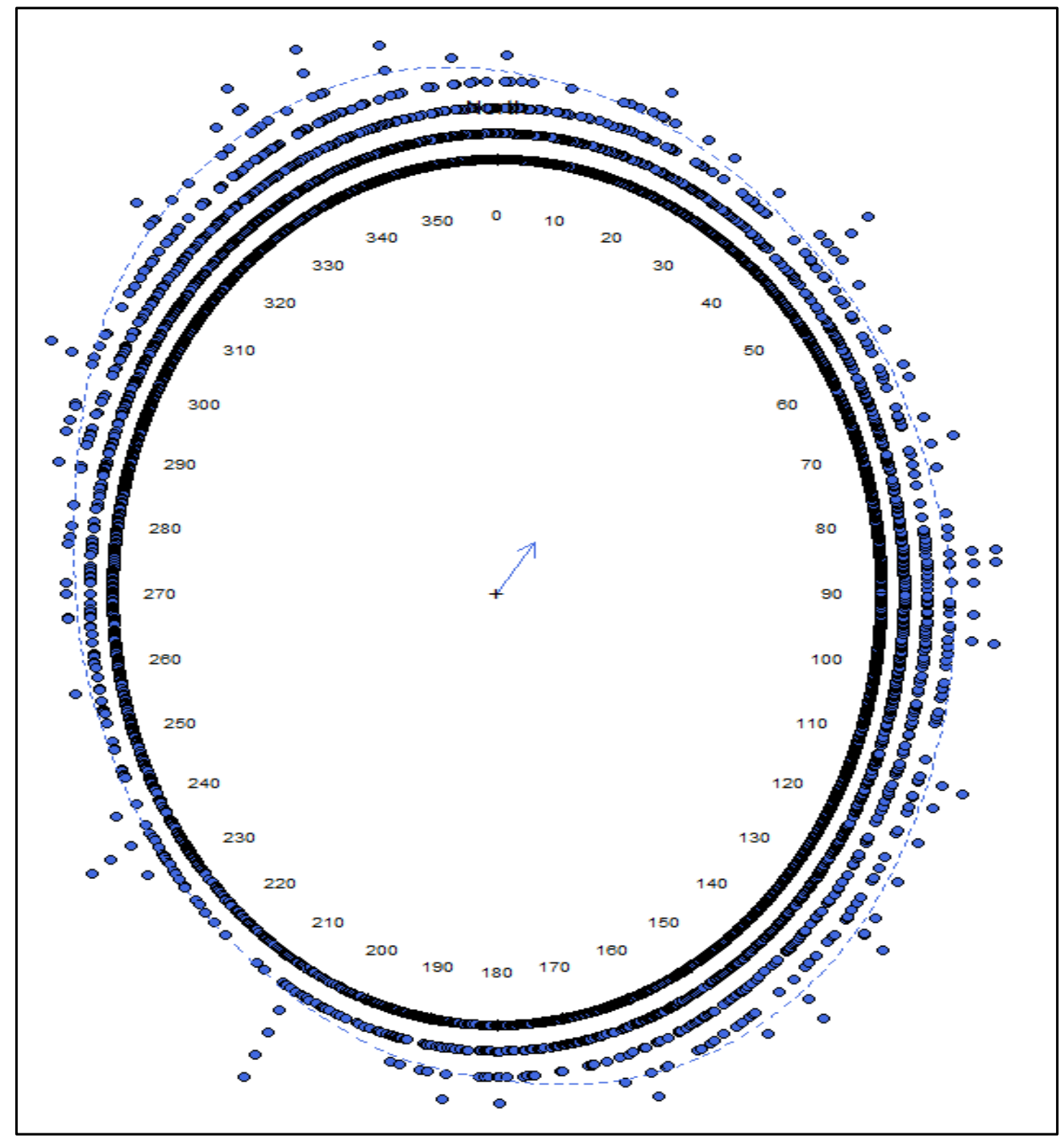

Results 
Figure R-17: Circular Aspect Histogram of Kill Turbines

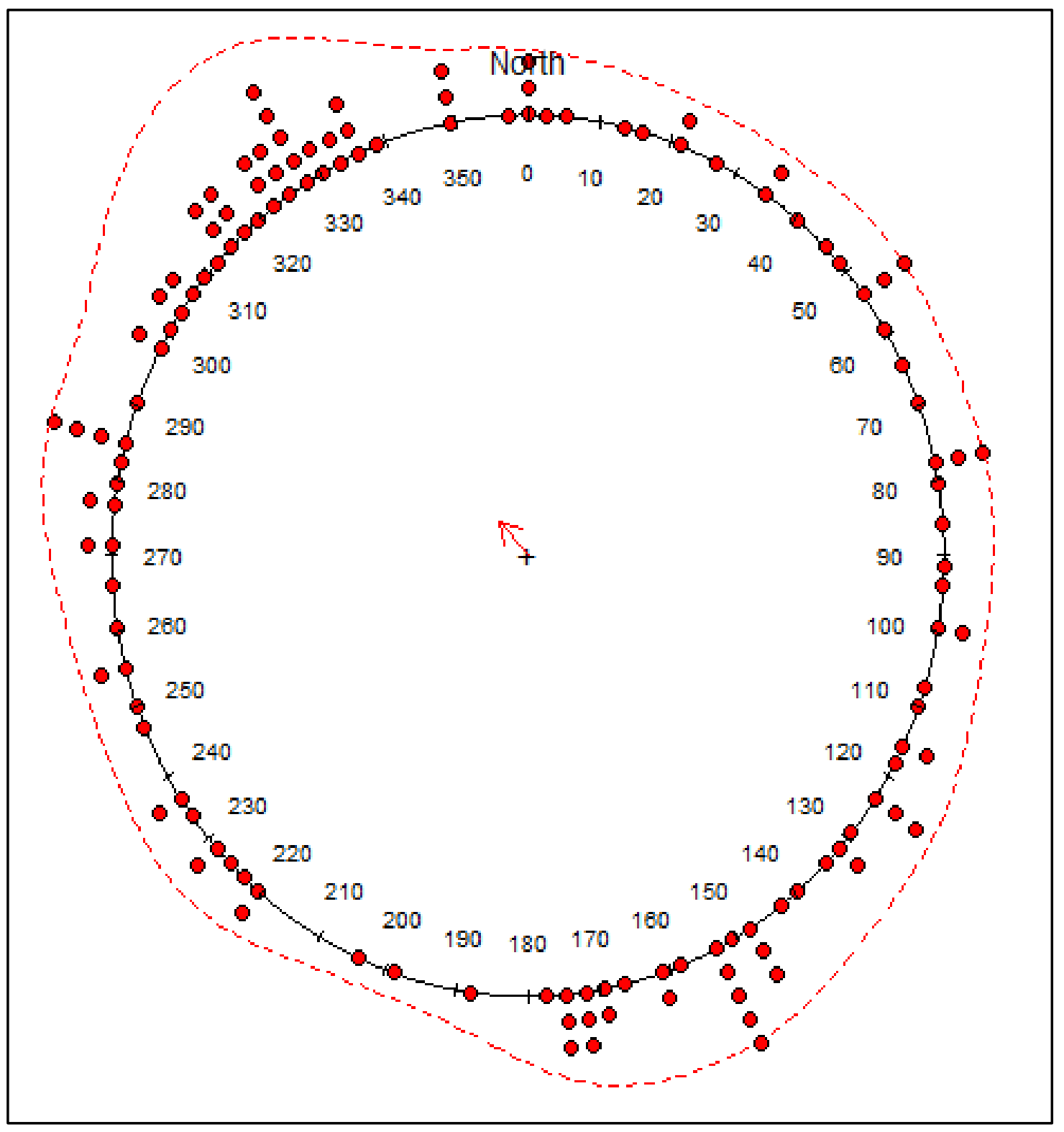


Figure R-18: Golden Eagle Fatalities by Quarter of Death Date

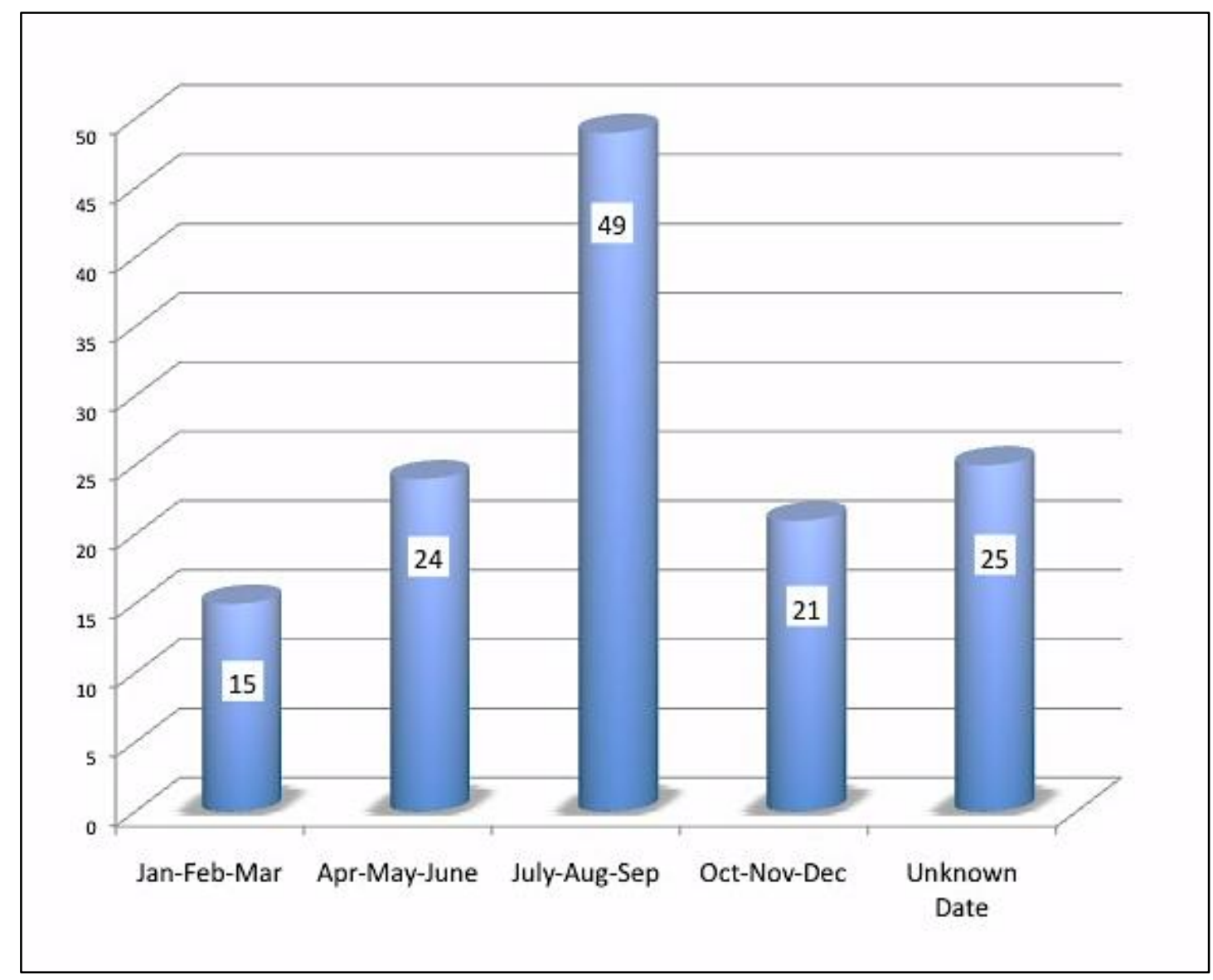


Figure R-19: Golden Eagle Fatalities by Month of Death Date

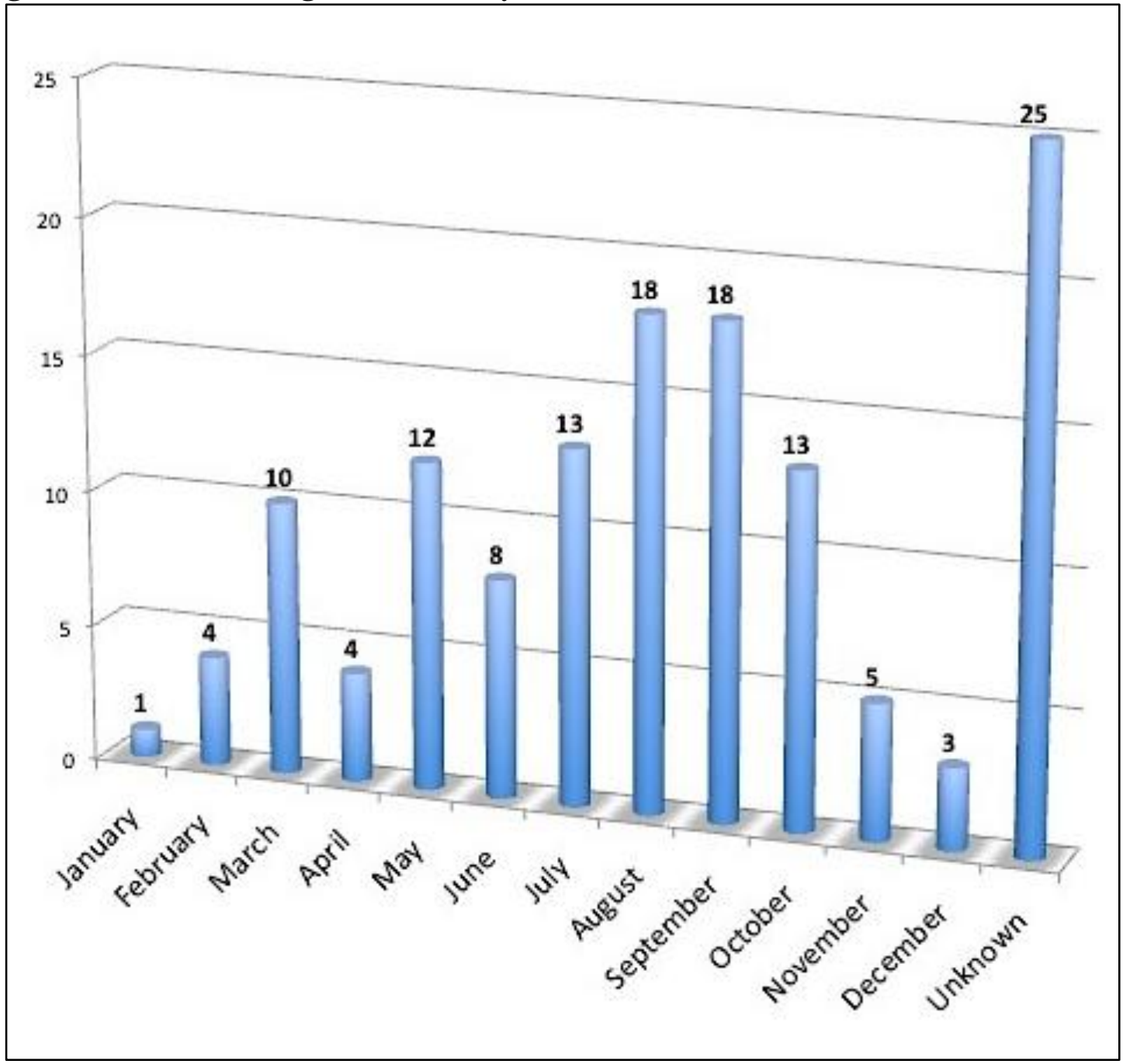

Results 
Figure R-20: Radar Chart of Golden Eagle Fatalities with Known Death Dates

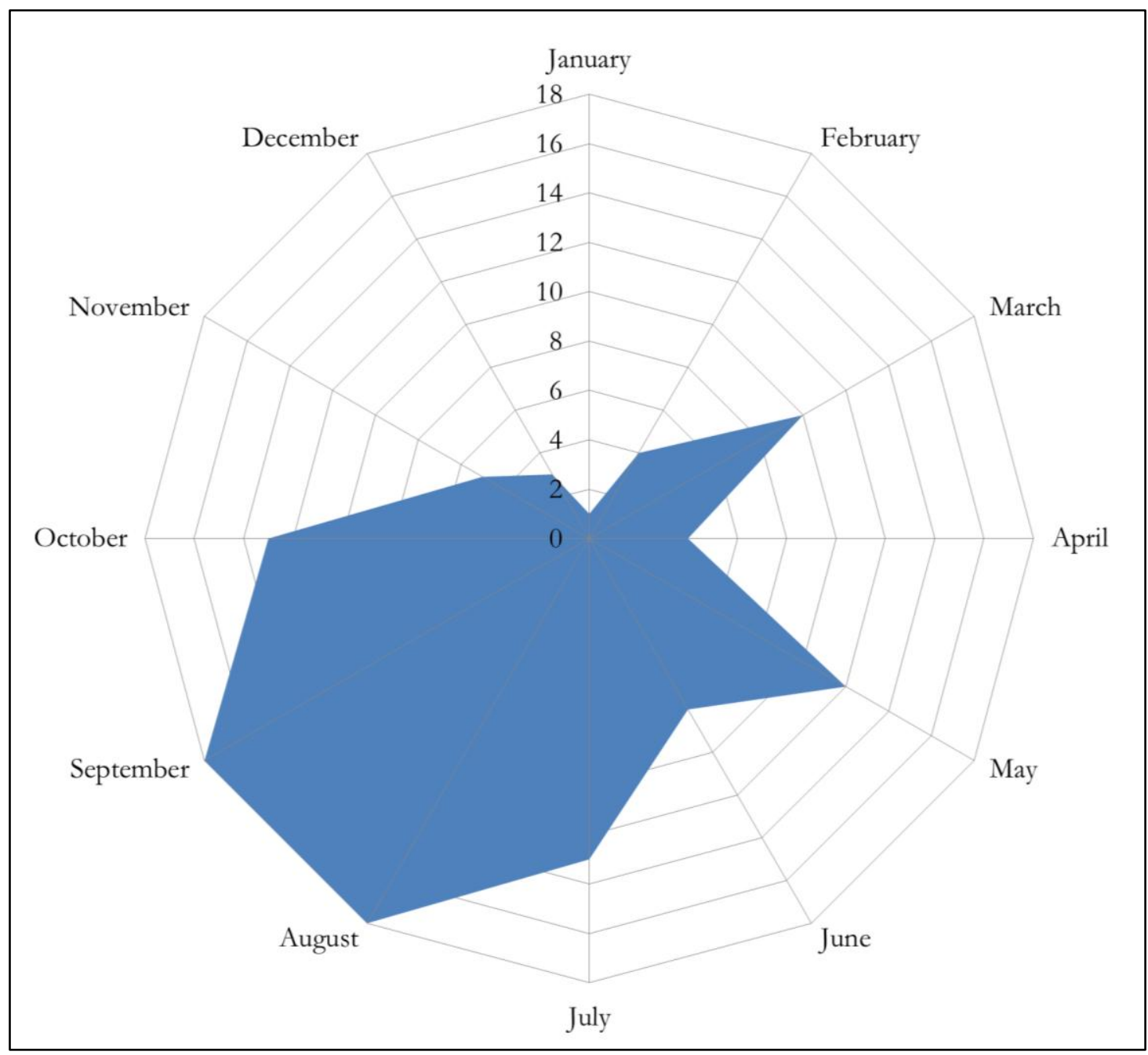


Figure R-21: Age Class and Death Dates of Golden Eagle Fatalities

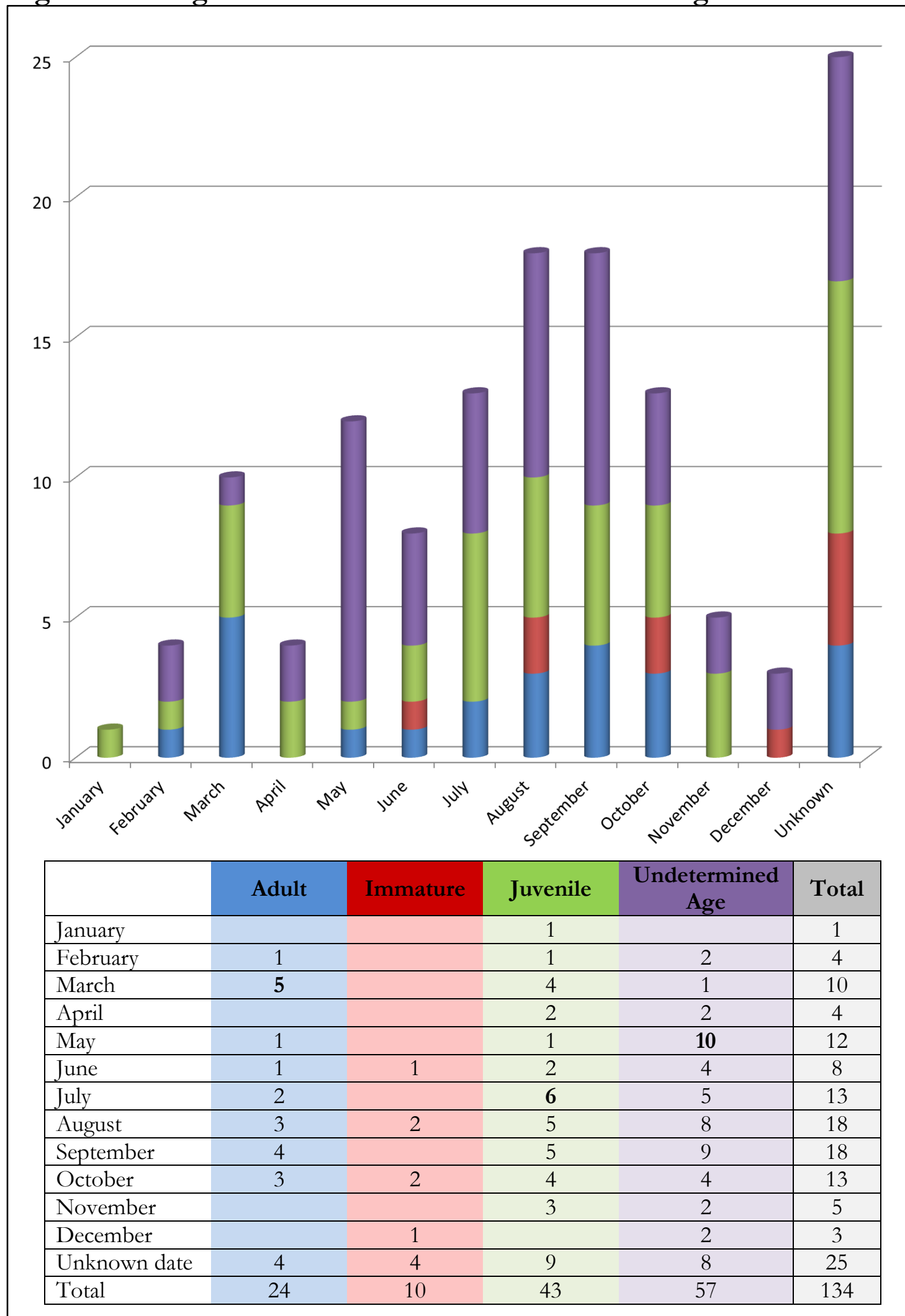

Results 
Figure R-22: Golden Eagle Fatalities by Age

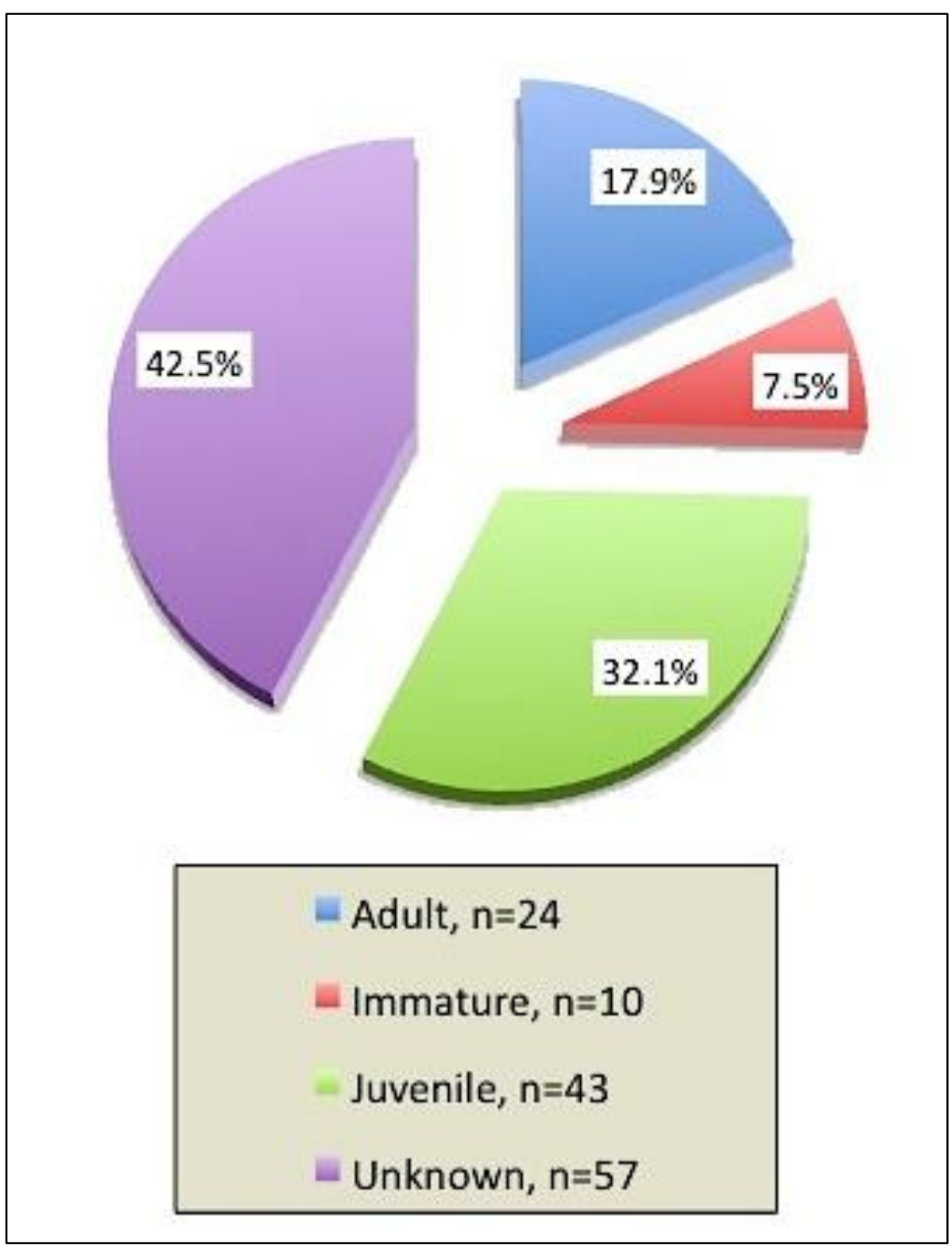


TableR-14: End Row Status by Golden Eagle Age Class

\begin{tabular}{|c|c|c|c|c|c|}
\hline Age Class & n & False & True & $\begin{array}{c}\text { \% } \\
\text { True }\end{array}$ & $\begin{array}{c}\text { Difference from } \\
\text { Total Mean } \\
\mathbf{( 3 8 . 1 \% )}\end{array}$ \\
\hline Adult & 25 & 15 & 10 & $40.0 \%$ & $1.9 \%$ \\
\hline Immature & 9 & 7 & 2 & $22.2 \%$ & $-15.8 \%$ \\
\hline Juvenile & 42 & 31 & 11 & $26.2 \%$ & $-11.9 \%$ \\
\hline Undetermined & 58 & 30 & 28 & $48.3 \%$ & $10.2 \%$ \\
\hline Total & 134 & 83 & 51 & $38.1 \%$ & \\
\hline
\end{tabular}

Table R-15: Tower Type by Golden Eagle Age Class

\begin{tabular}{|c|c|c|c|c|c|}
\hline Age Class & $\mathbf{n}$ & Lattice & Tubular & $\begin{array}{c}\% \\
\text { Lattice }\end{array}$ & $\begin{array}{c}\text { Difference from } \\
\text { Total Mean } \\
(70.9 \%)\end{array}$ \\
\hline Adult & 25 & 14 & 11 & $56.0 \%$ & $-14.9 \%$ \\
\hline Immature & 9 & 6 & 3 & $66.7 \%$ & $-4.2 \%$ \\
\hline Juvenile & 42 & 27 & 15 & $64.3 \%$ & $-6.6 \%$ \\
\hline Undetermined & 58 & 48 & 10 & $82.8 \%$ & $11.9 \%$ \\
\hline Total & 134 & 95 & 39 & $70.9 \%$ & \\
\hline
\end{tabular}

Table R-16: Rotor Swept Area by Golden Eagle Age Class

\begin{tabular}{|c|c|c|c|}
\hline Age Class & $\mathbf{n}$ & $\begin{array}{c}\text { Average } \\
\mathbf{( m}^{\mathbf{2}} \mathbf{r}\end{array}$ & $\begin{array}{c}\text { Difference from } \\
\text { Total Mean } \\
\mathbf{( 2 9 2 . 1 9 )} \mathbf{~ m}^{\mathbf{2}}\end{array}$ \\
\hline Adult & 25 & 303.03 & 10.84 \\
\hline Immature & 9 & 349.90 & 57.71 \\
\hline Juvenile & 42 & 267.35 & -24.84 \\
\hline Undetermined & 58 & 296.56 & 4.37 \\
\hline Total & 134 & $\mathbf{2 9 2 . 1 9}$ & \\
\hline
\end{tabular}


Table R-17: Ridgetop Status by Golden Eagle Age Class

\begin{tabular}{|c|c|c|c|c|c|}
\hline Age Class & \multicolumn{4}{c}{ F } & \multicolumn{4}{c|}{ False } & True & $\begin{array}{c}\text { \% } \\
\text { True }\end{array}$ & $\begin{array}{c}\text { Difference from } \\
\text { Total Mean } \\
(\mathbf{5 . 2 \% )}\end{array}$ \\
\hline Adult & 25 & 25 & 0 & $0.0 \%$ & $-5.2 \%$ \\
\hline Immature & 9 & 8 & 1 & $11.1 \%$ & $5.9 \%$ \\
\hline Juvenile & 42 & 39 & 3 & $7.1 \%$ & $1.9 \%$ \\
\hline Undetermined & 58 & 55 & 3 & $5.2 \%$ & $-0.1 \%$ \\
\hline Total & 134 & 127 & 7 & $\mathbf{5 . 2 \%}$ & \\
\hline
\end{tabular}

Table R-18: Nearest Turbine Distance by Golden Eagle Age Class

\begin{tabular}{|c|c|c|c|}
\hline Age Class & $\mathbf{n}$ & $\begin{array}{c}\text { Mean } \\
\text { (m) }\end{array}$ & $\begin{array}{c}\text { Difference from } \\
\text { Total Mean } \\
\mathbf{( 3 9 . 2 3 ) ~ m ~}\end{array}$ \\
\hline Adult & 25 & 34.57 & -4.66 \\
\hline Immature & 9 & 32.67 & -6.55 \\
\hline Juvenile & 42 & 31.52 & -7.70 \\
\hline Undetermined & 58 & 47.83 & 8.60 \\
\hline Total & 134 & $\mathbf{3 9 . 2 3}$ & \\
\hline
\end{tabular}

Table R-19: Sex Ratio of Golden Eagle Fatalities

\begin{tabular}{|c|c|c|}
\hline Sex & $\mathbf{n}$ & Percentage of Total \\
\hline Female & 2 & $1.5 \%$ \\
\hline Male & 0 & $0.0 \%$ \\
\hline Undetermined & 132 & $98.5 \%$ \\
\hline Total & 134 & \\
\hline
\end{tabular}

Results 


\section{Discussion}

In this study I characterized the wind turbines of the Altamont Pass Wind Resource Area according to geographic placement properties and by innate characteristics of the turbine model. This was done to test the hypothesis that certain of these characteristics may make individual turbines more deadly to golden eagles. Of the 5,086 valid turbine related fatalities during the study period, 134 were golden eagles. These 134 golden eagles were killed by 123 individual wind turbines out of the 5,400 that stand at Altamont. The data indicate that there are significant differences between turbines that have killed golden eagles and those that have not killed golden eagles do exist.

\section{Innate Turbine Characteristics}

Among innate characteristics, the differences in frequencies of tower types was significant $(p<0.05)$. In kill turbines, the lattice tower occurred more frequently - $70.9 \%$ of kill turbines were on lattice towers: tubular towers accounted for the remaining $29.1 \%$. No vertical axis tower turbines resulted in golden eagles fatalities. Among nonkill turbines, lattice towers constitute $58.8 \%$ while tubular towers make up $39.9 \%$ of the array. Vertical axis towers account for the remaining 1.3\%. Thus turbines built on lattice-structured towers occur at higher rates among kill turbines. A potential rationale for this lies in that birds are often seen perched in or on the open lattice of the tower structure, so there may be an additional attraction to these turbine tower types for resting or roosting that results in a disproportionate number of fatalities.

The difference between the mean values of rotor swept areas of kill turbines and nonkill turbines is also significant $(\mathrm{p}=0.046)$. For kill turbines, mean rotor swept area was $292.2 \mathrm{~m}^{2}$, while nonkill turbines mean value was smaller at $264.2 \mathrm{~m}^{2}$. This finding is 
somewhat counterintuitive in that it has been posited that in order to make a turbine array safer, operators should concentrate on installing fewer, larger turbines. This idea leads to a lower density turbine array with towers that have longer blades spinning over a greater area. Longer slower blades, it is thought, should be easier for a bird to notice and to avoid. Smaller blades (with a corresponding smaller rotor swept area) spin at a faster rate, and are theoretically more difficult for birds to detect and avoid. This idea is at the heart of the Altamont repowering scheme in which many smaller turbines are currently being removed and replaced by fewer larger turbines. Perhaps the speed of the turbine propellers has nothing to do with killing golden eagles. Instead, turbines with larger rotor swept areas may have the ability to swing out further and make contact with passing eagles. Like a boxer with a reach advantage, a longer turbine blade can strike from a further distance.

Of the innate characteristics that were not significant, the results of the turbine model chi-squared tests were most surprising. The Kenetech 56-100 turbine model has been responsible for $67.9 \%$ of the known turbine related golden eagle fatalities at Altamont, yet statistically this figure is not significant. This is of course, because this model makes up a large portion of the monitored array each year, between $36.0 \%$ (1999) and 73.9\% (2003) of all turbines searched. This result is consistent with Hunt's study where he found $73 \%$ (27 of 42) of the golden eagles killed at Altamont were killed by Kenetech turbines (Hunt 2002). Hunt's study did not publish statistical analysis such as was conducted in this study. Nevertheless, the authors conclude that areas that containing the Kenetech turbine type are more hazardous to golden eagles. Thelander did calculate through chi-square analysis that turbine model was significant in golden eagle fatalities, but those results showed that the Bonus model being more represented in kill turbines (Thelander 2003). 
Generating capacity was another innate characteristic that did not show a significant difference between kill and nonkill turbines. Among all of the variables tested, this one was a bit more abstract and had the least potential to interact with any golden eagle at Altamont. It would have been a surprise had generating capacity been significantly different in kill turbines. Thelander's study concurs that generating capacity is not significant (Thelander 2003). The differences in tower height between kill and nonkill turbines also are not significant, and once again Thelander' results agree.

\section{Geographic Placement Characteristics}

Among the geographic placement characteristics with significant differences is elevation, aspect, settling party, ridgetop, end row, turbine density, nearest turbine distance and monitored count variables. The elevation data show that when golden eagles are killed, the turbines are at a mean elevation of $250.8 \mathrm{~m}, 20 \mathrm{~m}$ lower than the mean elevation of nonkill turbines at $270.5 \mathrm{~m}$. This lower elevation also fits with the finding that kill turbines were found significantly less frequently on hilltop ridgelines than nonkill turbines $(\mathrm{p}<0.05)$. Of the 134 kill turbines, only 7 were on ridgelines. This is just $5.2 \%$ while the nonkill rate of ridgeline turbines was $11.2 \%$. The proportion of turbines that were on ridgelines was lower than I had expected to find. I assumed that ridgelines represented some of the best areas to capture eolian energy, and that there would be more than just $11 \%$ of turbines there. If this assumption is true, then perhaps the method I used to calculate ridgelines was too strict to accurately identify them all. Or it may be that the ridgelines are not the best locations to capture wind resources, or that ridgelines are difficult to develop into turbine locations.

Hill aspect was also found to be significantly different between killer turbines and nonkill turbines. The mean aspect for kill turbines was $317^{\circ}$ while nonkill turbines were on 
slopes oriented towards $41^{\circ}$. This means that the average direction of the hillside of a kill turbine faces northwest, while the nonkill average faces northeast. The histograms calculated in R (Fig. R-16 and R-17) illustrate that in neither group do a large proportion of turbines reside on a hillside that faces west or southwest, where the prevailing winds come from at Altamont. I have no doubt that the engineers and surveyors that site turbines know very well what they are doing, but it was a surprise for one of my assumptions to be dismantled. Aspect was shown as not significance Orloff's (1992) and Thelander's studies (2003).

Among the more interesting findings is that the turbines that killed golden eagles were in a less dense array and further away from the next nearest turbine neighbor. The mean measure of density of kill turbines was 41.83 turbines per $\mathrm{Km}^{2}$, while the mean density for nonkill turbines was higher at 49.85 turbines per $\mathrm{Km}^{2}$. The next nearest turbine for a kill turbine had a mean distance of $39.2 \mathrm{~m}$; while the nonkill turbines' nearest turbine neighbor was closer at a mean distance of $30.7 \mathrm{~m}$. Both of these measurements indicate that kill turbines are not among the densest, most closely arrayed turbine groupings. This concurs with Orloff's findings that turbines with lower structure density had significantly higher mortality rates for both raptors and non-raptors (1992).

The measure of density used in this study however, is not without flaws. Both the diversity and density calculations are based on a grid made of nearly $1 \mathrm{Km}^{2}$ polygons that was calculated and rendered in ArcMap. This grid is a static layer based on of the maximum extent of Altamont's turbine array and it has enabled a number of simple calculations in the current study. This grid also represents a single sample and single measurement of the space. A more robust study would recalculate the grid a number of times after random placements over the array. By doing this, many measurements would be taken and average values could be calculated that better represent the space. The same measurements of diversity and Discussion 
turbine density within the space could be better analyzed. A sampling regime such as this may potentially provide more reliable results. An alternative for these calculations would have been to generate a 500-1000 meter buffer around each turbine, calculated annually, and use those buffer zones as polygons to calculate a diversity index and density figure. This technique would establish each turbine as the center of its own zone and may lead to a better description of the turbine's relationships with its nearest neighbors and other geographic features. It would be interesting to see how the measurements of density may change depending upon how the samples are taken. Would a density measure based on each turbine as the center of its own territory yield a more accurate result and would it support the finding reported herein that kill turbines are found in a less dense array?

Comparing nonkill and kill turbines that are at the end of turbine rows demonstrates another area of significant difference between the two groups. Of the 134 kill turbines, $38.1 \%$ were end row turbines, while only $22.4 \%$ of nonkill turbines were end row features. If this is indeed a variable that influences golden eagle fatalities, then the repowering plan at Altamont may be creating additional danger for golden eagles. As turbines are being removed, the long rows ("screens" in this study) are being broken up to create more gaps with the idea that the long rows constitute a dangerous impediment to birds. One of the effects of this practice is to create more end row turbines. If a row of turbines is broken in the middle by removing three units, then two more end row turbines are established on either side of the removals. In this study, there was no significant difference between screen counts of kill and nonkill turbines, so my findings do not support the practice of breaking apart long turbine rows into smaller entities.

The difference in monitored count mean values between kill and nonkill turbines $\frac{\text { was found to be significant }(p=0.001) \text {. Although the mean values are not largely disparate at }}{\text { Discussion }}$ 
9.03 for kill turbines and 7.05 for nonkill turbines, it makes logical sense that golden eagle fatalities will be found at turbines that are searched more often. An average of two additional searches at the kill turbines may have made a difference in detecting an individual bird fatality.

The differences between kill turbines versus nonkill turbines have also been found to be significant in the character of settling party. Every single turbine credited with a golden eagle death is owned by one of the wind operator settling parties at Altamont. Among the nonkill turbines, a small portion, 5.8\% are not owned by any member of the settling party. This figure is suspicious because monitoring for bird fatalities was a condition of the settlement and is paid for in part by wind operators and Alameda County as part of the settlement. It does not make complete sense that turbines are being monitored, unless it was under an alternative arrangement that I am unaware of. This could also be an indication that there is error in the data that must be rectified. This variable was included in the study to determine if there was a difference between settling party turbines, some of which go through seasonal shutdown (as part of the settlement), and those that do not go through the seasonal shutdown. I do not have confidence in the veracity of the data in this field, so I do not find that it supports or doesn't support my hypothesis.

The data also do not support differences in saddle turbines or turbine diversity as significant between kill and nonkill turbines. The Shannon index mean values between the two groups are nearly indistinguishable, at 1.34 for kill turbines and 1.36 for nonkill turbines. Just two kill turbines are located on hilltop saddles (1.5\%) while slightly more nonkill turbines reside there $(2.5 \%)$.

\section{Temporal Distribution, Age and Sex Frequencies}

Discussion 
The most deadly time of the year for golden eagles at Altamont is during the months of July, August and September. This corresponds with Altamont's windy season and follows the breeding period that starts at the beginning of the year (Hunt 1995). This is well illustrated in the radar chart (Fig. R-20), where the bulk of fatalities are seen to occur between July and October, with two noticeable spikes in March and May. The lack of fatalities recorded in the wintertime may be due in part to the seasonal shutdowns of turbines in the off season, or it could be a reflection of less golden eagle activity during that time of year.

The age class data provides an interesting look at the assemblage of fatalities. Most notable are the large number of juveniles $(n=43)$ and the great number of fatalities with undetermined age $(n=57)$. As was suggested earlier, the juvenile number is out of agreement with Hunt's study (2002) where juveniles were a small percentage of fatalities caused by wind turbines. It is possible the numbers reported here for juvenile fatalities are skewed young, depending upon the criteria used by field biologist when they determined the age class of the bird at time of detection. This idea is supported by the low numbers of immature bird fatalities $(n=10)$. A population census including age class distributions of golden eagles at Altamont has not been published, but Hunt suggested a hypothetical population that consisted 280 adults (30.7\%), 169 immature (50.9\%), and 101 juveniles (18.4\%) for a population of 550 at equilibrium (1995). These figures suggest that immature birds make up half of the population, but in the present study, they only account for $7.4 \%$ of the fatality data tested. It is possible that immature birds possess some behavioral trait that keeps them relatively safe from turbine strikes, but a more parsimonious explanation is that their low number is a relic of mischaracterization at time of discovery. Juvenile birds are those that are in their first year of life, and it is reasonable to think that a biologist may mistake a carcass's \begin{tabular}{lr}
\hline Discussion & 99
\end{tabular} 
plumage patterns as those of a younger bird. The other possibility is that there is no error in the age class designations of golden eagle fatalies and juvenile birds are killed by turbines at Altamont at disproportionate rate compared to Hunt's suggested population age class distribution. This would be a disturbing trend because without replacement or recruitment from outside golden eagle poplulations, a higher death rate for juveniles at Altamont would eventually lead to a collapse, which has yet to happen.

The results of the sex ratio analysis of the 134 fatalities do not provide much insight into which sex is more or less disposed to fatal turbine interactions. With only 2 of 134 birds being positively characterized, there is little that can be discussed. The other 132 birds were not characterized as either female or male, so the sex of these records remains a mystery.

The undetermined ages of $43.0 \%$ (58 of 134) of the sample makes it difficult to detect trends in age class mortality, but when looking at age classes and significant turbine variables, several interesting results appear. Considering end row status, Table R-14 shows that for non-adult birds $(\mathrm{n}=51)$, the percentage killed by end row turbines is cumulatively $25.5 \%$ (13 of 51 ), which is lower than the average for all fatalities of $38.1 \%$. This is then offset by the 58 undetermined birds that were more often killed by end row turbines $(28$ of $58,48.3 \%)$.

Fewer adult birds were killed at lattice towers (10 of 25, 56.0\%) than the average of $70.9 \%$, but again, the undetermined birds $(n=58)$ were killed by lattice tower turbines $82.8 \%$ of the time (48 of 58). In fact, all birds with determined age classes were killed at lattice tower turbines less than the calculated mean (Table R-15).

Rotor swept area (Table R-16) showed differences among age classes with juvenile birds falling victim to smaller turbines on average and immature birds tending toward larger 
blade diameters. Four of 51 non-adults $(7.8 \%)$ were killed by ridgetop turbines. This is higher than the calculated mean of $5.2 \%$.

Each of the mean nearest turbine distances for all fatalities with classified age classes are below the total mean of 39.23 meters. This mean is balanced by the higher than average nearest turbine distance for fatalities of undetermined age (Table R-18). 


\section{Conclusions}

There are characteristics of wind turbines fatal to golden eagles at Altamont that are significantly different from characteristics of those turbines that do not result in fatalities. Among the differences are that kill turbines are found at lower elevations and the aspect of the hill where the kill turbine averages $317^{\circ}$ while nonkill turbines face $41^{\circ}$ on average.

Kill turbines are more often situated on lattice structure towers and they have larger rotor swept areas than nonkill turbines. Kill turbines are placed in less dense turbine arrays and are less often placed on top of ridgelines. Compared to nonkill turbines, they have a longer distance to the next nearest turbine, and they are monitored more often. Finally, kill turbines are more often situated at the end of a turbine row than are nonkill turbines.

Among the characteristics that are not significantly different between kill and nonkill turbines are the slope of the hill upon which a turbine stands, the model of turbine, height of the turbine tower, generating capacity, diversity of the turbine array, the number of other turbines in its row, and whether or not the turbine stands in the saddle of a hilltop ridge.

\section{Future Directions}

The tests conducted in this study are simple, but they reflect the standard approaches to measuring wind turbine interactions with birds. These tests however cannot explain how a wind turbine is more or less capable or better equipped or better placed to result in a golden eagle fatality. Multivariate analysis on these and other characteristics of wind turbines may be able to fill in more of our understanding of why and how eagles are killed.

Perhaps one way to better understand why some turbines have killed golden eagles would be to perform duplicate studies of turbine characteristics as they apply to fatalities of other species. By analyzing characteristics that may be important in turbines that result in 
fatalities of rock dove, red-tailed hawks, American kestrels, or any of the other often killed birds at Altamont, it may become, in a comparative framework, more clear which elements apply to only to golden eagles, and which do not.

Potential extensions of this research include a further analysis of the remaining turbines and how many of them fall into a range of values that this study has found significant. This could lead to predictive modeling of future fatalities and could better inform fatality reduction efforts. A more robust study also could be conducted using more tools in ArcMap, LiDAR data, and three-dimensional modeling to better understand the terrain, and flight paths of golden eagles and other raptors that frequent Altamont.

Efforts to reduce bird deaths at Altamont have attracted many brilliant thinkers, impassioned activists, field biologists, business people and scientists all in the service of reducing the damages to bird populations. There are some common-sense solutions that seem to have not gotten to the table. For example, of the 123 turbines that have killed golden eagles at Altamont, 84 remain present and in operation. Among these, turbines with the ids 305, 2674, 895 and 2608 still stand. Each of these four turbines has already killed two golden eagles during the timeframe of this study. Also turbine 2697 is still present in the array. It is already responsible for three golden eagle fatalities. In 1994, California enacted a three strikes law that provided stiff penalties for habitual felony offenders: this law has arguably had some success in curbing violent crimes. Perhaps the wind operators could offer a similar penalty for those turbines that are found to habitually kill protected species.

Conclusions 


\section{Acknowledgments}

I must acknowledge the teachers in my life that have inspired me to pursue biology as a topic of study, an area of wonder and as a professional calling. Among them are the members of my thesis committee, Drs. Luis A. Ruedas, Deborah A. Duffield and Michael T. Murphy, as well as Craig Tufts, Dr. Robert Pinger and Tom Brown Jr.

I must acknowledge and thank those field biologists that for years collected data, walking transects, searching for the slightest hint of a feather. I don't know your names, but I thank you for the project. I do however know Levin Nason, Doug Leslie, Karl Dickman, Jesse Schwartz and Chip McConnaha, all of whom work on the Altamont project at ICFI, and informed this research.

Finally, I acknowledge and thank my wife Laura for her support and patience as I began and finally completed this research. 


\section{Photo Credits}

Tubular: http://www.powerworks.com/Pictures/WEG-turbine-string-lo-res b.JPG

Lattice: http://matrixwindsolutions.com/kenetech-kvs-33-wind-turbine/\#!prettyPhoto[4689]/0/

Vertical axis: http://www.fiddlersgreen.net/models/miscellanous/Wind-Turbine.html 


\section{References}

Aiken, R., \& Harris, A. (2011). Deer Hunting in the United States Demographics \& Trends Addendum to the 2006 National Survey of Fishing, Hunting and Wildlife Associated Recreation. 2006-10. Retrieved from http://digitalmedia.fws.gov/cdm/ref/collection/document/id/207

Applegate, R. D., Berger, D.D., Chochran, W. W., Raim, A. J. (1987). Observations of a Radiotagged Golden Eagle Terminating Fall Migration. J. Raptor Res 21, 68-70

American Wind Energy Association. (2012). Wind Industry Statistics Quarterly Report. 2012(4)

Barclay, R. M. R., Baerwald, E. F., \& Gruver, J. C. (2007). Variation in bat and bird fatalities at wind energy facilities: assessing the effects of rotor size and tower height. Can. J. Zool., 85(3), 381-387. doi: 10.1139/Z07-011

Bortolotti, G. R. (1984). Age and Sex Size Variation in Golden Eagles. Journal of Field Ornithology, 55(1), 54-66. Retrieved from http://www.jstor.org/stable/4512857.

Brower, J. E., Zar, J., von Ende, C.N. (1998). Field and Laboratory Methods for General Ecology. Fourth ed., WCB/McGraw-Hill, 1998.

California Energy Commission. (2007). California Guidelines for Reducing Impacts to Birds and Bats From Wind Energy Development. CEC-700-2007-008-CMF. 125.

Cameron, E. S. (1908). Observations on the Golden Eagle in Montana. The Auk 25. 251-68.

Carnie, S K. (1954). Food Habits of Nesting Golden Eagles in the Coast Ranges of California. The Condor (56)1, 3-12.

Collopy, M. W. (1983). A Comparison of Direct Observations and Collections of Prey Remains in Determining the Diet of Golden Eagles. The Journal of Wildlife Management, 47(2), 360-368. Retrieved from http://www.jstor.org/stable/3808508

Collopy, M. W. (1983). Foraging Behavior and Success of Golden Eagles. The Auk, 100(3), 747-749. Retrieved from http://www.jstor.org/stable/4086484

Coonan, T. J., Schwemm, C. A., et al. (2005). Decline of an Island Fox Subspecies to Near Extinction. The Southwestern Naturalist (50)1, 32-41.

Dixon, J. B. (1937). The Golden Eagle in San Diego County, California. Condor 49-56.

References 
Edwards, T. C. J., \& Collopy, M. W. (1983). Obligate and Facultative Brood Reduction in Eagles: An Examination of Factors That Influence Fratricide. The Auk, 100(3), 630-635. Retrieved from http://www.jstor.org/stable/4086464

Edwards, T. C. J., \& Kochert, M. N. (1986). Use of Body Weight and Length of Footpad as Predictors of Sex in Golden Eagles. Journal of Field Ornithology, 57(4), 317-319.

Ellis, D. H. (2004) Mottling in the Plumage of Juvenile Golden Eagles. North American Bird Bander (29)2, 53-58.

Erickson, W. P., Johnson, G. D., Strickland, M. D., Young Jr., D. P., Sernka, K. J., \& Good, R. E. (2001). Avian Collisions with Wind Turbines: A Summary of existing studies and comparisons to other sources of avian collision mortality in the United States., 62. Retrieved from http:/ / www.osti.gov/energycitations/product.biblio.jsp?osti id $=822418$

Esri Knowledge Base- Technical Articles, (2011). How To: Identify ridgelines from a DEM., Article ID 39093. Retrieved from http://support.esri.com/en/knowledgebase/techarticles/detail/39093

Franson, J. C., L. Sileo, and N. J. Thomas. 1995. Causes of eagle deaths. Page 68 in E. T. LaRoe, G. S. Farris, C. E. Puckett, and P. D. Doran, editors. Our Living Resources: A Report to the Nation on the Distribution, Abundance, and Health of the U.S. Plants, Animals, and Ecosystems. U.S. Department of the Interior. National Biological Service, Washington, D.C., USA

Golden Gate Audubon Society, Ohlone Audubon Society, et al. (2007) S1 Final Settlement Agreement. 10. Retrieved from http://www.altamontsrc.org/alt doc/alt settlement/s1 board approved settlement agree ment(55464923 1).pdf

Good, R. E., Nielson, R. M., et al. (2007) A Population Estimate for Golden Eagles in the Western United States. Journal of Wildlife Management (71)2, 395-402.

Harmata, A. R., \& Restani, M. (1995). Environmental contaminants and cholinesterase in blood of vernal migrant Bald and Golden Eagles in Montana. Intermountain Journal of Science, 1, 1-15.

Hoover, S. L. (2002). The Response of Red-Tailed Hawks and Golden Eagles to Topographical Features, Weather, and Abundance of a Dominant Prey Species at the Altamont Pass Wind Resource Area, California. NREL/SR-500-30868,. Retrieved from http://www.osti.gov/energycitations/product.biblio.jsp?osti id=15000694

Hunt, G., Jackman, R. E., Brown, T. L., Gilardi, J. G., Driscoll, D. E., \& Culp, L. (1995). A Pilot Golden Eagle Population Study in the Altamont Pass Wind Resource Area, California.

References 
Hunt, G., Jackman, R. E., Hunt, T. L., Driscoll, D. E., \& Culp, L. (1999). A Population Study of Golden Eagles in the Altamont Pass Wind Resource Area: Population Trend Analysis 1994-1997. NREL/SR-500-26092, 32. Retrieved from http://www.nrel.gov/wind/pdfs/26092.pdf

Hunt, G. (2002). Golden Eagles in a Perilous Landscape: Predicting the Effects of Mitigation for Wind Turbine Bladestrike Mortality. P500-02-043F, 52.

Hunt, G., Burnham, W., Parish, C. N., Burnham, K. K., Mutch, B., \& Oaks, J. L. (2006). Bullet fragments in deer remains: implications for lead exposure in avian scavengers. Wildlife Society Bulletin, 34(1), 167-170.

ICFI International. (2011). Altamont Pass Wind Resource Area Bird Fatality Study. M(21)

Kochert, M. N., \& Steenhof, K. (2002). Golden Eagles in the U.S. \& Canada: Status, Trends, \& Conservation Challenges. Journal of Raptor Research, 36(1 Supplement), 32-40. Retrieved from http://fresc.usgs.gov/products/papers/1092 Kochert.pdf

Kochert, M. N., Steenhof, K., Mcintyre, C. L., \& Craig, E. H. (2002). Golden Eagle (Aquila chrysaetos), The Birds of North America Online. Ithaca: Cornell Lab of Ornithology. Retrieved from http://bna.birds.cornell.edu/bna/species/684

Leslie, D., Schwartz, J., \& Karas, B. R. (2012) Altamont Pass Wind Resource Area Bird Fatality Study, Bird Years 2005-2010. M(87), 171.

Liguori, J. (2004) How to Age Golden Eagles; Techniques for Birds Observed in Flight. Birding. (36)3, 278-283.

Lund, U., Agostinelli, C. (2011). Circular Statistics. Package 'circular': Circular Statistics (version 0.4-3). URL https://r-forge.r-project.org/projects/circular/

Lutmerding, J. A., \& Love, A. S. (2013). Longevity Records of North American Birds. Version 2013.1. Patuxent Wildlife Research Center. Bird Banding Laboratory. Laurel MD.

McIntyre, C. L., \& Collopy, M. W. (2006). Postfledging Dependence Period of Migratory Golden Eagles (Aquila chrysaetos) in Denali National Park and Preserve, Alaska. The Auk, 123(3), 877-884. Retrieved from http://environment.unr.edu/academy/about/CollopyPubs/McIntyreCollopy2006.pdf

Menkens, G. E. J., \& Anderson, S. H. (1987). Nest Site Characteristics of Predominantly Tree-nesting Population of Golden Eagles. Journal of Field Ornithology, 58(1), 22-25.

National Renewable Energy Laboratory. (2010). Estimates of Windy Land Area and Wind Energy Potential, by State, for Area $>=30 \%$ Capacity Factor at $80 \mathrm{~m}$. Retrieved from http://www.windpoweringamerica.gov/pdfs/wind maps/wind potential 80m 30percent.p $\underline{\text { df }}$

References 
National Research Council. (2007) Environmental Impacts of Wind-Energy Projects.

Olendorff, R. R. (1976). The Food Habits of North American Golden Eagles. American Midland Naturalist, 95(1), 231-236. Retrieved from http://www.jstor.org/stable/2424254.

Omland, K. S., \& Hoffman, S. W. (1996). Seasonal, Diel, and Spatial Dispersion Patterns of Golden Eagle Autumn Migration in Southwestern Montana. The Condor (98)3, 633-36.

Orloff, S. G., \& Flannery, A. (1992). Wind Turbine Effects on Avian Activity, Habitat Use, and Mortality in Altamont Pass and Solano County Wind Resource Areas 1989-1991. P700$92-401$

Pattee, O. H., Bloom, P. H., Scott, J. M., \& Smith, M. R. (1990). Lead Hazards within the Range of the California Condor. The Condor, 92(4), 931-937. Retrieved from http://www.jstor.org/stable/1368729.

Phillips, R. L., J. L. Cummings, et al. (1996). Golden Eagle Predation on Domestic Calves. Wildlife Society Bulletin (24)3, 468-70.

Scientific Review Committee, Altamont Pass Wind Resource Area. (2007). Altamont Pass Wind Resource Area Bird and Bat Mortality Monitoring Protocols. (M)1. Retrieved from http://www.altamontsrc.org/alt doc/M1 APWRA monitoring protocol 711 07.pdf

Scientific Review Committee, Altamont Pass Wind Resource Area, \& Chatfield, A. (2008a). Determination of Cause of Death Protocol. (M)11. Retrieved from http://www.altamontsrc.org/alt doc/m11 cause of death protocol.pdf

Scientific Review Committee, Altamont Pass Wind Resource Area. (2008b). Working Decision Tree for Altamont Bird Fatality Data Filtering. (M)26. Retrieved from http://www.altamontsrc.org/alt doc/m26 decision tree for bird fatality data filtering.pd $\underline{f}$

Smallwood, K. S., \& Neher, L. (2004). Repowering the APWRA: Forecasting and minimizing avian mortality without significant loss of power generation. CEC-500-2005-005. Retrieved from http://2011gift.biologicaldiversity.org/campaigns/protecting birds of prey at altamont p ass/pdfs/cec-repowering.pdf

Smallwood, K. S., \& Thelander, C. (2001). Bird Mortality At the Altamont Pass Wind Resource Area March 1998-September 2001. NREL/SR-500-36973, 411.

Strickland, M. D., Arnett, E. B., et al. (2011). Comprehensive Guide to Studying Wind Energy/ Wildlife Interactions. National Wind Coordinating Collaborative. 289.

References 
Thelander, C. G., Smallwood, K. S., \& Rugge, L. (2003). Bird Risk Behaviors and Fatalities At the Altamont Pass Wind Resource Area, Period Performance March 1998 - December 2000. NREL/SR-500-33829, 86.

Tigner, James R. (1973). Golden Eagle Predation on a Pronghorn Fawn. The Southwestern Naturalist 18, 346-48.

U.S. Department of Energy. (2008). 20\% Wind Energy By 2030 Increasing Wind Energy's Contribution to U.S. Electricity Supply. DOE/GO-102008-2567, 248.

U.S. Government Accountability Office. "Impacts on Wildlife and Government Responsibilities for Regulating Development and Protecting Wildlife.” US Government Accountability Office, Washington, DC GAO-05-906 (2005): 60.

Yates, Richard E., B. Riley, P.T. McClelland et al. "The Influence of Weather on Golden Eagle Migration in Northwestern Montana.” Journal of Raptor Research 35.2 (2001): 81-90. 
Appendix A: List of Fields in the SRC Fatality Table

Field Name

Project ID

Project

Fatality ID

Primary Detection ID

Fatality \#

Primary Detection \#

Was Injured

Is Wrrs

Transect Protocol

Transect Type

Detection Date

Detection Monitoring Year

Detection Year Month

Species Code

\section{Description of field}

Internal consultant code for management purposes

Project name - Altamont Pass Wind Resource Area

Unique ID, database generated

Computer generated unique number

Fatality number assigned by field crew leader in the format of 4 digit year, two digit month, two digit day-two digit number of fatality discovered that day. For example, 20110526-01 is the first fatality discovered on May 26, 2011

Detection number assigned by the discovering biologist. Similar naming convention as fatality number, but the number is appended to include the discoverer's initials and the number of detection the discoverer made that day. For example, 20110526-LTN01 is the first fatality that LTN made on May 26, 2011

TRUE/FALSE whether the bird was still alive and injured when it was discovered.

TRUE/FALSE whether a bird was initially detected by the Wildlife Reporting and Response System.

Identity of the protocol of monitoring that was being done at the time of discovery - current study, QAQC, Incidental, etc.

The type of transect performed at time of discovery primary, secondary, follow-up, etc.

Date of detection

Different than calendar year, monitoring year starts in October and continues into the next year's calendar by 9 months

Coded month and year

4 digit species code for birds and mammals. GOEA=Golden Eagle

Appendix A 
Age

Sex

String \#

Turbine Label

Turbine Bearing

Turbine Distance

Structure Type

Structure Identifier

Structure Bearing

Structure Distance

Position X

Position Y

Body Parts

Cause of Death ID

Cause of Death

Days Dead Range

Days Dead

Death Date

Death Monitoring Year

Death Year Month

Was Scavenged

Carcass Condition

Were Insects Present

Insect Types
Age of fatality at time of death, adult, sub adult, juvenile, nestling, unknown

Sex, female, male or unknown

Non-unique string identifier

Label on the turbine nearest the carcass

Back bearing from the carcass

Distance from the carcass to the nearest turbine

Notable structure near corpse - fence, powerline, building

Sign or other identifier

Back-bearing from the carcass, used to locate structure

Distance to the structure

$\mathrm{X}$ coordinate on GPS

Y coordinate on GPS

Description of all body parts found, or missing

Code for the diagnosed cause of death

Diagnosed cause of death determined in the field

Categorical listing of days dead range

Corresponds to the days dead range, but set to an integer

Backdated using days dead and the detection date

Monitoring year in which the fatality will be counted

Year and month in which the fatality will be counted

Binomial variable based on evidence of scavenging

Description of the carcass to help the death date determination

Binomial variable

Categorical variable listing of typical insect types present

Appendix A 
Was Flesh Present

Flesh Textures

Was Head Present

Eye Condition

Was Enamel Present

Enamel Presence

Were Bones Present

Bone Colors

Was Sample Taken

Sample Types

Distance Sighted

Parts Sighted

Discoverer

Notes

Status ID

Status

Transect Status ID

Transect Status
Binomial variable, used to determine carcass age

Categorical variable used to determine carcass age

Binomial variable

Categorical variable used to indicate carcass age

Binomial variable used to determine carcass age

Categorical variable used to determine carcass age

Binomial variable used to determine carcass age

Categorical variable used to determine carcass age

Binomial variable recording whether samples will be on file

Feather, flesh, or both

Continuous variable used to track searcher statistics

Variable used to track searcher statistics

Categorical variable, used to track searcher proficiency

Blank field in which notes on weather, conditions, etc.

One or two digit code for how the fatality will be categorized

Description of the status ID

Code for the transect type that was being conducted when the carcass was detected

Description of the transect status ID

The following 17 fields are the Status, followed by the status ID as seen above. In the database these fields are filled in with either True or False. These fields are a redundancy, but are there to better manipulate the data for reports.

Unreviewed (0)

Valid (1)

No Group or Size (2)

Appendix A 
No TurbineID (3)

$>125 \mathrm{~m}$ from turbine (4)

Cause of death not turbine-related (5)

$>90$ days dead (6)

Incidental/WRRS (7)

Injured (8)

No transect or detection (9)

Off-site carcass for placement (10)

Redundant fatality (11)

Duplicate, chicken, or test (12)

First detected in non-primary search (13)

Additional parts (14)

Later detection was 13 (15)

Undetermined death date (16)

Appendix A 
Appendix B: Fatality Detection Form

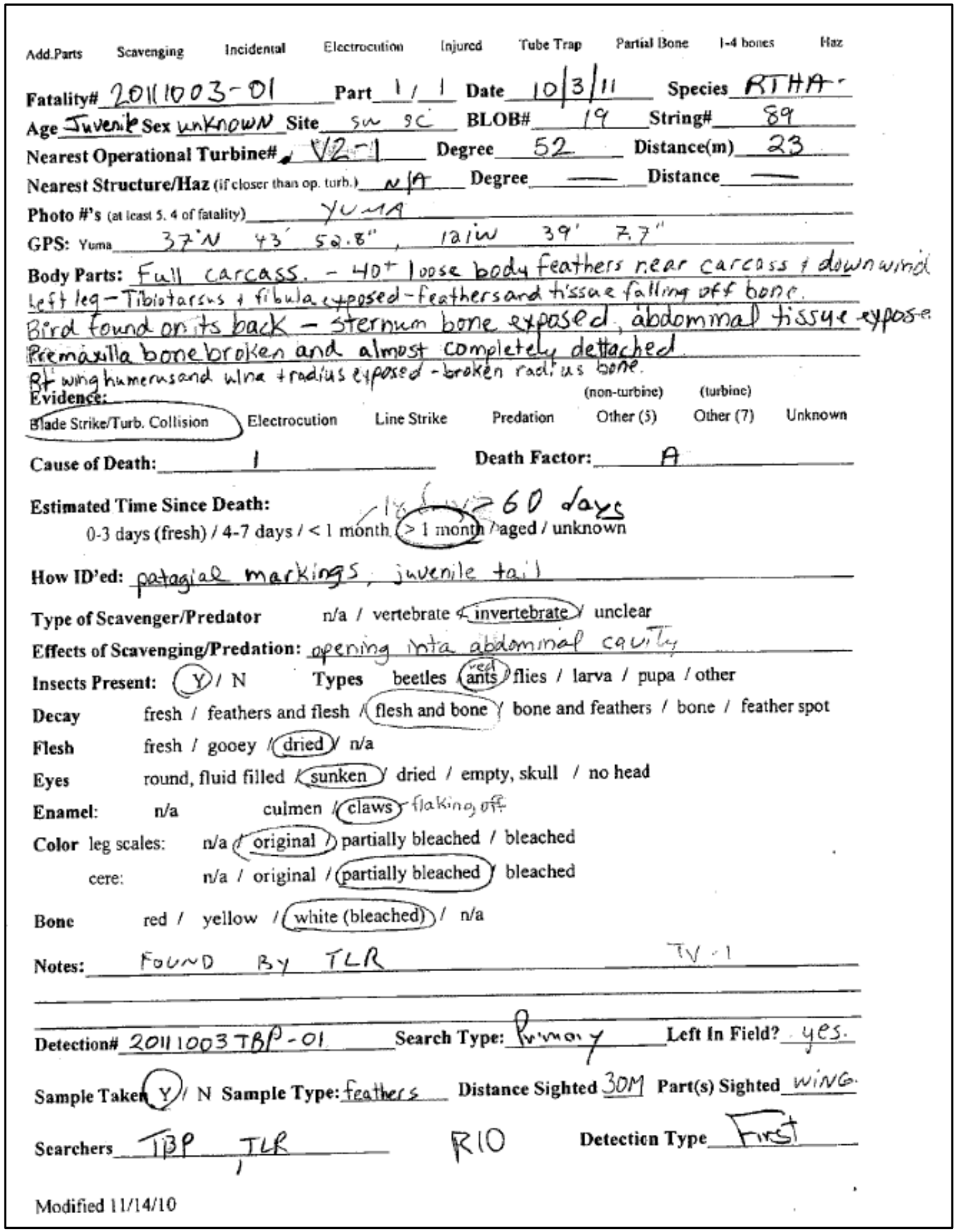




\section{Appendix C: Document M11: Determination of Cause of Death (Adapted)}

\section{Determination of Cause of Death}

The following guidelines are used to determine the most likely cause of death for each fatality encountered in the field. Cause of death is judged on the basis of 3 main variables:

1) Species (non-predated species versus all other species,

2) Proximity to turbines, power lines, and other structures, and

3) The condition of the carcass including type of injury and scavenging. The cause of death is circled on the fatality data form. If a cause of death cannot be determined, the unknown option is circled and the most likely cause/s is underlined. Justification for the determination of cause of death is provided on the data form. Illness/old age, crippling bias, or scavenger removal is not accounted for in our determination of cause of death. See glossary at end of document for definitions of terms used.

\section{Blade Strike/Turbine Collision}

A. Fatality is any non-predated species (i.e., golden eagle, red-tailed hawk or other large buteo, great-horned owl, etc.), found within the search area.

B. Fatality is an intact (no evidence of scavenging) carcass with no apparent injuries and is found within the search radius.

C. Fatality is any bird or bat species that has not been scavenged and has injuries consistent with a turbine blade strike or tower collision (i.e., blunt force trauma, severed wings, legs or torso, decapitation, etc.). This determination can only be made when the carcass has not been scavenged by vertebrates, as scavenging may obscure or mimic turbine-induced injury.

(Exceptions: electrocutions, line strikes, and BUOW fatalities at burrows; see sections 2,3 , and $4 \mathrm{~B}$ below)

\section{Electrocution}

A. Carcass exhibits obvious signs of electrocution (i.e., singed feathers, clenched talons, etc.).

B. Intact carcass with no apparent injuries is found within $3 \mathrm{~m}$ of a power pole, and is greater than $10 \mathrm{~m}$ from turbine string axis (see Blade Strike, part B)

\section{Line Strike}

A. Intact carcass with or without apparent injury is found outside of search radius beneath power lines or guy wires (within $3 \mathrm{~m}$ of line), and no evidence of electrocution (see Electrocution).

\section{Predation}

A. Fatalities of non-predated species (i.e., GOEA, RTHA, SWHA, FEHA, and GHOW) are never attributed to predation. 
B. Scavenged/predated BUOW fatality within $1 \mathrm{~m}$ of an active burrow is always considered predation, regardless of proximity to other sources of mortality.

\section{Other}

This category is reserved for any other obvious or suspected cause of death. Evidence to support this assessment is provided on the data form. These may include but are not limited to:

- Fence collisions

- Auto collisions

- Collisions with other structures such as transformer boxes or buildings

- Entanglement in netting (present on some non-operational turbines to prevent perching)

- Nestling fatalities found at base of turbine when young birds fall from the nest or when old nests are cleaned out of turbine housing.

- Significant turbine oil/grease on feathers

\section{Unknown}

A. Blade strike/turbine collision underlined Intact or scavenged carcass of any species with competing or uncertain causes of death. (For exception see Predation, part C)

B. Predation underlined

Scavenged/predated carcass of non-predated species found outside of search area with competing or uncertain causes of death.

Scavenged/predated carcass of any other species found within or outside of search area with competing or uncertain causes of death.

C. Electrocution underlined

Any bird species found within $3 \mathrm{~m}$ of a power pole with competing or uncertain causes of death.

D. Line Strike underlined

Any bird species found within $3 \mathrm{~m}$ of power lines or guy wires with competing or uncertain causes of death.

E. Other underlined

Carcass of any species exhibiting evidence of non-listed (other) source of mortality with competing or uncertain causes of death. 


\section{Appendix D: List of Fields in the SRC Turbine Table}

\begin{tabular}{|c|c|}
\hline Field Name & Description \\
\hline Project ID & Internal ICFI code for programming purposes \\
\hline Project & Project name - Altamont Pass Wind Resource Area \\
\hline Turbine ID & Unique numerical identifier for a turbine \\
\hline Turbine Label & $\begin{array}{l}\text { Non unique alphanumeric identifier physically posted on a } \\
\text { turbine tower }\end{array}$ \\
\hline String Number & $\begin{array}{l}\text { Non unique numerical identifier of row/sectional grouping of } \\
\text { turbines }\end{array}$ \\
\hline Position X & Latitudinal coordinate value based on NAD1927 Datum \\
\hline Position Y & Longitudinal coordinate value base on NAD1927 Datum \\
\hline Company ID & Name of the company that operates the turbine \\
\hline Project Site & $\begin{array}{l}\text { A geographically defined area within the APWRA, where } \\
\text { wind companies operate turbine arrays }\end{array}$ \\
\hline Turbine Model & Model/manufacturer of the wind turbine \\
\hline Tower Type & Lattice, tubular or vertical axis \\
\hline Tower Height & Height from ground to turbine axis \\
\hline Blade Length & Length of blade from axis to tip \\
\hline Rotor Swept Area & Total area covered by a rotating turbine propeller \\
\hline Generating Capacity & The rated energy generating capacity for a wind turbine \\
\hline Is AIC & Is owned by the AIC partnership \\
\hline Installation Date & Date that the turbine/tower was installed \\
\hline Removal Date & Date that the turbine/tower was removed \\
\hline Removal Reason & $\begin{array}{l}\text { A note field with details on why a turbine/tower was } \\
\text { removed }\end{array}$ \\
\hline Tier & Rating of the turbine following a hazardous turbine survey \\
\hline Hrt2007 & Rating of turbine in 2007 \\
\hline
\end{tabular}

Appendix D 
Hrt2010

Notes

Grid ID

Elevation

Slope

Aspect

County
Rating of turbine in 2010

Additional note field

Elevation of the ground at the turbine base

Slope of the hill on which the turbine was built

Direction the hill on which the turbine was built faces, measured in degrees.

Which county in California - Alameda or Contra Costa 
Appendix E: List of Fields in the SRC Transects Table

\begin{tabular}{|c|c|}
\hline Field Name & Description \\
\hline Project ID & Internal code of consulting company \\
\hline Project & Project name - Altamont Pass Wind Resource Area \\
\hline Transect GUID & $\begin{array}{l}\text { Computer generated unique identifier of a single transect } \\
\text { (search) }\end{array}$ \\
\hline Transect Date & Date the transect was performed \\
\hline Calendar year & The calendar year in which the transect was performed \\
\hline Monitoring Year & $\begin{array}{l}\text { The avian monitoring year in which the transect was } \\
\text { performed }\end{array}$ \\
\hline Year Month & The calendar year, followed by the name of the month \\
\hline String ID & $\begin{array}{l}\text { Unique numerical identifier of row/sectional grouping of } \\
\text { turbines }\end{array}$ \\
\hline String \# & $\begin{array}{l}\text { Non unique numerical identifier of row/sectional grouping of } \\
\text { turbines }\end{array}$ \\
\hline \# of Turbines & Count of turbines within that String ID \\
\hline Installed Capacity & Sum of turbine generating capacities within that String ID \\
\hline Study ID & $\begin{array}{l}\text { Unique identity of the study that the transect was conducted } \\
\text { to support }\end{array}$ \\
\hline Study Code & $\begin{array}{l}\text { Abbreviation of the full study name, for example CS-current } \\
\text { Study }\end{array}$ \\
\hline Transect Type ID & $\begin{array}{l}\text { Unique identity of the type of transect conducted. } \\
\text { Corresponds to transect type }\end{array}$ \\
\hline Transect Type & $\begin{array}{l}\text { Identity of the type of transect conducted, for example } \\
\text { primary search, secondary, clearing, Incidental, etc. }\end{array}$ \\
\hline Transect Protocol ID & $\begin{array}{l}\text { Unique identity of the transect protocol. Corresponds to } \\
\text { transect type. }\end{array}$ \\
\hline Transect Protocol & $\begin{array}{l}\text { Identity of the protocol under which the transect was } \\
\text { conducted, for example KB clearing, current study primary, } \\
\text { QAQC fatality check, etc. }\end{array}$ \\
\hline
\end{tabular}

Appendix E 120 
Notes

Transect Status ID

Transect Status
Note field contains information about changes and alterations to the record

Code for reviewed and unreviewed transects

Status of reviewed or unreviewed. 


\section{Appendix F: Use of the Circular Package in R to Calculate Aspect Statistics}

Package 'circular' http://cran.r-project.org/web/packages/circular/circular.pdf

http://casoilresource.lawr.ucdavis.edu/drupal/node/1042

\section{Scripts for Nonkill Turbine Aspect Calculations and Histogram}

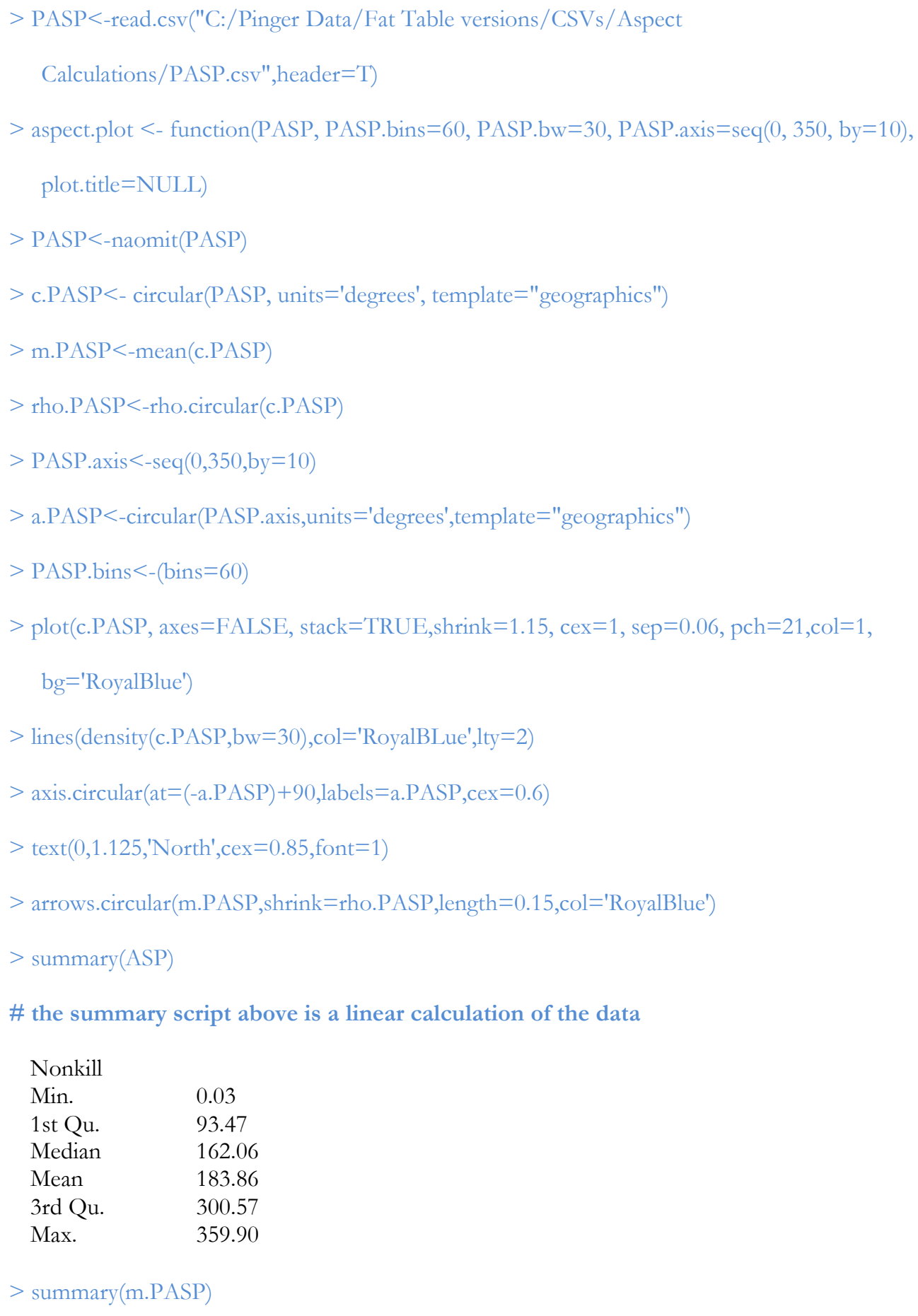


\# This calculation is the circular calculation of the mean value

$\begin{array}{lll}\mathrm{n} & \text { Mean } & \text { Rho } \\ 1.00000 & 41.23038 & 1.00000\end{array}$

\section{Scripts for Kill Turbine Aspect Calculations and Histogram}

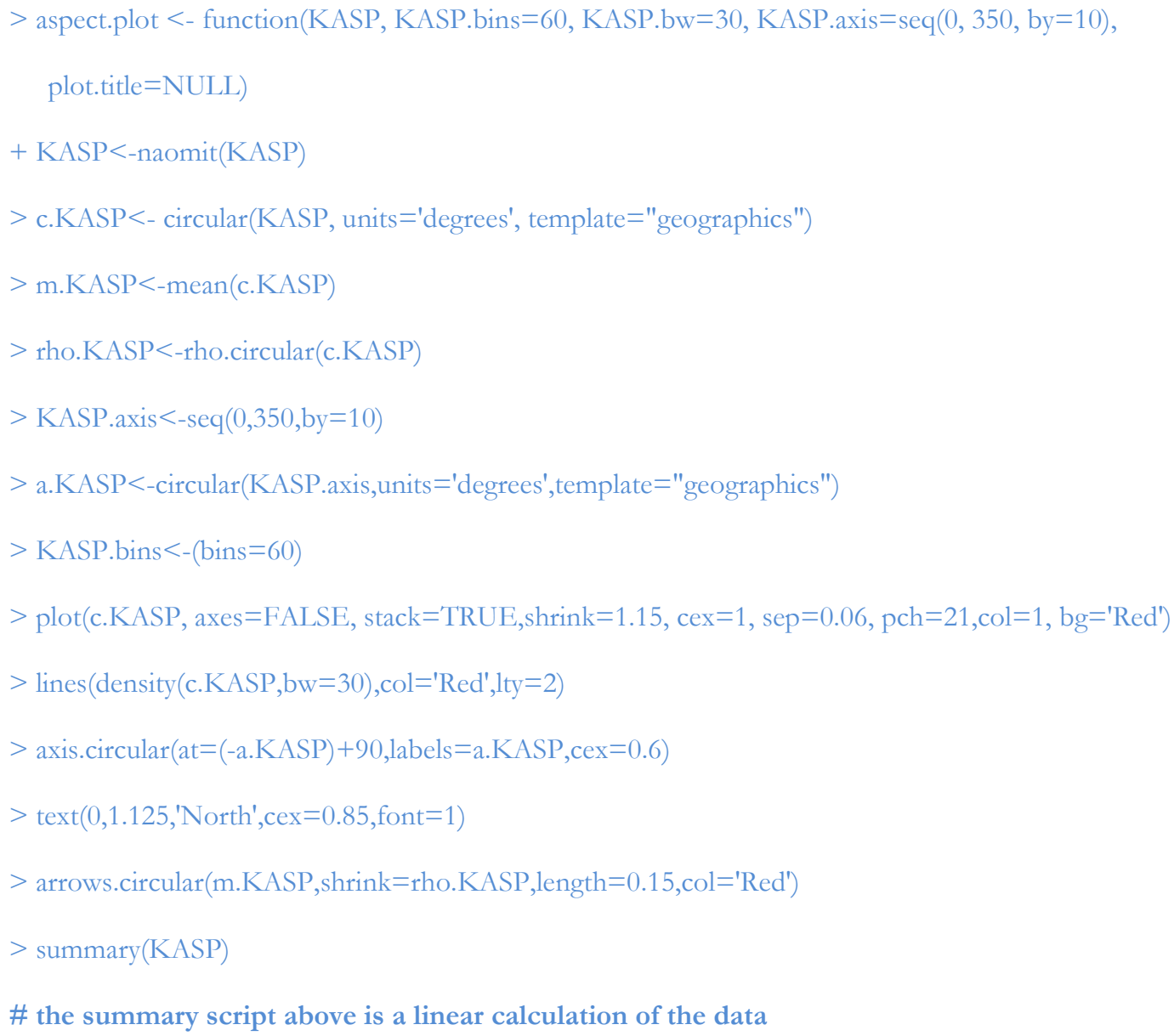

Kill Aspect Review

Minimum 2.82

1st Quarter $\quad 126.64$

Median $\quad 219.41$

Mean 205.54

3rd Quarter $\quad 305.83$

Maximum $\quad 359.44$

$>$ summary(m.KASP)

Mean

$-61.24193$

\# This calculation is the circular calculation of the mean value
$\mathrm{n}$
Mean
Rho
1.00000
317.99896 (-61.24193)
1.00000 


\section{Appendix G: Calculations of Hilltop Ridgelines}

Adapted from Article 39093 October 2011 Calculating

http://support.esri.com/en/knowledgebase/techarticles/detail/39093

How To: Identify ridgelines from a DEM

\begin{tabular}{ll|}
\hline Article ID: & 39093 \\
Software: & ArcGIS - ArcEditor 9.3.1, 10 ArcGIS - ArcInfo 9.3.1, 10 ArcGIS - ArcView 9.3.1, \\
& 10 \\
Platforms: & Windows XP, 2003Server, Vista, 2008Server, Win 7
\end{tabular}

\section{Summary}

The instructions provided describe how to identify ridgelines from a DEM. Spatial Analyst and the Hydrology Toolset can be used to identify and extract ridgeline features from an elevation raster (DEM) in the same manner as a stream network can be created by reversing the DEM cell values.

\section{Procedure}

This workflow uses Map Algebra and the Hydrology Toolset to derive ridgeline features from a DEM.

1. Fill the DEM using the Fill tool in the Hydrology Toolset.

2. Switch the high/low values in the Fill DEM by using the Raster Calculator to multiply the Fill DEM by -1 .

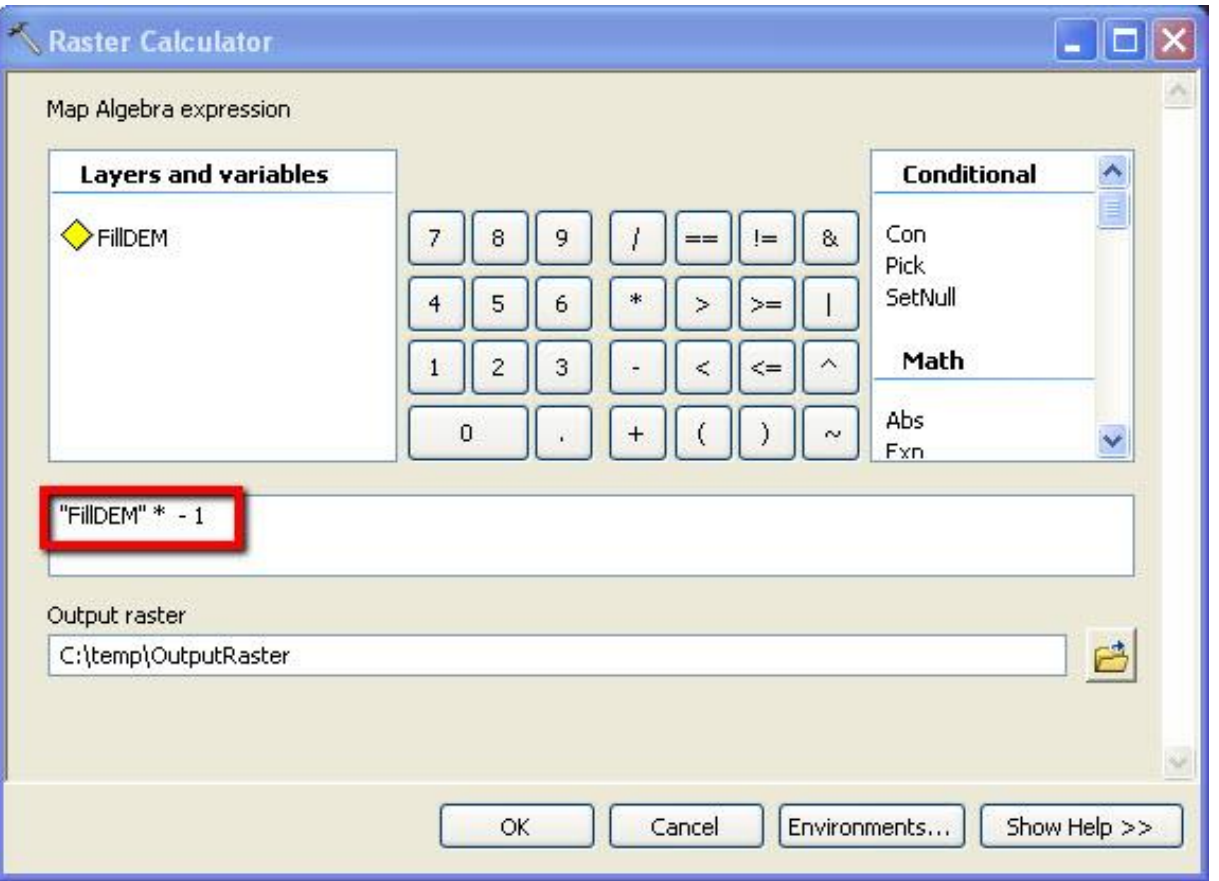

3. Run the Flow Direction tool using the output raster from step 2 as the 'Input surface raster' and checking 'Force all edge cells to flow outward'.

4. Run the Flow Accumulation tool using the output raster from step 3 as the 'Input flow direction raster'. 
5. Set the Flow Accumulation threshold and create the stream network raster using the Raster Calculator.

For 9.3.1:
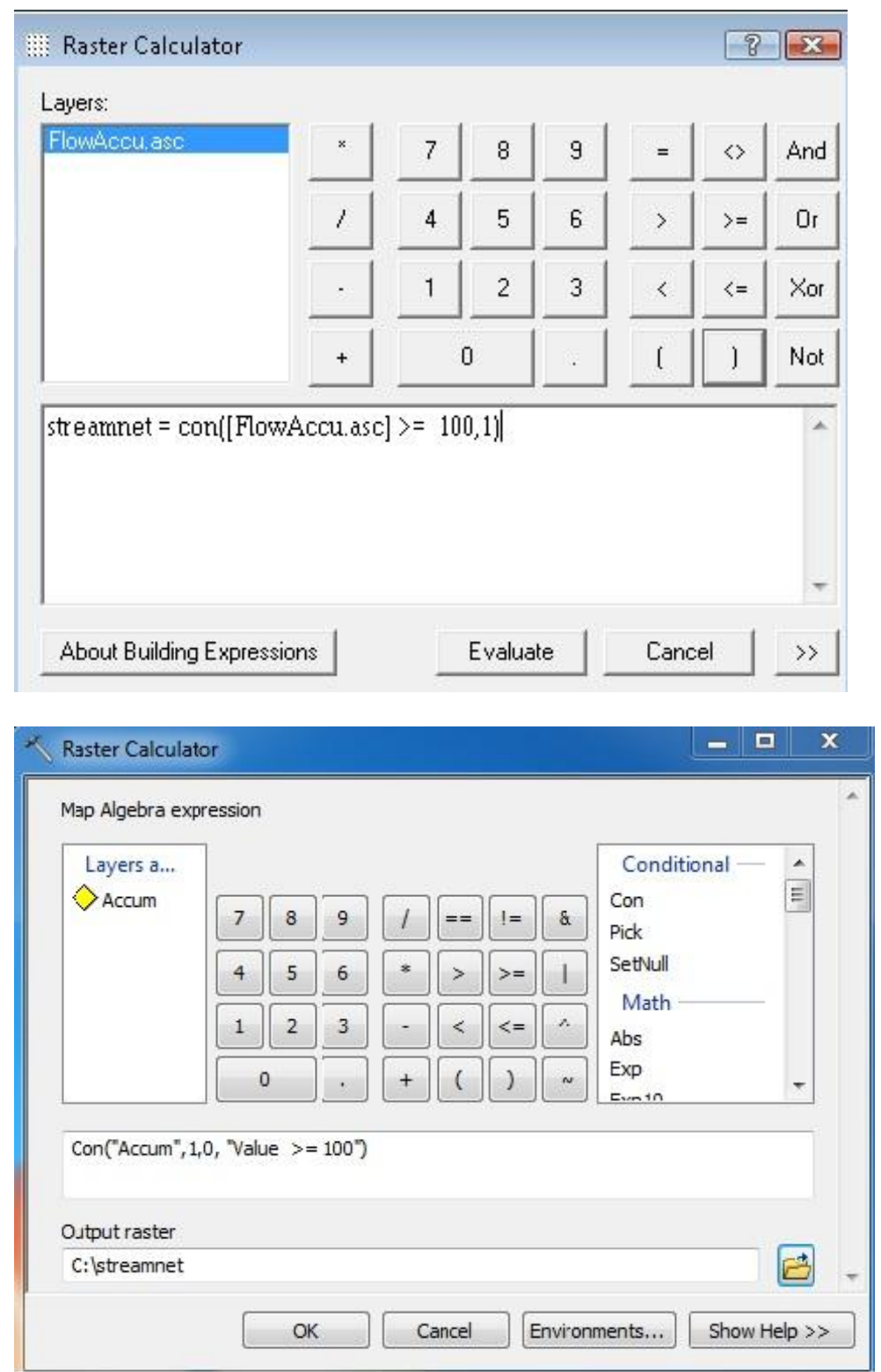

6. Create a Stream Order raster using the stream network raster (step 5) for the 'Input steam raster' and the Flow Direction raster (step 3) for the 'Input flow direction raster'.

7. Create a ridgeline shapefile by running the Stream to Feature tool with the Stream Order raster as the 'Input stream raster'.

Created: 6/24/2011Last Modified: 10/26/2011

Appendix G 
To measure whether a turbine was near a ridgeline, The Analysis toolbox/Proximity/near Tool

A search radius of 10 meters was used. Any turbine within the 10 meters is considered on the ridge top. 
Appendix H: Fishnet Square Turbine Count Table

\begin{tabular}{|l|l|}
$\begin{array}{l}\text { Turbine } \\
\text { Model }\end{array}$ & Code \\
\hline 250KW & 1 \\
\hline Bonus & 2 \\
\hline Danwin & 3 \\
\hline Enertech & 4 \\
\hline Flowind & 5 \\
\hline Howden & 6 \\
\hline $\begin{array}{l}\text { Kenetech 56- } \\
100\end{array}$ & 7 \\
\hline KVS 33 & 8 \\
\hline
\end{tabular}

\begin{tabular}{l|l|}
$\begin{array}{l}\text { Turbine } \\
\text { Model }\end{array}$ \\
\hline Micon & 9 \\
\hline $\begin{array}{l}\text { Mitsubishi } \\
\text { 1000A }\end{array}$ & 10 \\
\hline Nordtank & 11 \\
\hline Polenko & 12 \\
\hline V-47 & 13 \\
\hline Vestas & 14 \\
\hline Windmaster & 15 \\
\hline Windmatic & 16 \\
\hline
\end{tabular}

Turbines Present in 1999

\begin{tabular}{|c|c|c|c|c|c|c|c|c|c|c|c|c|c|c|c|c|c|}
\hline $\begin{array}{l}\frac{\text { 은 }}{\frac{5}{4}} \\
\frac{17}{2}\end{array}$ & 1 & 2 & 3 & 4 & 5 & 6 & 7 & 8 & 9 & 10 & 11 & 12 & 13 & 14 & 15 & 16 & 흉 \\
\hline 13 & 0 & 0 & 0 & 0 & 0 & 0 & 22 & 0 & 0 & 0 & 0 & 0 & 0 & 0 & 0 & 0 & 22 \\
\hline 14 & 0 & 0 & 0 & 0 & 0 & 0 & 60 & 0 & 0 & 0 & 0 & 0 & 0 & 0 & 0 & 0 & 60 \\
\hline 15 & 0 & 0 & 0 & 0 & 0 & 0 & 10 & 0 & 0 & 0 & 0 & 0 & 0 & 0 & 0 & 0 & 10 \\
\hline 27 & 0 & 0 & 0 & 0 & 0 & 0 & 15 & 0 & 0 & 0 & 0 & 0 & 0 & 0 & 0 & 0 & 15 \\
\hline 28 & 0 & 0 & 0 & 0 & 0 & 0 & 14 & 0 & 0 & 0 & 0 & 0 & 0 & 0 & 0 & 0 & 14 \\
\hline 29 & 0 & 0 & 0 & 0 & 0 & 0 & 30 & 0 & 0 & 0 & 0 & 0 & 0 & 0 & 0 & 0 & 30 \\
\hline 30 & 0 & 0 & 0 & 0 & 0 & 0 & 51 & 0 & 0 & 0 & 0 & 0 & 0 & 0 & 0 & 0 & 51 \\
\hline 31 & 0 & 0 & 0 & 0 & 0 & 0 & 27 & 0 & 0 & 0 & 0 & 0 & 0 & 0 & 0 & 0 & 27 \\
\hline 42 & 0 & 10 & 0 & 0 & 0 & 0 & 0 & 0 & 0 & 0 & 0 & 0 & 0 & 0 & 0 & 0 & 10 \\
\hline 43 & 0 & 47 & 0 & 0 & 0 & 0 & 28 & 0 & 0 & 0 & 0 & 0 & 0 & 0 & 0 & 0 & 75 \\
\hline 44 & 0 & 15 & 0 & 0 & 0 & 0 & 29 & 0 & 0 & 0 & 0 & 0 & 0 & 0 & 0 & 0 & 44 \\
\hline 45 & 0 & 0 & 0 & 0 & 0 & 0 & 87 & 0 & 0 & 0 & 0 & 0 & 0 & 0 & 0 & 0 & 87 \\
\hline 46 & 0 & 0 & 0 & 0 & 0 & 0 & 23 & 0 & 0 & 0 & 0 & 0 & 0 & 0 & 0 & 0 & 23 \\
\hline 47 & 0 & 0 & 0 & 0 & 0 & 0 & 29 & 0 & 0 & 0 & 0 & 0 & 0 & 0 & 0 & 0 & 29 \\
\hline
\end{tabular}




\begin{tabular}{|c|c|c|c|c|c|c|c|c|c|c|c|c|c|c|c|c|c|}
\hline 58 & 0 & 27 & 0 & 0 & 0 & 0 & 0 & 0 & 0 & 0 & 41 & 0 & 0 & 0 & 0 & 0 & 68 \\
\hline 59 & 0 & 21 & 0 & 0 & 0 & 0 & 0 & 0 & 0 & 0 & 62 & 0 & 0 & 0 & 0 & 0 & 83 \\
\hline 60 & 0 & 14 & 0 & 0 & 0 & 0 & 26 & 1 & 0 & 0 & 1 & 0 & 0 & 0 & 0 & 0 & 42 \\
\hline 61 & 3 & 0 & 0 & 0 & 0 & 0 & 46 & 0 & 0 & 0 & 0 & 0 & 0 & 0 & 0 & 0 & 49 \\
\hline 62 & 0 & 0 & 0 & 0 & 0 & 0 & 6 & 0 & 0 & 0 & 0 & 0 & 0 & 0 & 0 & 0 & 6 \\
\hline 70 & 0 & 0 & 0 & 0 & 0 & 0 & 4 & 1 & 0 & 0 & 0 & 0 & 0 & 0 & 0 & 0 & 5 \\
\hline 71 & 0 & 0 & 0 & 0 & 0 & 0 & 52 & 0 & 0 & 0 & 0 & 0 & 0 & 0 & 0 & 0 & 52 \\
\hline 72 & 4 & 0 & 0 & 0 & 0 & 0 & 37 & 0 & 0 & 0 & 0 & 0 & 0 & 0 & 0 & 0 & 41 \\
\hline 73 & 0 & 0 & 0 & 0 & 0 & 0 & 71 & 0 & 0 & 0 & 0 & 0 & 0 & 0 & 0 & 0 & 71 \\
\hline 74 & 0 & 24 & 0 & 0 & 0 & 0 & 0 & 0 & 0 & 0 & 15 & 0 & 0 & 0 & 0 & 0 & 39 \\
\hline 75 & 0 & 53 & 0 & 0 & 0 & 0 & 10 & 0 & 0 & 0 & 6 & 0 & 0 & 0 & 0 & 0 & 69 \\
\hline 76 & 9 & 0 & 0 & 0 & 0 & 0 & 65 & 0 & 0 & 0 & 0 & 0 & 0 & 0 & 0 & 0 & 74 \\
\hline 77 & 4 & 0 & 0 & 0 & 0 & 0 & 2 & 0 & 0 & 0 & 0 & 0 & 0 & 0 & 0 & 0 & 6 \\
\hline 85 & 0 & 0 & 0 & 0 & 0 & 0 & 25 & 7 & 0 & 0 & 0 & 0 & 0 & 0 & 0 & 0 & 32 \\
\hline 86 & 0 & 0 & 0 & 0 & 0 & 0 & 28 & 8 & 0 & 0 & 0 & 0 & 0 & 0 & 0 & 0 & 36 \\
\hline 87 & 0 & 0 & 0 & 0 & 0 & 0 & 39 & 2 & 0 & 0 & 0 & 0 & 0 & 0 & 0 & 0 & 41 \\
\hline 88 & 0 & 0 & 0 & 0 & 0 & 0 & 119 & 0 & 0 & 0 & 0 & 0 & 0 & 0 & 0 & 0 & 119 \\
\hline 89 & 0 & 0 & 0 & 0 & 0 & 0 & 84 & 0 & 0 & 0 & 0 & 0 & 0 & 0 & 0 & 0 & 84 \\
\hline 90 & 0 & 0 & 0 & 0 & 0 & 0 & 22 & 0 & 0 & 0 & 0 & 0 & 0 & 0 & 0 & 0 & 22 \\
\hline 91 & 0 & 0 & 0 & 0 & 0 & 0 & 81 & 0 & 0 & 0 & 0 & 0 & 0 & 0 & 0 & 0 & 81 \\
\hline 92 & 0 & 0 & 0 & 0 & 0 & 0 & 49 & 0 & 0 & 0 & 0 & 0 & 0 & 0 & 0 & 0 & 49 \\
\hline 93 & 0 & 0 & 0 & 0 & 0 & 0 & 16 & 0 & 0 & 0 & 0 & 0 & 0 & 0 & 0 & 0 & 16 \\
\hline 101 & 0 & 0 & 0 & 0 & 8 & 0 & 0 & 0 & 0 & 0 & 0 & 0 & 0 & 0 & 0 & 0 & 8 \\
\hline 102 & 0 & 0 & 0 & 0 & 48 & 0 & 0 & 0 & 0 & 0 & 0 & 0 & 0 & 0 & 0 & 0 & 48 \\
\hline 103 & 0 & 11 & 0 & 0 & 2 & 0 & 8 & 0 & 0 & 0 & 0 & 0 & 0 & 0 & 0 & 0 & 21 \\
\hline 104 & 0 & 0 & 1 & 0 & 0 & 0 & 21 & 0 & 0 & 0 & 0 & 0 & 0 & 0 & 0 & 0 & 22 \\
\hline
\end{tabular}




\begin{tabular}{|c|c|c|c|c|c|c|c|c|c|c|c|c|c|c|c|c|c|}
\hline 105 & 0 & 0 & 0 & 0 & 0 & 0 & 38 & 0 & 0 & 0 & 0 & 0 & 0 & 0 & 0 & 0 & 38 \\
\hline 106 & 0 & 0 & 0 & 0 & 0 & 0 & 29 & 0 & 0 & 0 & 0 & 0 & 0 & 0 & 0 & 0 & 29 \\
\hline 107 & 0 & 0 & 0 & 0 & 0 & 0 & 34 & 0 & 0 & 0 & 0 & 0 & 0 & 0 & 0 & 0 & 34 \\
\hline 108 & 0 & 0 & 0 & 0 & 0 & 0 & 8 & 0 & 0 & 0 & 0 & 0 & 0 & 0 & 0 & 0 & 8 \\
\hline 109 & 0 & 0 & 0 & 0 & 0 & 0 & 1 & 0 & 0 & 0 & 0 & 0 & 0 & 0 & 0 & 0 & 1 \\
\hline 111 & 0 & 0 & 0 & 0 & 0 & 0 & 0 & 0 & 18 & 0 & 0 & 0 & 0 & 0 & 0 & 0 & 18 \\
\hline 116 & 0 & 0 & 0 & 0 & 0 & 0 & 42 & 0 & 0 & 0 & 0 & 0 & 0 & 0 & 0 & 0 & 42 \\
\hline 117 & 0 & 0 & 0 & 0 & 5 & 0 & 0 & 0 & 0 & 0 & 0 & 0 & 0 & 0 & 0 & 0 & 5 \\
\hline 118 & 0 & 0 & 0 & 0 & 11 & 0 & 0 & 0 & 0 & 0 & 0 & 0 & 0 & 0 & 0 & 0 & 11 \\
\hline 119 & 0 & 3 & 0 & 0 & 3 & 0 & 0 & 0 & 0 & 0 & 0 & 0 & 0 & 86 & 0 & 0 & 92 \\
\hline 120 & 0 & 15 & 15 & 0 & 0 & 0 & 0 & 0 & 0 & 0 & 0 & 0 & 0 & 27 & 0 & 0 & 57 \\
\hline 121 & 0 & 0 & 2 & 0 & 0 & 0 & 8 & 0 & 0 & 0 & 0 & 0 & 0 & 0 & 0 & 0 & 10 \\
\hline 127 & 0 & 0 & 0 & 0 & 0 & 0 & 0 & 0 & 34 & 0 & 0 & 0 & 0 & 0 & 0 & 0 & 34 \\
\hline 131 & 0 & 0 & 0 & 0 & 0 & 0 & 60 & 0 & 0 & 0 & 0 & 0 & 0 & 0 & 0 & 0 & 60 \\
\hline 132 & 0 & 0 & 0 & 0 & 0 & 0 & 28 & 0 & 0 & 0 & 0 & 0 & 0 & 0 & 0 & 0 & 28 \\
\hline 134 & 0 & 0 & 0 & 0 & 0 & 0 & 0 & 0 & 0 & 0 & 0 & 0 & 0 & 2 & 0 & 0 & 2 \\
\hline 135 & 0 & 0 & 0 & 0 & 0 & 0 & 2 & 0 & 0 & 0 & 0 & 0 & 0 & 67 & 0 & 0 & 69 \\
\hline 136 & 0 & 0 & 0 & 0 & 0 & 0 & 0 & 0 & 0 & 0 & 0 & 0 & 0 & 20 & 0 & 0 & 20 \\
\hline 137 & 0 & 0 & 0 & 0 & 2 & 0 & 21 & 0 & 0 & 0 & 0 & 0 & 0 & 0 & 0 & 0 & 23 \\
\hline 138 & 0 & 0 & 0 & 23 & 5 & 0 & 40 & 0 & 0 & 0 & 0 & 0 & 0 & 0 & 0 & 0 & 68 \\
\hline 139 & 0 & 0 & 0 & 60 & 0 & 0 & 0 & 0 & 0 & 0 & 0 & 1 & 0 & 0 & 0 & 24 & 85 \\
\hline 140 & 0 & 0 & 0 & 0 & 0 & 0 & 0 & 0 & 0 & 0 & 0 & 11 & 0 & 0 & 0 & 2 & 13 \\
\hline 147 & 0 & 0 & 0 & 0 & 0 & 0 & 38 & 0 & 0 & 0 & 0 & 0 & 0 & 0 & 0 & 0 & 38 \\
\hline 148 & 0 & 0 & 0 & 0 & 0 & 0 & 40 & 0 & 0 & 0 & 0 & 0 & 0 & 0 & 0 & 0 & 40 \\
\hline 150 & 0 & 0 & 0 & 0 & 0 & 0 & 17 & 0 & 0 & 0 & 0 & 0 & 0 & 0 & 0 & 0 & 17 \\
\hline 151 & 0 & 0 & 0 & 0 & 0 & 0 & 2 & 0 & 0 & 0 & 0 & 0 & 0 & 0 & 0 & 0 & 2 \\
\hline
\end{tabular}




\begin{tabular}{|c|c|c|c|c|c|c|c|c|c|c|c|c|c|c|c|c|c|}
\hline 152 & 0 & 5 & 1 & 0 & 0 & 0 & 12 & 0 & 0 & 0 & 0 & 0 & 0 & 0 & 0 & 0 & 18 \\
\hline 153 & 0 & 12 & 6 & 0 & 15 & 0 & 0 & 0 & 0 & 0 & 0 & 0 & 0 & 0 & 0 & 0 & 33 \\
\hline 154 & 0 & 9 & 0 & 19 & 18 & 0 & 3 & 0 & 12 & 0 & 0 & 0 & 0 & 0 & 0 & 0 & 61 \\
\hline 155 & 0 & 0 & 0 & 68 & 0 & 0 & 11 & 0 & 26 & 0 & 0 & 0 & 0 & 0 & 0 & 0 & 105 \\
\hline 163 & 0 & 0 & 0 & 0 & 0 & 0 & 33 & 0 & 0 & 0 & 0 & 0 & 0 & 0 & 0 & 0 & 33 \\
\hline 164 & 0 & 0 & 0 & 0 & 0 & 0 & 27 & 0 & 0 & 0 & 0 & 0 & 0 & 0 & 0 & 0 & 27 \\
\hline 165 & 0 & 0 & 0 & 0 & 0 & 0 & 14 & 0 & 0 & 0 & 0 & 0 & 0 & 0 & 0 & 0 & 14 \\
\hline 166 & 0 & 0 & 0 & 0 & 0 & 0 & 34 & 0 & 0 & 0 & 0 & 0 & 0 & 0 & 0 & 0 & 34 \\
\hline 167 & 0 & 0 & 0 & 0 & 0 & 0 & 46 & 0 & 0 & 0 & 0 & 0 & 0 & 0 & 0 & 0 & 46 \\
\hline 168 & 0 & 0 & 0 & 0 & 0 & 0 & 46 & 2 & 0 & 0 & 0 & 0 & 0 & 0 & 0 & 0 & 48 \\
\hline 169 & 0 & 0 & 0 & 0 & 0 & 0 & 54 & 0 & 0 & 0 & 0 & 0 & 0 & 0 & 0 & 0 & 54 \\
\hline 170 & 0 & 33 & 0 & 0 & 23 & 0 & 19 & 0 & 0 & 0 & 0 & 0 & 0 & 0 & 0 & 0 & 75 \\
\hline 171 & 0 & 0 & 0 & 0 & 0 & 0 & 62 & 0 & 0 & 0 & 0 & 0 & 0 & 0 & 0 & 0 & 62 \\
\hline 173 & 0 & 0 & 0 & 0 & 0 & 0 & 0 & 0 & 29 & 0 & 0 & 0 & 0 & 0 & 0 & 0 & 29 \\
\hline 174 & 0 & 0 & 0 & 0 & 0 & 0 & 0 & 0 & 10 & 0 & 0 & 0 & 0 & 0 & 0 & 0 & 10 \\
\hline 179 & 0 & 0 & 0 & 0 & 0 & 0 & 16 & 0 & 0 & 0 & 0 & 0 & 0 & 0 & 0 & 0 & 16 \\
\hline 180 & 0 & 0 & 0 & 0 & 0 & 0 & 4 & 0 & 0 & 0 & 0 & 0 & 0 & 0 & 0 & 0 & 4 \\
\hline 181 & 0 & 0 & 0 & 0 & 0 & 0 & 41 & 0 & 0 & 0 & 0 & 0 & 0 & 0 & 0 & 0 & 41 \\
\hline 182 & 0 & 0 & 0 & 0 & 0 & 0 & 56 & 0 & 0 & 0 & 0 & 0 & 0 & 0 & 0 & 0 & 56 \\
\hline 183 & 0 & 3 & 0 & 0 & 0 & 0 & 3 & 0 & 0 & 0 & 0 & 0 & 0 & 0 & 0 & 0 & 6 \\
\hline 184 & 0 & 37 & 0 & 0 & 6 & 0 & 3 & 0 & 0 & 0 & 0 & 0 & 0 & 0 & 0 & 0 & 46 \\
\hline 185 & 0 & 44 & 0 & 0 & 3 & 0 & 1 & 0 & 0 & 0 & 0 & 0 & 0 & 0 & 0 & 0 & 48 \\
\hline 186 & 0 & 0 & 0 & 0 & 9 & 0 & 46 & 0 & 0 & 0 & 0 & 0 & 0 & 0 & 0 & 0 & 55 \\
\hline 187 & 0 & 0 & 0 & 0 & 0 & 0 & 51 & 0 & 0 & 0 & 0 & 0 & 0 & 0 & 0 & 0 & 51 \\
\hline 189 & 0 & 0 & 0 & 0 & 0 & 0 & 0 & 0 & 88 & 0 & 0 & 0 & 0 & 0 & 0 & 0 & 88 \\
\hline 190 & 0 & 0 & 0 & 0 & 0 & 0 & 0 & 0 & 4 & 0 & 0 & 0 & 0 & 0 & 0 & 0 & 4 \\
\hline
\end{tabular}




\begin{tabular}{|c|c|c|c|c|c|c|c|c|c|c|c|c|c|c|c|c|c|}
\hline 193 & 0 & 0 & 0 & 0 & 0 & 0 & 20 & 0 & 0 & 0 & 0 & 0 & 0 & 0 & 0 & 0 & 20 \\
\hline 194 & 0 & 0 & 0 & 0 & 0 & 0 & 44 & 0 & 0 & 0 & 0 & 0 & 0 & 0 & 0 & 0 & 44 \\
\hline 195 & 0 & 0 & 0 & 0 & 0 & 0 & 33 & 0 & 0 & 0 & 0 & 0 & 0 & 0 & 0 & 0 & 33 \\
\hline 196 & 0 & 0 & 0 & 0 & 0 & 0 & 56 & 0 & 0 & 0 & 0 & 0 & 0 & 0 & 0 & 0 & 56 \\
\hline 197 & 0 & 0 & 0 & 0 & 0 & 0 & 37 & 0 & 0 & 0 & 0 & 0 & 0 & 0 & 0 & 0 & 37 \\
\hline 198 & 0 & 11 & 0 & 0 & 0 & 0 & 17 & 0 & 0 & 0 & 0 & 0 & 0 & 0 & 0 & 0 & 28 \\
\hline 199 & 0 & 28 & 0 & 0 & 0 & 0 & 0 & 0 & 0 & 0 & 0 & 0 & 0 & 0 & 0 & 0 & 28 \\
\hline 200 & 0 & 21 & 0 & 0 & 9 & 0 & 10 & 0 & 0 & 0 & 0 & 0 & 0 & 0 & 0 & 0 & 40 \\
\hline 201 & 0 & 13 & 0 & 0 & 2 & 0 & 12 & 0 & 0 & 0 & 0 & 0 & 0 & 0 & 0 & 0 & 27 \\
\hline 202 & 0 & 0 & 0 & 0 & 0 & 0 & 41 & 0 & 0 & 0 & 0 & 0 & 0 & 0 & 0 & 0 & 41 \\
\hline 203 & 0 & 0 & 0 & 0 & 0 & 0 & 4 & 0 & 0 & 0 & 0 & 0 & 0 & 0 & 0 & 0 & 4 \\
\hline 208 & 0 & 0 & 0 & 0 & 0 & 0 & 44 & 0 & 0 & 0 & 0 & 0 & 0 & 0 & 0 & 0 & 44 \\
\hline 209 & 0 & 0 & 0 & 0 & 0 & 0 & 94 & 0 & 0 & 0 & 0 & 0 & 0 & 0 & 0 & 0 & 94 \\
\hline 210 & 0 & 0 & 0 & 0 & 0 & 0 & 96 & 0 & 0 & 0 & 0 & 0 & 0 & 0 & 0 & 0 & 96 \\
\hline 211 & 0 & 0 & 0 & 0 & 0 & 0 & 54 & 0 & 0 & 0 & 0 & 0 & 0 & 0 & 0 & 0 & 54 \\
\hline 212 & 0 & 0 & 0 & 0 & 0 & 0 & 18 & 0 & 0 & 0 & 0 & 0 & 0 & 0 & 0 & 0 & 18 \\
\hline 213 & 0 & 0 & 0 & 0 & 0 & 0 & 17 & 0 & 0 & 0 & 0 & 0 & 0 & 0 & 0 & 0 & 17 \\
\hline 214 & 0 & 17 & 0 & 0 & 0 & 0 & 0 & 0 & 0 & 0 & 0 & 0 & 0 & 0 & 0 & 0 & 17 \\
\hline 215 & 0 & 41 & 0 & 0 & 0 & 0 & 0 & 0 & 0 & 0 & 0 & 0 & 0 & 0 & 0 & 0 & 41 \\
\hline 216 & 0 & 8 & 0 & 0 & 0 & 0 & 58 & 0 & 0 & 0 & 0 & 0 & 0 & 0 & 0 & 0 & 66 \\
\hline 217 & 0 & 0 & 0 & 0 & 0 & 0 & 55 & 0 & 0 & 0 & 0 & 0 & 0 & 0 & 0 & 0 & 55 \\
\hline 224 & 0 & 0 & 0 & 0 & 0 & 0 & 61 & 0 & 0 & 0 & 0 & 0 & 0 & 0 & 0 & 0 & 61 \\
\hline 225 & 0 & 0 & 0 & 0 & 0 & 0 & 69 & 0 & 0 & 0 & 0 & 0 & 0 & 0 & 0 & 0 & 69 \\
\hline 226 & 0 & 0 & 0 & 0 & 0 & 0 & 93 & 0 & 0 & 0 & 0 & 0 & 0 & 0 & 0 & 0 & 93 \\
\hline 227 & 0 & 0 & 0 & 0 & 0 & 0 & 47 & 0 & 0 & 0 & 0 & 0 & 0 & 0 & 0 & 0 & 47 \\
\hline 228 & 0 & 0 & 0 & 0 & 0 & 0 & 13 & 0 & 0 & 0 & 0 & 0 & 0 & 0 & 0 & 0 & 13 \\
\hline
\end{tabular}




\begin{tabular}{|c|c|c|c|c|c|c|c|c|c|c|c|c|c|c|c|c|c|}
\hline 229 & 0 & 0 & 0 & 0 & 0 & 0 & 0 & 0 & 0 & 0 & 0 & 0 & 0 & 0 & 0 & 0 & 0 \\
\hline 230 & 0 & 0 & 4 & 0 & 0 & 0 & 0 & 0 & 0 & 0 & 12 & 0 & 0 & 0 & 0 & 0 & 16 \\
\hline 231 & 0 & 8 & 5 & 0 & 0 & 0 & 0 & 0 & 0 & 0 & 0 & 0 & 0 & 0 & 0 & 0 & 13 \\
\hline 232 & 0 & 6 & 0 & 0 & 0 & 0 & 13 & 0 & 0 & 0 & 9 & 0 & 0 & 0 & 4 & 0 & 32 \\
\hline 233 & 0 & 0 & 0 & 0 & 0 & 0 & 20 & 0 & 0 & 0 & 0 & 0 & 0 & 0 & 7 & 0 & 27 \\
\hline 240 & 0 & 0 & 0 & 0 & 0 & 0 & 5 & 14 & 0 & 0 & 0 & 0 & 0 & 0 & 0 & 0 & 19 \\
\hline 241 & 0 & 0 & 0 & 0 & 0 & 0 & 30 & 6 & 0 & 0 & 0 & 0 & 0 & 0 & 0 & 0 & 36 \\
\hline 242 & 0 & 0 & 0 & 0 & 0 & 0 & 81 & 0 & 0 & 0 & 0 & 0 & 0 & 0 & 0 & 0 & 81 \\
\hline 243 & 0 & 0 & 0 & 0 & 0 & 3 & 5 & 0 & 0 & 0 & 0 & 0 & 0 & 0 & 0 & 0 & 8 \\
\hline 244 & 0 & 0 & 0 & 0 & 0 & 8 & 0 & 0 & 0 & 0 & 0 & 0 & 0 & 0 & 0 & 0 & 8 \\
\hline 245 & 0 & 0 & 0 & 0 & 0 & 0 & 0 & 0 & 0 & 0 & 10 & 0 & 0 & 0 & 0 & 0 & 10 \\
\hline 246 & 0 & 0 & 0 & 0 & 0 & 0 & 0 & 0 & 0 & 0 & 11 & 0 & 0 & 0 & 26 & 0 & 37 \\
\hline 247 & 0 & 0 & 5 & 0 & 0 & 0 & 0 & 0 & 0 & 0 & 11 & 0 & 0 & 0 & 13 & 0 & 29 \\
\hline 248 & 0 & 0 & 0 & 0 & 0 & 0 & 0 & 0 & 0 & 0 & 5 & 0 & 0 & 0 & 1 & 0 & 6 \\
\hline 249 & 0 & 0 & 0 & 0 & 0 & 0 & 0 & 0 & 0 & 0 & 2 & 0 & 0 & 0 & 13 & 0 & 15 \\
\hline 259 & 0 & 0 & 0 & 0 & 0 & 13 & 0 & 0 & 0 & 0 & 0 & 0 & 0 & 0 & 0 & 0 & 13 \\
\hline 260 & 0 & 0 & 0 & 0 & 0 & 34 & 0 & 0 & 0 & 0 & 0 & 0 & 0 & 0 & 0 & 0 & 34 \\
\hline 261 & 0 & 0 & 0 & 0 & 0 & 0 & 0 & 0 & 0 & 0 & 43 & 0 & 0 & 0 & 0 & 0 & 43 \\
\hline 262 & 0 & 0 & 0 & 0 & 0 & 0 & 0 & 0 & 0 & 0 & 23 & 0 & 0 & 0 & 16 & 0 & 39 \\
\hline 263 & 0 & 0 & 0 & 0 & 0 & 0 & 0 & 0 & 0 & 0 & 0 & 0 & 0 & 0 & 17 & 0 & 17 \\
\hline 264 & 0 & 0 & 0 & 0 & 0 & 0 & 0 & 0 & 0 & 0 & 0 & 0 & 0 & 0 & 4 & 0 & 4 \\
\hline 275 & 0 & 0 & 0 & 0 & 0 & 9 & 0 & 0 & 0 & 0 & 0 & 0 & 0 & 0 & 0 & 0 & 9 \\
\hline 276 & 0 & 0 & 0 & 0 & 0 & 9 & 0 & 0 & 0 & 0 & 0 & 0 & 0 & 0 & 0 & 0 & 9 \\
\hline 277 & 0 & 0 & 0 & 0 & 0 & 10 & 0 & 0 & 0 & 0 & 14 & 0 & 0 & 0 & 0 & 0 & 24 \\
\hline 278 & 0 & 0 & 0 & 0 & 0 & 0 & 0 & 0 & 0 & 0 & 29 & 0 & 0 & 0 & 0 & 0 & 29 \\
\hline 292 & 0 & 0 & 0 & 0 & 0 & 0 & 0 & 0 & 0 & 0 & 34 & 0 & 0 & 0 & 0 & 0 & 34 \\
\hline
\end{tabular}




\begin{tabular}{|l|l|l|l|l|l|l|l|l|l|l|l|l|l|l|l|l|l|}
\hline 293 & 0 & 0 & 0 & 0 & 0 & 0 & 0 & 0 & 0 & 0 & 43 & 0 & 0 & 0 & 0 & 0 & 43 \\
\hline 294 & 0 & 0 & 0 & 0 & 0 & 0 & 0 & 0 & 0 & 0 & 0 & 0 & 0 & 0 & 0 & 0 & 0 \\
\hline Total & 20 & 536 & 39 & 170 & 169 & 86 & 3373 & 41 & 221 & 0 & 371 & 12 & 0 & 202 & 101 & 26 & 5367 \\
\hline
\end{tabular}

Appendix H 133 


\section{Appendix I: Abridged Records of Status 1 Golden Eagle Fatalities}

\begin{tabular}{|c|c|c|c|c|c|c|c|}
\hline $\begin{array}{l}\text { Fatality } \\
\text { Number }\end{array}$ & $\begin{array}{l}\text { Detection } \\
\text { Date }\end{array}$ & Age & Sex & $\begin{array}{l}\text { String } \\
\text { Number }\end{array}$ & $\begin{array}{c}\text { Turbine } \\
\text { Label }\end{array}$ & $\begin{array}{l}\text { Turbine } \\
\text { Bearing }\end{array}$ & $\begin{array}{l}\text { Turbine } \\
\text { Distance }\end{array}$ \\
\hline BLMT07 & $05 / 21 / 98$ & Unk & Unk & 64 & 1205 & 160 & 31 \\
\hline BL3.1 & $06 / 09 / 98$ & Immature & Unk & 63 & 1190 & 261 & 25.5 \\
\hline BL3.12 & $06 / 10 / 98$ & Juvenile & Unk & 77 & 1296 & 303 & 3.5 \\
\hline BL3.18 & $07 / 02 / 98$ & Juvenile & Unk & 76 & 1279 & 263 & 28.8 \\
\hline BL3.47 & $09 / 25 / 98$ & Juvenile & Unk & 68 & 1222 & 151 & 81 \\
\hline BL5.057 & $10 / 08 / 99$ & Adult & Female & 70 & 1244 & 38 & 62 \\
\hline BL5.091 & $11 / 03 / 99$ & Juvenile & Unk & 140 & 6514 & 118 & 19 \\
\hline BL5.122 & $11 / 22 / 99$ & Immature & Unk & 79 & 1312 & 247 & 46 \\
\hline BL4.006 & $06 / 15 / 00$ & Immature & Unk & 55 & 1154 & 96 & 13 \\
\hline BL4.031 & 08/18/00 & Juvenile & Unk & 65 & 1207 & 62 & 10 \\
\hline BL4.037 & 08/26/00 & Juvenile & Unk & 66 & 1216 & 82 & 12 \\
\hline BL4.097 & $01 / 25 / 01$ & Immature & Unk & 165 & $\mathrm{I}-10$ & 340 & 43 \\
\hline BL1.005 & 07/03/01 & Unk & Unk & 85 & 1343 & 211 & 15 \\
\hline BL1041 & $12 / 18 / 01$ & Adult & Unk & 63 & 1190 & 166 & 3 \\
\hline BL1214 & $07 / 08 / 02$ & Unk & Unk & 148 & 6316 & 196 & 20 \\
\hline BL1242 & $08 / 26 / 02$ & Unk & Unk & 121 & 5285 & 244 & 41 \\
\hline BL1244 & $10 / 15 / 02$ & Unk & Unk & 363 & 964 & 228 & 16 \\
\hline BL1258 & $10 / 28 / 02$ & Adult & Unk & 312.1 & 2965 & 216 & 44 \\
\hline BL1288 & $11 / 13 / 02$ & Unk & Unk & 306 & 2719 & 250 & 24 \\
\hline BL1301 & $11 / 19 / 02$ & Unk & Unk & 329 & 4325 & 206 & 28 \\
\hline BL1303 & $11 / 20 / 02$ & Unk & Unk & 331 & 4418 & 196 & 15 \\
\hline BL1439 & $02 / 27 / 03$ & Adult & Unk & 244 & $\mathrm{H} 4$ & 196 & 37 \\
\hline BL1444 & $03 / 05 / 03$ & Juvenile & Unk & 335 & 41 & 194 & 22 \\
\hline
\end{tabular}




\begin{tabular}{|c|c|c|c|c|c|c|c|}
\hline BL1459 & $03 / 11 / 03$ & Juvenile & Unk & 328 & 4323 & 222 & 50 \\
\hline BL1474 & 03/18/03 & Juvenile & Unk & 408 & 697 & 258 & 12 \\
\hline $\begin{array}{l}20051018- \\
02\end{array}$ & $10 / 18 / 05$ & Juvenile & Unk & 72 & 1251 & 27 & 46 \\
\hline $\begin{array}{l}20051025- \\
09\end{array}$ & $10 / 25 / 05$ & Juvenile & Unk & 361 & 4537 & 8 & 25 \\
\hline $\begin{array}{l}20051102- \\
07\end{array}$ & $11 / 02 / 05$ & Undetermined & Unk & 279 & 2389 & 0 & 0 \\
\hline $\begin{array}{l}20051102- \\
12\end{array}$ & $11 / 02 / 05$ & Juvenile & Unk & 517 & 2654 & 75 & 36 \\
\hline $\begin{array}{l}20060111- \\
03\end{array}$ & $01 / 11 / 06$ & Juvenile & Unk & 43 & 1102 & 306 & 6 \\
\hline $\begin{array}{l}20060523- \\
02\end{array}$ & $05 / 23 / 06$ & Unk & Unk & 517 & 2657 & 127 & 12 \\
\hline $\begin{array}{l}20060524- \\
04\end{array}$ & $05 / 24 / 06$ & Unk & Unk & 348.99 & 4394 & 36 & 36 \\
\hline 2336 & $06 / 06 / 06$ & Unk & Unk & 282 & 215 & 0 & \\
\hline $\begin{array}{l}20060705- \\
02\end{array}$ & $07 / 05 / 06$ & Unk & Unk & 324 & 4303 & 41 & 30 \\
\hline $\begin{array}{l}20060710- \\
02\end{array}$ & $07 / 10 / 06$ & Unk & Unk & 342 & 4030 & 30 & 10 \\
\hline $\begin{array}{l}20060717- \\
01\end{array}$ & $07 / 17 / 06$ & Unk & Unk & 363 & 954 & 342 & 24 \\
\hline $\begin{array}{l}20060717- \\
10\end{array}$ & $07 / 17 / 06$ & Unk & Unk & 403 & 1414 & 40 & 36 \\
\hline $\begin{array}{l}20060717- \\
09\end{array}$ & $07 / 17 / 06$ & Unk & Unk & 403 & 1410 & 326 & 41 \\
\hline $\begin{array}{l}20060718- \\
10\end{array}$ & $07 / 18 / 06$ & Unk & Unk & 397.99 & 794 & 31 & 53 \\
\hline X06-82 & $07 / 31 / 06$ & Immature & Unk & 63 & 1199 & 305 & 45 \\
\hline $\begin{array}{l}20060807- \\
04\end{array}$ & 08/07/06 & Adult & Unk & 683.2 & 2363 & 8 & 72 \\
\hline $\begin{array}{l}20060907- \\
06\end{array}$ & $09 / 07 / 06$ & Unk & Unk & 665 & 6350 & 101 & 65 \\
\hline
\end{tabular}

Appendix I 


\begin{tabular}{|c|c|c|c|c|c|c|c|}
\hline $\begin{array}{l}20061009- \\
01\end{array}$ & $10 / 09 / 06$ & Juvenile & Unk & 342 & 4001 & 38 & 36 \\
\hline $\begin{array}{l}20061017- \\
06\end{array}$ & $10 / 17 / 06$ & Juvenile & Unk & 399.99 & 3022 & 20 & 17 \\
\hline $\begin{array}{l}20061018- \\
02\end{array}$ & $10 / 18 / 06$ & Adult & Unk & 404 & 1358 & 49 & 13 \\
\hline $\begin{array}{l}20061026- \\
14\end{array}$ & $10 / 26 / 06$ & Unk & Unk & 85 & 1343 & 206 & 51 \\
\hline $\begin{array}{l}20061031- \\
11\end{array}$ & $10 / 31 / 06$ & Unk & Unk & 596 & 1058 & 19 & 32 \\
\hline $\begin{array}{l}20061215- \\
01\end{array}$ & $12 / 15 / 06$ & Juvenile & Unk & 427 & 331 & 60 & 36 \\
\hline 2672 & $02 / 22 / 07$ & Adult & Unk & 138 & 1176 & 350 & 24 \\
\hline $\begin{array}{l}20070228- \\
01\end{array}$ & $02 / 28 / 07$ & Juvenile & Unk & 372.99 & 1332 & 189 & 4 \\
\hline $\begin{array}{l}20070319- \\
05\end{array}$ & $03 / 19 / 07$ & Adult & Unk & 70 & 1243 & 28 & 37 \\
\hline $\begin{array}{l}20070328- \\
08\end{array}$ & $03 / 28 / 07$ & Unk & Unk & 629 & 1297 & 15 & 95 \\
\hline $\begin{array}{l}20070405- \\
01\end{array}$ & $04 / 05 / 07$ & Unk & Unk & 588 & 6530 & 86 & 14 \\
\hline $\begin{array}{l}20070411- \\
07\end{array}$ & $04 / 11 / 07$ & Adult & Unk & 145 & 6342 & 48 & 20 \\
\hline 2774 & $04 / 16 / 07$ & Adult & Unk & 277 & 207 & 260 & 40 \\
\hline $\begin{array}{l}20070504- \\
01\end{array}$ & 05/04/07 & Juvenile & Unk & 305 & 2675 & 224 & 28 \\
\hline 2791 & $05 / 15 / 07$ & Und & Unk & 517 & 2659 & 80 & 44 \\
\hline 2860 & $05 / 28 / 07$ & Adult & Unk & 138 & 1176 & 330 & 77 \\
\hline $\begin{array}{l}20070613- \\
02\end{array}$ & $06 / 13 / 07$ & Unk & Unk & 308 & 2803 & 300 & 79 \\
\hline $\begin{array}{l}20070618- \\
05\end{array}$ & $06 / 18 / 07$ & Juvenile & Unk & 271 & 4684 & 56 & 23 \\
\hline $\begin{array}{l}20070703- \\
05\end{array}$ & $07 / 03 / 07$ & Und & Unk & 451 & 39 & 41 & 18 \\
\hline
\end{tabular}

Appendix I 


\begin{tabular}{|c|c|c|c|c|c|c|c|}
\hline $\begin{array}{l}20070711- \\
11\end{array}$ & $07 / 11 / 07$ & Juvenile & Unk & 361 & 4538 & 360 & 22 \\
\hline $\begin{array}{l}20070712- \\
03\end{array}$ & $07 / 12 / 07$ & Unk & Unk & 629 & 1288 & 50 & 26 \\
\hline $\begin{array}{l}20070725- \\
06\end{array}$ & $07 / 25 / 07$ & Juvenile & Unk & 654 & 5194 & 53 & 51 \\
\hline $\begin{array}{l}20070815- \\
02\end{array}$ & $08 / 15 / 07$ & Unk & Unk & 615 & 1162 & 162 & 1 \\
\hline $\begin{array}{l}20070821- \\
02\end{array}$ & $08 / 21 / 07$ & Unk & Unk & 312.99 & 3649 & 103 & 77 \\
\hline $\begin{array}{l}20070821- \\
01\end{array}$ & $08 / 21 / 07$ & Unk & Unk & 328 & 4321 & 237 & 32 \\
\hline $\begin{array}{l}20070828- \\
01\end{array}$ & $08 / 28 / 07$ & Adult & Female & 365 & 1089 & 0 & 0 \\
\hline $\begin{array}{l}20070829- \\
07\end{array}$ & $08 / 29 / 07$ & Adult & Unk & 62 & 1188 & 360 & 28 \\
\hline $\begin{array}{l}20070904- \\
01\end{array}$ & $09 / 04 / 07$ & Unk & Unk & 116 & 5159 & 355 & 14 \\
\hline C07-238 & 09/04/07 & Adult & Unk & 180.1 & AB-8 & 20 & 12 \\
\hline $\begin{array}{l}20070905- \\
06\end{array}$ & $09 / 05 / 07$ & Juvenile & Unk & 361 & 4540 & 349 & 8 \\
\hline $\begin{array}{l}20070906- \\
13\end{array}$ & $09 / 06 / 07$ & Adult & Unk & 566 & 6130 & 42 & 35 \\
\hline $\begin{array}{l}20070911- \\
03\end{array}$ & $09 / 11 / 07$ & Unk & Unk & 588 & 6529 & 27 & 22 \\
\hline $\begin{array}{l}20070912- \\
01\end{array}$ & $09 / 12 / 07$ & Adult & Unk & 505 & 2516 & 83 & 5 \\
\hline $\begin{array}{l}20071003- \\
05\end{array}$ & $10 / 03 / 07$ & Unk & Unk & 348.99 & 4386 & 234 & 91 \\
\hline $\begin{array}{l}20071009- \\
20\end{array}$ & $10 / 09 / 07$ & Unk & Unk & 146 & 6368 & 110 & 23 \\
\hline $\begin{array}{l}20071016- \\
06\end{array}$ & $10 / 16 / 07$ & Unk & Unk & 583 & 6491 & 43 & 59 \\
\hline $\begin{array}{l}20071016- \\
07\end{array}$ & $10 / 16 / 07$ & Unk & Unk & 588 & 6530 & 348 & 14 \\
\hline
\end{tabular}

Appendix I 


\begin{tabular}{|c|c|c|c|c|c|c|c|}
\hline $\begin{array}{l}20071019- \\
01\end{array}$ & $10 / 19 / 07$ & Juvenile & Unk & 361 & 4538 & 84 & 4 \\
\hline $\begin{array}{l}20071102- \\
01\end{array}$ & $11 / 02 / 07$ & Adult & Unk & 397.99 & 793 & 42 & 13 \\
\hline 3194 & $11 / 12 / 07$ & Immature & Unk & 348.99 & 3625 & 60 & 64 \\
\hline $\begin{array}{l}20071114- \\
07\end{array}$ & $11 / 14 / 07$ & Unk & Unk & 573 & 6343 & 324 & 29 \\
\hline 3271 & $12 / 13 / 07$ & Unk & Unk & 580.99 & 6450 & 355 & 5 \\
\hline $\begin{array}{l}20080205- \\
04\end{array}$ & $02 / 05 / 08$ & Immature & Unk & 583 & 6491 & 212 & 72 \\
\hline 147 & 02/19/08 & Unk & Unk & 517 & 2639 & 45 & 50 \\
\hline $\begin{array}{l}20080311- \\
06\end{array}$ & 03/11/08 & Juvenile & Unk & 267 & 4732 & 344 & 13 \\
\hline C08-077 & $03 / 25 / 08$ & Adult & Unk & 189 & GB-7 & 136 & 13 \\
\hline $\begin{array}{l}20080506- \\
05\end{array}$ & $05 / 06 / 08$ & Juvenile & Unk & 389.99 & 3066 & 346 & 43 \\
\hline $\begin{array}{l}20080702- \\
03\end{array}$ & $07 / 02 / 08$ & Adult & Unk & 224 & A3001 & 180 & 28 \\
\hline $\begin{array}{l}20080717- \\
01\end{array}$ & $07 / 17 / 08$ & Juvenile & Unk & 67 & 1224 & 300 & 5 \\
\hline $\begin{array}{l}20080724- \\
02\end{array}$ & $07 / 24 / 08$ & Unk & Unk & 5088 & 6503 & 30 & 50 \\
\hline $\begin{array}{l}20080804- \\
03\end{array}$ & $08 / 04 / 08$ & Juvenile & Unk & 430 & 249 & 95 & 61 \\
\hline $\begin{array}{l}20080903- \\
09\end{array}$ & 09/03/08 & Juvenile & Unk & 428 & 239 & 26 & 43 \\
\hline $\begin{array}{l}20080915- \\
06\end{array}$ & $09 / 15 / 08$ & Unk & Unk & 364 & 953 & 15 & 34 \\
\hline $\begin{array}{l}20080923- \\
01\end{array}$ & $09 / 23 / 08$ & Unk & Unk & 52 & 1144 & 161 & 27 \\
\hline $\begin{array}{l}20080923- \\
02\end{array}$ & $09 / 23 / 08$ & Adult & Unk & 71 & 1246 & 66 & 44 \\
\hline X08-164 & $10 / 02 / 08$ & Unk & Unk & 55 & 1154 & 50 & 35 \\
\hline
\end{tabular}

Appendix I 


\begin{tabular}{|c|c|c|c|c|c|c|c|}
\hline $\begin{array}{l}20081201- \\
04\end{array}$ & $12 / 01 / 08$ & Juvenile & Unk & 156 & TV-3 & 355 & 8 \\
\hline $\begin{array}{l}20081215- \\
04\end{array}$ & $12 / 15 / 08$ & Juvenile & Unk & 397.99 & 3074 & 123 & 30 \\
\hline $\begin{array}{l}20090115- \\
02\end{array}$ & $01 / 15 / 09$ & Unk & Unk & 1005 & $\begin{array}{c}\text { WTG- } \\
12\end{array}$ & 210 & 28 \\
\hline $\begin{array}{l}20090311- \\
05\end{array}$ & 03/11/09 & Juvenile & Unk & 348.99 & 4394 & 54 & 47 \\
\hline 4164 & $05 / 27 / 09$ & Unk & Unk & 629 & 1285 & 358 & 14 \\
\hline 4301 & $07 / 06 / 09$ & Unk & Unk & 342 & 4005 & 35 & 9 \\
\hline $\begin{array}{l}20090727- \\
06\end{array}$ & $07 / 27 / 09$ & Adult & Unk & 647 & 5124 & 84 & 26 \\
\hline 4351 & $08 / 14 / 09$ & Immature & Unk & 282 & 217 & 4 & 16 \\
\hline $\begin{array}{l}20090929- \\
02\end{array}$ & $09 / 29 / 09$ & Unk & Unk & 5085 & 6473 & 150 & 7 \\
\hline X09-082 & $09 / 29 / 09$ & Unk & Unk & 69 & 1234 & 345 & 17 \\
\hline $\begin{array}{l}20091021- \\
02\end{array}$ & $10 / 21 / 09$ & Unk & Unk & 335 & 37 & 16 & 63 \\
\hline $\begin{array}{l}20091026- \\
02\end{array}$ & $10 / 26 / 09$ & Juvenile & Unk & 271 & 4687 & 2 & 37 \\
\hline $\begin{array}{l}20091103- \\
04\end{array}$ & $11 / 03 / 09$ & Juvenile & Unk & 582 & 6477 & 40 & 7 \\
\hline $\begin{array}{l}20091104- \\
05\end{array}$ & $11 / 04 / 09$ & Unk & Unk & 145 & 6342 & 212 & 36 \\
\hline 4467 & $11 / 10 / 09$ & Immature & Unk & 335 & 63 & 100 & 18 \\
\hline $\begin{array}{l}20100607- \\
01\end{array}$ & $06 / 07 / 10$ & Unk & Unk & 505 & 2518 & 87 & 24 \\
\hline $\begin{array}{l}20100610- \\
02\end{array}$ & $06 / 10 / 10$ & Juvenile & Unk & 347 & 4377 & 114 & 59 \\
\hline $\begin{array}{l}20100622- \\
02\end{array}$ & $06 / 22 / 10$ & Juvenile & Unk & 53 & 1148 & 86 & 64 \\
\hline $\begin{array}{l}20100722- \\
01\end{array}$ & $07 / 22 / 10$ & Juvenile & Unk & 360 & 4534 & 322 & 66 \\
\hline
\end{tabular}

Appendix I 


\begin{tabular}{|c|c|c|c|c|c|c|c|}
\hline $\begin{array}{l}20100726- \\
01\end{array}$ & $07 / 26 / 10$ & Juvenile & Unk & 345 & 4220 & 21 & 30 \\
\hline X10-066 & $08 / 24 / 10$ & Immature & Unk & 69 & 1227 & 42 & 29 \\
\hline 4896 & $09 / 21 / 10$ & Unk & Unk & 325 & 4312 & & \\
\hline $\begin{array}{l}20100923- \\
03\end{array}$ & $09 / 23 / 10$ & Juvenile & Unk & 342 & 4021 & 42 & 22 \\
\hline $\begin{array}{l}20101018- \\
09\end{array}$ & $10 / 18 / 10$ & Juvenile & Unk & 356 & 4524 & 86 & 18 \\
\hline $\begin{array}{l}20101019- \\
12\end{array}$ & $10 / 19 / 10$ & Unk & Unk & 346 & 4436 & 6 & 75 \\
\hline $\begin{array}{l}20110110- \\
01\end{array}$ & $01 / 10 / 11$ & Unk & Unk & 5110 & 5410 & 55 & 18 \\
\hline 5109 & $03 / 12 / 11$ & Unk & Unk & 597 & 4252 & & \\
\hline $\begin{array}{l}20110314- \\
05\end{array}$ & $03 / 14 / 11$ & Adult & Unk & 356 & 4523 & 35 & 29 \\
\hline $\begin{array}{l}20110526- \\
01\end{array}$ & $05 / 26 / 11$ & Juvenile & Unk & 566 & 6123 & 78 & 35 \\
\hline 5181 & 06/06/11 & Unk & Unk & 360 & 4534 & & \\
\hline $\begin{array}{l}20110725- \\
02\end{array}$ & $07 / 25 / 11$ & Juvenile & Unk & 88 & V1-11 & 239 & 1 \\
\hline $\begin{array}{l}20110802- \\
04\end{array}$ & 08/02/11 & Adult & Unk & 356 & 4524 & 62 & 21 \\
\hline $\begin{array}{l}20110824- \\
03\end{array}$ & $08 / 24 / 11$ & Juvenile & Unk & 83 & 1338 & 168 & 1 \\
\hline $\begin{array}{l}20110913- \\
01\end{array}$ & $09 / 13 / 11$ & Juvenile & Unk & 137 & 1214 & 98 & 11 \\
\hline 5335 & $09 / 14 / 11$ & Unk & Unk & 360 & 4534 & & \\
\hline $\begin{array}{l}20110831- \\
01\end{array}$ & $10 / 31 / 11$ & Adult & Unk & 101 & V9-12 & 109 & 7 \\
\hline $\begin{array}{l}20120419- \\
02\end{array}$ & $04 / 19 / 12$ & Juvenile & Unk & 566 & 6110 & 360 & 0 \\
\hline $\begin{array}{l}20120425- \\
01\end{array}$ & $04 / 25 / 12$ & Juvenile & Unk & 582 & 6477 & 338 & 4 \\
\hline
\end{tabular}

Appendix I 


\begin{tabular}{|l|c|c|c|c|c|c|c|}
\hline $\begin{array}{l}20120530- \\
03\end{array}$ & $05 / 30 / 12$ & Juvenile & Unk & 351.99 & 4460 & 69 & 41 \\
\hline $\begin{array}{l}20120606- \\
06\end{array}$ & $06 / 06 / 12$ & Juvenile & Unk & 5058.2 & 4635 & 55 & 22 \\
\hline $\begin{array}{l}20120716- \\
05\end{array}$ & $07 / 16 / 12$ & Immature & Unk & 329 & 4326 & 31 & 17 \\
\hline $\begin{array}{l}20121106- \\
03\end{array}$ & $11 / 06 / 12$ & Unk & Unk & 335 & 61 & 158 & 3 \\
\hline
\end{tabular}

Appendix I 
Appendix J: Additional fields calculated for the turbines table

\begin{tabular}{|c|c|c|}
\hline Field & \multirow{2}{*}{$\begin{array}{l}\text { Description } \\
\text { Ridge top turbine }\end{array}$} & Year \\
\hline RDGTP & & Constant \\
\hline SP & Settling party turbine & Constant \\
\hline SDDL & Saddle turbine & Constant \\
\hline KILL & \multicolumn{2}{|l|}{ Turbine has killed a GOEA } \\
\hline D98 & Number of dead GOEAs & 1998 \\
\hline D99 & ، 6 & 1998 \\
\hline D00 & “ & 2000 \\
\hline D01 & ، & 2001 \\
\hline D02 & “ & 2002 \\
\hline D03 & “ & 2003 \\
\hline D05 & “ & 2005 \\
\hline D06 & “ & 2006 \\
\hline D07 & “ & 2007 \\
\hline D08 & “ & 2008 \\
\hline D09 & “ & 2009 \\
\hline D10 & “ & 2010 \\
\hline D11 & " $\quad$ " & 2011 \\
\hline DT & Total number of dead GOEAs & Total \\
\hline FISHID & ID of the turbine's fishnet square & Constant \\
\hline DIV98 & Diversity of trb's fishnet square & 1998 \\
\hline DIV99 & “ & 1999 \\
\hline DIV00 & “ & 2000 \\
\hline DIV01 & “ & 2001 \\
\hline DIV02 & “ & 2002 \\
\hline DIV03 & “ & 2003 \\
\hline DIV05 & “ & 2005 \\
\hline DIV06 & “ & 2006 \\
\hline DIV07 & “ & 2007 \\
\hline DIV08 & “ & 2008 \\
\hline DIV09 & “ & 2009 \\
\hline DIV10 & “ & 2010 \\
\hline DIV11 & ، & 2011 \\
\hline DIVKILL & \multicolumn{2}{|c|}{ Diversity of turbine's fishnet id in year GOEA was killed } \\
\hline DNS98 & Turbine density of fishnet square & 1998 \\
\hline DNS99 & ، & 1999 \\
\hline DNSOO & “ & 2000 \\
\hline DNS01 & “ & 2001 \\
\hline DNSO2 & “ & 2002 \\
\hline
\end{tabular}

Appendix J 


\begin{tabular}{|c|c|c|c|}
\hline DNS03 & “ & “ & 2003 \\
\hline DNS05 & “ & “ & 2004 \\
\hline DNS06 & “" & “ & 2006 \\
\hline DNS07 & “ & “ & 2007 \\
\hline DNS08 & “ & “ & 2008 \\
\hline DNS09 & “ & 6 & 2009 \\
\hline DNS10 & “ & “6 & 2010 \\
\hline DNS11 & “ & “ & 2011 \\
\hline DNSKILL & \multicolumn{3}{|c|}{ Density of turbine's fishnetID in year GOEA was killed. } \\
\hline NTD98 & \multicolumn{2}{|c|}{ Nearest turbine distance } & 1998 \\
\hline NTD99 & \multicolumn{3}{|c|}{ Nearest turbine distance } \\
\hline NTM98 & \multicolumn{2}{|c|}{ Nearest turbine model } & 1998 \\
\hline NTM99 & “ & “ & 1999 \\
\hline NTM00 & “ & “ & 2000 \\
\hline NTM01 & “ & “ & 2001 \\
\hline NTM02 & “ & “ & 2002 \\
\hline NTM03 & “ & “ & 2003 \\
\hline NTM05 & “ & “ & 2005 \\
\hline NTM06 & “ & “6 & 2006 \\
\hline NTM07 & “ & “ & 2007 \\
\hline NTM08 & “ & “ & 2008 \\
\hline NTM09 & “ & “ & 2009 \\
\hline NTM10 & “ & “ & 2010 \\
\hline NTM11 & “ & “ & 2011 \\
\hline NTMKILL & \multicolumn{3}{|c|}{ Nearest turbine model in year GOEA was killed } \\
\hline NTD98 & \multicolumn{2}{|c|}{ Distance to nearest turbine } & 1998 \\
\hline NTD99 & “ & “ & 1999 \\
\hline NTD00 & “ & “ & 2000 \\
\hline NTD01 & “ & “ & 2001 \\
\hline NTD02 & “ & “ & 2002 \\
\hline NTD03 & “ & “ & 2003 \\
\hline NTD05 & “ & “ & 2005 \\
\hline NTD06 & “ & “ & 2006 \\
\hline NTD07 & “ & “ & 2007 \\
\hline NTD08 & “ & “ & 2008 \\
\hline NTD09 & “ & “ & 2009 \\
\hline NTD10 & “ & “ & 2010 \\
\hline NTD11 & “6 & “ & 2011 \\
\hline NTDKILL & \multicolumn{3}{|c|}{ Nearest turbine distance in year GOEA was killed } \\
\hline MC98 & \multicolumn{2}{|c|}{ Yearly monitored count } & 1998 \\
\hline MC99 & “ & “ & 1999 \\
\hline MCO0 & “ & " & 2000 \\
\hline
\end{tabular}

Appendix J 


\begin{tabular}{|c|c|c|c|}
\hline MC01 & “ & “ & 2001 \\
\hline MC02 & “ & “ & 2002 \\
\hline MC03 & “ & “ & 2003 \\
\hline MC05 & “ & “ & 2005 \\
\hline MC06 & “ & “ & 2006 \\
\hline MC07 & “ & “ & 2007 \\
\hline MC08 & “ & “ & 2008 \\
\hline MC09 & “ & “ & 2009 \\
\hline MC10 & “ & “ & 2010 \\
\hline MC11 & “ & “ & 2011 \\
\hline MCT & \multicolumn{2}{|c|}{ Total a turbine was monitored } & Total \\
\hline SOHi & \multicolumn{3}{|c|}{ Screen order in the historic array } \\
\hline SCHi & \multicolumn{3}{|c|}{ Historic array screen count } \\
\hline SIDHi & \multicolumn{3}{|c|}{ Historic array screen id } \\
\hline ERHi & \multicolumn{3}{|c|}{ End row historic array } \\
\hline ER98 & \multicolumn{2}{|c|}{ End row status } & 1998 \\
\hline ER99 & “ & “ & 1999 \\
\hline ER00 & “ & “ & 2000 \\
\hline ER01 & “ & “ & 2001 \\
\hline ER02 & “ & “ & 2002 \\
\hline ER03 & “ & “ & 2003 \\
\hline ER05 & “ & “ & 2005 \\
\hline ER06 & “ & “ & 2006 \\
\hline ER07 & “ & “ & 2007 \\
\hline ER08 & “ & “ & 2008 \\
\hline ER09 & “ & “ & 2009 \\
\hline ER10 & ، & “ & 2010 \\
\hline ER11 & “ & " & 2011 \\
\hline ERKILL & \multicolumn{3}{|c|}{ End row status of turbine in year GOEA was killed } \\
\hline SC98 & \multicolumn{2}{|c|}{ Number of turbines in screen } & 1998 \\
\hline SC99 & “ & “ & 1999 \\
\hline SCOO & “ & “ & 2000 \\
\hline SC01 & “ & “ & 2001 \\
\hline SC02 & “ & “ & 2002 \\
\hline SC03 & “ & “ & 2003 \\
\hline SC05 & “ & “ & 2005 \\
\hline SC06 & “ & “ & 2006 \\
\hline $\mathrm{SC} 07$ & “ & “ & 2007 \\
\hline SC08 & “ & “ & 2008 \\
\hline SC09 & “ & “ & 2009 \\
\hline SC10 & “ & “ & 2010 \\
\hline SC11 & “ & " & 2011 \\
\hline SCKILL & \multicolumn{3}{|c|}{ Screen count of turbine in year GOEA was killed } \\
\hline
\end{tabular}

Appendix J 


\begin{tabular}{|c|c|c|}
\hline SCID98 & Turbine screen identity & 1998 \\
\hline SCID99 & " & 1999 \\
\hline SCID 00 & “ & 2000 \\
\hline SCID01 & “ & 2001 \\
\hline SCID02 & ، & 2002 \\
\hline SCID03 & “ & 2003 \\
\hline SCID05 & “ & 2005 \\
\hline SCID06 & “ & 2006 \\
\hline SCID07 & “ & 2007 \\
\hline SCID08 & “ & 2008 \\
\hline SCID09 & “ & 2009 \\
\hline SCID10 & “ & 2010 \\
\hline SCID11 & “ & 2011 \\
\hline PRE98 & Presence in the array & 1998 \\
\hline PRE99 & ، & 1999 \\
\hline PRE00 & “ & 2000 \\
\hline PRE01 & “ & 2001 \\
\hline PRE02 & “ & 2002 \\
\hline PRE03 & “ & 2003 \\
\hline PRE05 & “ & 2005 \\
\hline PRE06 & “ & 2006 \\
\hline PRE07 & 6 & 2007 \\
\hline PRE08 & “ & 2008 \\
\hline PRE09 & “ & 2009 \\
\hline PRE10 & “ & 2010 \\
\hline PRE11 & ، & 2011 \\
\hline MON98 & Monitored status & 1998 \\
\hline MON99 & “ & 1999 \\
\hline MON00 & ، & 2000 \\
\hline MON01 & “ & 2001 \\
\hline MON02 & “ & 2002 \\
\hline MON03 & 6 & 2003 \\
\hline MON05 & " & 2005 \\
\hline MON06 & " & 2006 \\
\hline MON07 & " & 2007 \\
\hline MON08 & "6 & 2008 \\
\hline MON09 & “ & 2009 \\
\hline MON10 & "6 & 2010 \\
\hline MON11 & “ & 2011 \\
\hline
\end{tabular}

Appendix J 